Universidad de Lima

Facultad de Psicología

Carrera de Psicología

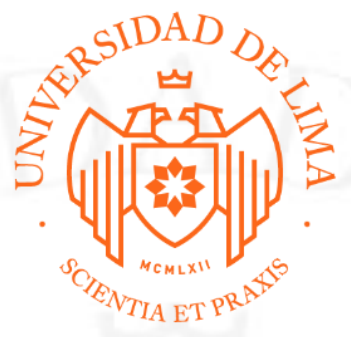

\title{
RELACIÓN ENTRE ESTILOS PARENTALES \\ DISFUNCIONALES E INTELIGENCIA \\ EMOCIONAL EN ADOLESCENTES DE \\ INSTITUCIONES EDUCATIVAS \\ PARTICULARES DE LIMA
}

Tesis para optar el Título Profesional de Licenciado en Psicología

Claudia Alessandra Bio Sam

Código 20130170

\author{
Asesor \\ Susana Gavidia Velezmoro \\ Lima - Perú
}

Febrero de 2020 


\section{RELACIÓN ENTRE ESTILOS PARENTALES}

DISFUNCIONALES E INTELIGENCIA EMOCIONAL EN ADOLESCENTES DE INSTITUCIONES EDUCATIVAS PARTICULARES DE LIMA 


\section{RELATIONSHIP BETWEEN \\ DYSFUNCTIONAL PARENTING STYLES \\ AND EMOTIONAL INTELLIGENCE IN \\ ADOLESCENTS OF PRIVATE \\ EDUCATIONAL INSTITUTIONS FROM \\ LIMA}




\section{TABLA DE CONTENIDO}

RESUMEN.....................................................................................................................1

CAPÍTULO I: PLANTEAMIENTO DEL PROBLEMA...................................3

1.1 Descripción del problema ...........................................................................

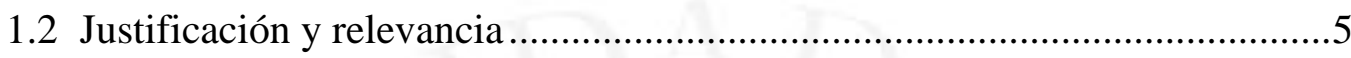

CAPÍTULO II: MARCO TEÓRICO...........................................................8

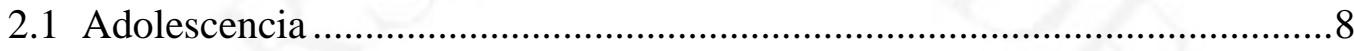

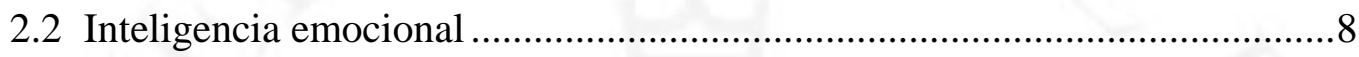

2.2.1 Modelo de la inteligencia emocional-social de BarOn ...........................11

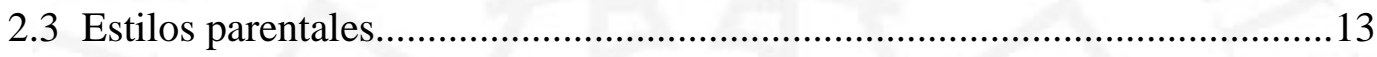

2.3.1 Estilos parentales en la adolescencia .................................................... 16

2.4 Inteligencia emocional y estilos parentales en los adolescentes ....................19

CAPÍTULO III: OBJETIVOS, HIPÓTESIS Y DEFINICIÓN DE

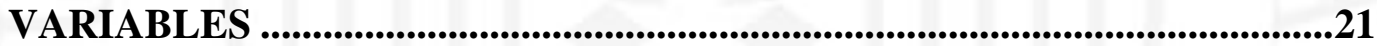

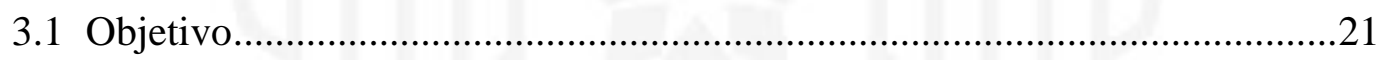

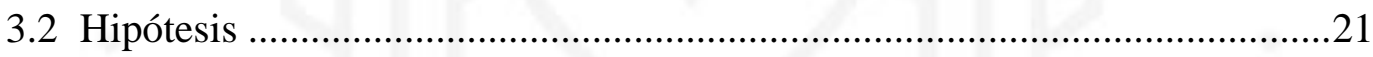

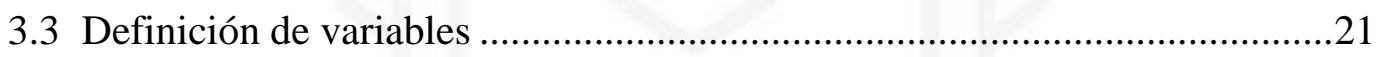

CAPÍTULO IV: MÉTODO....................................................................................23

4.1 Tipo y diseño de investigación................................................................23

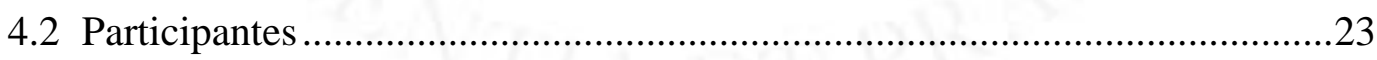

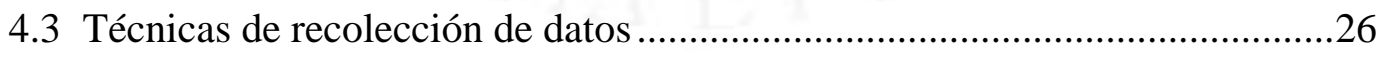

4.3.1 Encuesta sociodemográfica para los adolescentes ...............................26

4.3.2 Escala de Estilos Parentales Disfuncionales .........................................26

4.3.3 ICE NA Inventario de la Inteligencia Emocional de BarOn (I-CE) ........30

4.4 Procedimiento de recolección de datos ........................................................33

CAPÍTULO V: RESULTADOS ...................................................................35

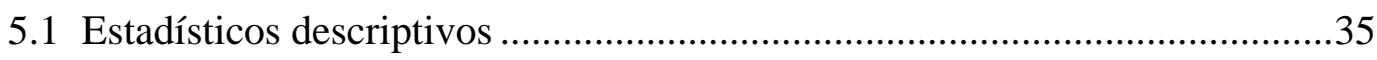




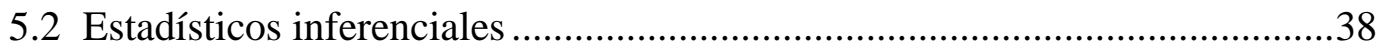

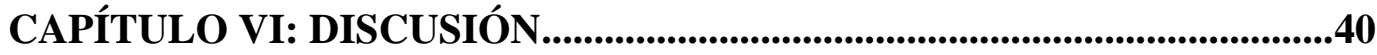

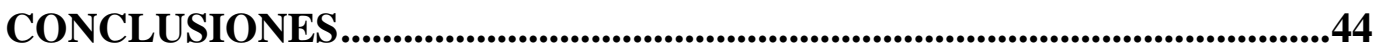

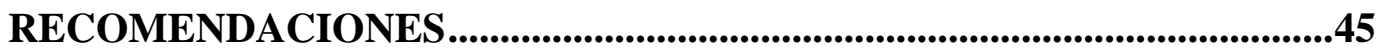

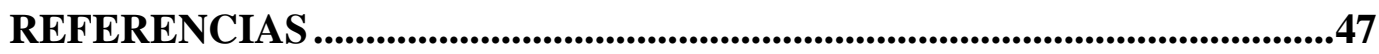

APÉNDICES.....................................................................................................58 


\section{ÍNDICE DE TABLAS}

Tabla 4.1 Distribución de la muestra según edad, cantidad de hermanos y posición ordinal $(\mathrm{N}=77)$

Tabla 4.2 Distribución de la muestra según grado, sexo, con quiénes vive y estado civil de los padres $(\mathrm{N}=77)$.

Tabla 4.3 Puntajes directos y categorías diagnósticas de la escala de estilos parentales disfuncionales del padre

Tabla 4.4 Puntajes directos y categorías diagnósticas de la escala de estilos parentales disfuncionales de la madre .27

Tabla 4.5 Índices de ajuste del análisis factorial confirmatorio (modelo de 3 factores).. 28

Tabla 4.6 Estimadores para el uso del análisis factorial exploratorio .29

Tabla 4.7 Estructura factorial de la Escala de Estilos Parentales Disfuncionales. .29

Tabla 4.8 Coeficientes emocionales e interpretaciones .31

Tabla 4.9 Pesos de los ítems en el Análisis Factorial Exploratorio (4 factores) del BarOn ICE: NA - Forma Larga. .32

Tabla 5.1 Características de las dimensiones de estilos parentales disfuncionales. .35

Tabla 5.2 Características de las dimensiones de inteligencia emocional .36

Tabla 5.3 Prueba de normalidad para las dimensiones de la variable de inteligencia emocional según Shapiro-Wilk .37

Tabla 5.4 Prueba de normalidad para las dimensiones de la variable de estilos parentales disfuncionales según Shapiro-Wilk .37

Tabla 5.5 Correlación entre las dimensiones de estilos parentales disfuncionales del padre y las dimensiones de la inteligencia emocional .38

Tabla 5.6 Correlación entre las dimensiones de estilos parentales disfuncionales de la madre y las dimensiones de la inteligencia emocional .39 


\section{ÍNDICE DE APÉNDICES}

Apéndice 1: Consentimiento informado..................................... 59

Apéndice 2: Encuesta sociodemográfica....................................... 60

Apéndice 3: Escala de Estilos Parentales Disfuncionales........................... 61

Apéndice 4: ICE NA Inventario de la Inteligencia Emocional de BarOn.............. 62

Apéndice 5: Libro de códigos...............................................63

Apéndice 6: Gráficos de dispersión...........................................77 


\section{RESUMEN}

El presente estudio tiene como objetivo establecer las relaciones entre las dimensiones de los estilos parentales (abuso, sobreprotección e indiferencia) y las dimensiones de la inteligencia emocional (intrapersonal, interpersonal, manejo del estrés, adaptabilidad y estado del ánimo). La muestra estuvo conformada por 77 adolescentes de 13 a 17 años de instituciones educativas particulares, que no se encontraran en proceso psicoterapéutico o farmacológico. Los instrumentos aplicados consistieron en una encuesta sociodemográfica, la Escala de Estilos Parentales Disfuncionales y el Inventario de la Inteligencia Emocional de BarOn para niños y adolescentes. Los resultados indicaron una relación inversa estadísticamente significativa entre las dimensiones de ambas variables. De este modo, se halló que, a mayor grado de abuso, sobreprotección o indiferencia, las capacidades emocionales del adolescente relacionadas al área intrapersonal, manejo del estrés, adaptabilidad y estado del ánimo, se veían disminuidas. Se concluye que los estilos parentales se relacionan con la inteligencia emocional de los adolescentes, aun cuando los primeros no muestren ser altamente disfuncionales.

Palabras claves: estilos parentales, inteligencia emocional, adolescentes, Lima

\section{ABSTRACT}

The aim of the present study was to establish the relationship between the dimensions of parenting styles (abuse, overprotection and indifference) and the dimensions of emotional intelligence (intrapersonal, interpersonal, stress management, adaptability and mood). The sample consisted of 77 adolescents from 13 to 17 years who were attending private educational institutions and were not in any type of psychotherapeutic or pharmacological intervention. Measures used to assess the variables of interest included, a sociodemographic survey, the BarOn Emotional Intelligence Inventory for children and adolescents and the Measure of Parenting Styles questionnaire. Findings revealed a significant statistical correlation between the dimensions of both variables. Greater degree of abuse, overprotection or indifference were associated with diminished 
adolescent's skills in the intrapersonal, stress management, adaptability and mood areas. It is concluded that parenting styles and emotional intelligence showed a significant correlation, even when parenting styles are not highly dysfunctional.

Key words: parenting styles, emotional intelligence, adolescents, Lima 


\section{CAPÍTULO I: PLANTEAMIENTO DEL PROBLEMA}

\subsection{Descripción del problema}

En el Perú, entre el 60\% y 70\% de pacientes atendidos por casos referidos a salud mental son menores de 18 años, es decir niños y adolescentes. Principalmente, los motivos de consulta responden a problemas emocionales (ansiedad y depresión), conductuales, de aprendizaje y de desarrollo (Más del 60\% de los pacientes de los servicios de Salud Mental son menores de 18 años, 2019). Los cambios característicos de la adolescencia en combinación con el entorno podrían explicar el desarrollo de alguno de estos problemas de salud mental. El desarrollo del adolescente, así como el de toda persona, unifica tres dominios: el físico, el cognitivo y el psicosocial, donde los dos primeros repercuten en el desarrollo psicosocial o emocional. El desarrollo cognitivo impacta en la vida emocional, debido a que cambia la habilidad para razonar acerca del mundo y las emociones. Por otro lado, los cambios fisiológicos, por ejemplo, los cambios en los niveles hormonales producen inestabilidad de emociones debido a que los adolescentes nunca han estado expuestos a estas reacciones químicas (Rosenblum y Lewis, 2003). A su vez, las tres dimensiones mencionadas se ven mediadas por las diferencias individuales, la herencia y el ambiente (Papalia, Wendkos y Duskin, 2009).

Este último, está constituido, principalmente, por la familia. Por ende, esta cumple un rol significativo en el desarrollo de la persona, y de manera relevante en el adolescente, dado que es, en primera instancia, el núcleo de la socialización y del aprendizaje emocional (Goleman, 2011; Olmedo, 2013), haciendo posible que el adolescente se convierta en una persona autónoma (Florenzano, 2002). Asimismo, las relaciones entre ambos agentes, la familia y el adolescente, afectan en la salud y bienestar en los tres dominios de este último (Papalia et al., 2009). Por lo tanto, el ambiente familiar en el que se desarrollará el individuo impacta en la persona, dándose una relación bidireccional entre estas (Bronfenbrenner, 1987).

Los estilos parentales (EP) surgen de la socialización en el ambiente familiar. De tal manera, los EP se refieren a las formas en que los padres piensan, sienten y se 
comportan con respecto a la crianza de sus hijos (Levin, 2011). Al respecto, se plantean dos dimensiones: el afecto y el control (Oliva, 2006). Ambas resultan en cuatro estilos: autoritativo, autoritario, permisivo y negligente (Galambos, Barker y Almeida, 2003; Moscatelli y Rubini, 2009; Levin, 2011). Cada uno de ellos tiene un impacto diferente sobre el individuo, pudiendo desarrollar sintomatología psicopatológica (Iglesias y Romero, 2009), por un lado, o un mejor ajuste emocional en el adolescente (Oliva, Parra y Arranz, 2008).

Cabe agregar que el grado de madurez o inteligencia emocional (IE) que manejen los padres también va a repercutir en sus hijos. Es decir, la capacidad de una persona para reconocer y “...comprender sus emociones y las de los demás, siendo habilidoso en su control y modificación para que estas sean constructivas y no hirientes, para sí mismo y para otras personas" (Sánchez, 2009, p. 21-22). De este modo, esta variable generaría un mejor control emocional, menos altibajos emocionales, menos problemas de conducta, alto rendimiento académico, mejor adaptación al entorno, etc. A su vez, la IE de los padres, la buena crianza, el apoyo familiar, la interacción positiva y lazos afectivos entre padres e hijos, son considerados como factores protectores para evitar el desarrollo de trastornos mentales como ansiedad, depresión y adicciones, además de conductas de riesgo como delincuencia, uso de alcohol, bajo rendimiento, etc. (Goleman, 2011; Organización Mundial de la Salud [OMS], 2004; Papalia et al., 2009).

Los adolescentes se encuentran más expuestos y vulnerables ante las diversas conductas de riesgo mencionadas, puesto que la adolescencia es un periodo que implica múltiples cambios. Ante ellos, evidencian su capacidad y recursos para manejarlos (Papalia et al., 2009). Por tanto, aquellos adolescentes que cuentan con un núcleo familiar positivo, así como también escolar y comunitario, tienen altas probabilidades de desarrollarse positiva y sanamente (Youngblade et al., 2007), y de incorporarse satisfactoriamente en la sociedad (Baumrind, 1971). De tal modo, estos factores ambientales impactarán en el grado de inteligencia emocional que desarrollen los adolescentes (Esnaola, Revuelta, Ros y Sarasa, 2017).

Se ha demostrado que la IE impacta en múltiples aspectos del desarrollo de la persona. Diversos autores han correlacionado la IE con otras variables como el éxito académico (Parker, Summerfeldt, Hogan, y Majeski, 2004), liderazgo (George, 2000), 
satisfacción general (Palmer, Donaldson, y Stough, 2002), clima familiar (SánchezNúñez y Latorre, 2012) entre las principales. De este modo, ha sido posible identificar que este tipo de inteligencia predice el éxito en diversos ámbitos como el educativo (Lam y Kirby, 2002) y en la salud mental en general (Ciarrochi, Deane, y Anderson, 2002; Parker, Taylor y Bagby, 2001; Salovey, Bedell, Detweiler, y Mayer, 1999).

Si bien pocas investigaciones han relacionado los EP y la IE, los resultados emergentes indican que existe una relación significativa entre ambas variables (Argyriou, Bakoyannis, y Tantaros, 2016; Batool y Bond, 2015; Esnaola et al., 2017; George et al., 2017; Goleman, 2011; Ramirez-Lucas, Ferrando, y Sainz, 2015). Asimismo, estas investigaciones y aquellas llevadas a cabo en nuestro contexto están enfocadas en la percepción de los padres (Becerra, Roldán y Aguirre., 2008), sin embargo, se ha demostrado que la información que proveen los hijos es fiable (Samper, Cortés, Mestre, Nácher y Tur, 2006) y más coherente que la reportada por los padres (Morris et al., 2002). De este modo, tomando en consideración estas premisas, se plantea la siguiente interrogante: ¿Existe una relación entre los estilos parentales y la inteligencia emocional de los adolescentes de 13 a 17 años de instituciones educativas particulares de la ciudad de Lima?

\subsection{Justificación y relevancia}

Se han llevado a cabo estudios que relacionan la IE y los EP en contextos que difieren del contexto peruano (Argyriou, et al., 2016; Batool y Bond, 2015; Esnaola, et al., 2017; George et al., 2017; Ramirez-Lucas et al., 2015). La cultura peruana se caracteriza por considerar a la familia como parte importante en el desarrollo de uno mismo, puesto que es percibida como fuente y recipiente de soporte emocional (Harwood, Leyendecker, Carlson, Asencio y Miller, 2002). Con respecto a ello, se sabe que los patrones culturales afectan el desarrollo infantil, ya que intervienen variables como la composición del hogar, los recursos sociales y económicos, la forma de interacción entre los miembros, la manera en que aprenden, el modo en que la comunidad piensa y percibe el mundo, entre otras (Papalia et al., 2009). Por lo tanto, resulta pertinente investigar cómo se comporta este 
constructo, los estilos parentales, relacionado a la inteligencia emocional, en nuestro contexto.

La presente investigación, al relacionar una variable individual y una variable contextual, evalúa empíricamente el modelo ecológico de Bronfenbrenner (1987). Así, la IE representa una característica individual, mientras que los estilos parentales corresponden a una variable o modo de interacción en el microsistema, entre los cuales existe una mutua influencia. De este modo, la relación entre el individuo y su ambiente resulta ser de naturaleza bidireccional (Bronfenbrenner, 1987). Por otro lado, el presente estudio respalda los hallazgos previos respecto a la relación entre IE y EP (Argyriou, Bakoyannis, y Tantaros, 2016; Batool y Bond, 2015; Esnaola et al., 2017; George et al., 2017; Goleman, 2011; Ramirez-Lucas et al., 2015), dándole mayor valor empírico a esta relación.

Resulta de suma importancia plantear programas de prevención centrada en los padres y los estilos de crianza, puesto que las intervenciones de esta naturaleza, buscan contrarrestar factores de riesgo y fortalecer factores protectores para aliviar problemas de salud mental. Estos programas tienen la finalidad de cambiar aquellos procesos, es decir los factores de riesgo, que pudieran desembocar en el desarrollo de la enfermedad mental (Irarrázaval, Prieto y Armijo, 2016). Al respecto, Iglesias y Romero (2009) han identificado una relación entre los estilos parentales y psicopatologías. De manera específica, los EP negativos se relacionan con síndromes clínicos como el uso inapropiado de sustancias y predisposición a la impulsividad y delincuencia. Además, encontraron una asociación entre el nivel de implicancia de los padres, así como también el nivel de aceptación por parte de estos, y sintomatología depresiva. Desde el punto de vista aplicado, en Lima, según el Instituto Nacional de Salud Mental Honorio DelgadoHideyo Noguchi (2012), el 8,6\% de adolescentes ha tenido un episodio depresivo y uno de cada ocho niños o adolescentes puede padecer un problema de salud mental en algún momento de su vida. Así, los estilos parentales, tales como el autoritario, permisivo y negligente, podrían actuar como un factor de riesgo para el desarrollo de estos trastornos mentales. En suma, el presente proyecto supondría una base para construir programas de prevención, considerando las necesidades encontradas. De esta manera, se reforzarían o 
desarrollarían prácticas beneficiosas para el desarrollo de los hijos; de lo contrario, se modificarían aquellas que impliquen consecuencias negativas para los menores.

Por medio de la presente investigación se podrán desarrollar programas que apoyen intervenciones sobre la inteligencia emocional de los adolescentes. Con relación a ello, se observa que, hoy en día, existe un decreciente nivel de autocontrol en niños y adolescentes, los cuales actúan priorizando sus emociones, dejándose llevar por estas y de manera irracional (Sánchez, 2009). Las evidencias indican que los programas de intervención de naturaleza preventiva, dirigidos a padres y adolescentes, resultan en el óptimo desarrollo de la inteligencia emocional (Argyriou et al., 2016). Asimismo, es evidente que el desarrollo emocional de los padres, las interacciones padres-hijos y la educación que les brindan tienen un impacto en el desarrollo emocional de los adolescentes. Este determinará su actuar, en vista de que la habilidad y el autocontrol emocional va a permitir que la conducta sea adecuada para la situación, sin descuidar sus sentimientos y emociones ni las de los demás. 


\section{CAPÍTULO II: MARCO TEÓRICO}

\subsection{Adolescencia}

La adolescencia es el período de transición del desarrollo entre la niñez y la adultez. Esta etapa involucra múltiples cambios en los aspectos físico, cognoscitivo y psicosocial (Papalia, Wendkos, y Duskin, 2010). La adolescencia comprende desde los 11 o 12 hasta los 19 o 20 años (Papalia et al., 2010; Estévez, 2013). En el Perú, según el Instituto Nacional de Estadística e Informática (2014), el grupo de edad de los adolescentes es entre los 12 y 17 años.

El área emocional cobra mayor importancia durante la adolescencia, dado que el conjunto de cambios físicos, psicológicos, cognitivos y sociales predispone a los adolescentes a la hipersensibilización ante sus propias emociones, haciéndolos más vulnerables (Graber y Sontag, 2009). Durante esta etapa, el cerebro del adolescente atraviesa por una serie de reestructuraciones referidas a las emociones, el juicio, la organización de la conducta y el autocontrol (Papalia et al., 2010). A su vez, se va desarrollando la capacidad de experimentar y reflexionar sobre emociones mixtas y conflictivas, habilidades más sofisticadas para afrontar la disconformidad emocional y la capacidad de experimentar la empatía de una manera más compleja. Sobre estas, se espera que sienten las bases para el funcionamiento emocional (Rosenblum y Lewis, 2003).

\subsection{Inteligencia emocional}

Durante muchos años se ha considerado a la inteligencia como un aspecto analítico, racional y cognitivo. Posteriormente, se reconoció el aspecto social, emocional y afectivo del concepto, de manera que impacta en cómo se relaciona el individuo con el entorno. De este modo, surge el concepto de inteligencia emocional (IE), el cual se refiere al procesamiento de información emocional, es decir, percibir, asimilar, comprender y regular las emociones y los estados de ánimos, propias y de los demás (Parra, Oliva, y Reina, 2015). 
Múltiples autores han definido este concepto. Mayer y Salovey (1997), la definen como el conjunto de habilidades utilizadas para percibir y comprender las emociones, propias y ajenas, así como también regularlas. También, Goleman (2011) explica la IE como el carácter, el cual engloba el autocontrol, el entusiasmo y la habilidad para la automotivación. Por último, otro representante de esta variable es Reuven Bar-On, quien conceptualiza la IE como un conjunto de capacidades, competencias y destrezas no cognitivas, que utilizamos para afrontar, de manera exitosa, las demandas y presiones del entorno (Bar-On, 2006).

Cada uno de estos autores pertenece a un modelo específico que explica la IE como una habilidad o como un rasgo. El modelo de habilidad se basa en aptitudes para el procesamiento de la información afectiva o emocional. Así, según este modelo, existen habilidades cognitivas o destrezas para percibir, evaluar, manejar, expresar y autorregular emociones, orientándose al bienestar del sujeto (García-Fernández y Giménez-Mas, 2010; Ramos, Enriquez y Recondo., 2012; Trujillo y Rivas, 2005). Dentro de este modelo, los principales representantes son Salovey y Mayer. Estos autores plantean que la IE es un conjunto de habilidades que implican procesos psicológicos básicos y complejos. Por lo tanto, es un modelo de tipo jerárquico, ya que son indispensables las mencionadas en primer lugar para alcanzar las más complejas (Ramos et al., 2012).

Por otro lado, se encuentra el modelo de rasgos o mixto, el cual postula que la IE está conformada por diversos rasgos de personalidad y rasgos de comportamiento estable (García-Fernández y Giménez-Mas, 2010; Ramos et al., 2012). Algunos de los representantes del modelo son Daniel Goleman y Reuven Bar-On. Por su parte, Goleman (2011) explica la IE como el reconocimiento de las propias emociones y el manejo de estas para expresarlas apropiadamente. Además, implica la automotivación, el reconocimiento de las emociones de los demás y establecer relaciones.

A pesar de los diferentes modelos planteados, se ha estudiado la IE y su asociación con distintas variables. De este modo, se analizó la relación entre la IE, tanto autoinformada por menores como la IE reportada sobre sus padres, y el clima familiar. La muestra estuvo conformada por 156 sujetos españoles, 71 hombres y 85 mujeres, entre 14 y 34 años que residan con sus padres. Los resultados reflejaron una relación significativa y positiva entre ambas variables. Por ello, se concluye que la IE se asocia con la expresividad en el clima familiar (Sánchez-Núñez y Latorre, 2012). 
Asimismo, se ha encontrado que a mayor grado de IE, existe una mejor percepción de competencia social y un menor uso de estrategias interpersonales negativas (Brackett, Rivers, Shiffman, Lerner y Salovey, 2006; Lopes et al., 2004), mejor calidad en las relaciones sociales, familiares y de pareja (Extremera y Fernández-Berrocal, 2004; Brackett, Warner, y Bosco, 2005). Además, las personas inteligentes emocionalmente son percibidas por su entorno como sociables y empáticas (Lopes, Salovey, Cote, Beers, y Petty, 2005). Por otro lado, la IE se relaciona con el nivel de autoestima, el bienestar (Brackett y Mayer, 2003), satisfacción general (Palmer et al., 2002), el éxito académico (Parker et al., 2004) y un bajo nivel de síntomas depresivos (Extremera, FernándezBerrocal, Ruiz-Aranda y Cabello, 2006). Por lo tanto, se identifica un beneficio en el bienestar del individuo y, por consiguiente, en sus relaciones interpersonales (Salguero, Fernández-Berrocal, Ruiz-Aranda, Castillo, y Palomera, 2011).

De manera específica, en la adolescencia, son de suma importancia las habilidades emocionales para predecir su ajuste psicosocial. Así, los jóvenes inteligentes emocionalmente entablan mejores relaciones interpersonales y parentales y perciben menos sentimientos de estrés y tensión en el ámbito social, sintiéndose estimados (Salguero et al., 2011). En un estudio realizado en España, con una muestra de 484 adolescentes de entre 12 años y 18 años de escuelas públicas y semi-privadas, se encontró que el desarrollo de la IE varía de acuerdo con el sexo y la dimensión de la IE a ser analizada y que existen diversos factores con mayor significancia que la edad, como la educación, la experiencia o el nivel de socialización, que explicarían las fluctuaciones en la IE en adolescentes (Esnaola et al., 2017).

A nivel nacional, se ha estudiado la inteligencia emocional y el autoconcepto en escolares de Lima Metropolitana en una muestra conformada por 203 adolescentes entre 15 y 18 años que cursaban el quinto año de secundaria de colegios estatales. Se encontró una relación positiva entre ambas variables y, de manera específica, se halló una relación entre la IE y los componentes social y emocional del autoconcepto (Matalinares et al., 2005).

Por otro lado, en un estudio realizado en Puno, con una muestra de 89 estudiantes de 5to año de secundaria de una institución educativa, se encontró una relación negativa entre la inteligencia emocional sus dimensiones y el riesgo suicida, en donde todas las dimensiones de la IE demostraban una relación negativa (Sumari y Vaca, 2017). Por 
último, en San Juan de Lurigancho, se estudió la inteligencia emocional, el género y el clima familiar en 127 adolescentes con edad promedio de 14 años. Los resultados demostraron una relación significativa entre ambas variables. De manera específica, se identificó que las mujeres presentaban un mejor nivel de empatía y mejores habilidades sociales. No se hallaron diferencias en cuanto al autoconocimiento de emociones, autocontrol de las mismas ni en la automotivación. Finalmente, quienes provenían de una familia nuclear, tenían un mejor autocontrol y automotivación que aquellos que tenían familias monoparentales (Ruiz y Carranza, 2018).

Sobre la IE, se concluye que impacta en la manera de desenvolvernos e interactuar con el entorno, así como también en la forma en que cada individuo se percibe a sí mismo, es decir, el autoconcepto. Cabe recalcar que, en la etapa adolescente, las habilidades emocionales, derivadas de la IE son indispensables para el ajuste psicosocial de la persona.

\subsubsection{Modelo de la inteligencia emocional-social de BarOn}

La inteligencia emocional-social, de acuerdo a este modelo, es una combinación entre competencias emocionales y sociales, habilidades y facilitadores que determinan qué tan efectivamente entendemos y nos expresamos, comprendemos a otros, nos relacionamos con ellos y enfrentamos las demandas del día a día (Bar-On, 2006). Además, influye en el bienestar emocional general (Ugarriza y Pajares, 2005).

Este modelo propone que la IE cuenta con cinco componentes. El componente intrapersonal implica la habilidad para comprender y expresar las propias emociones y a uno mismo. El componente interpersonal se refiere a la habilidad para comprender e identificarse con los sentimientos del otro. La adaptabilidad corresponde a la habilidad para manejar y controlar las propias emociones para utilizarlas en nuestro beneficio. El manejo del estrés hace referencia a la habilidad para manejar, cambiar y resolver problemas intra e interpersonales. Por último, el componente del estado de ánimo en general, referido a la habilidad para generar un estado de ánimo positivo y automotivarse (Bar-On, 2013).

Bar-On (2013) explica que estos cinco componentes cuentan con quince factores. El autoconcepto, la habilidad para percibir, comprender y aceptarse a uno mismo; la autoconciencia emocional, que es la habilidad para estar alerta e identificar y comprender 
las propias emociones; la asertividad, la habilidad para expresar los propios sentimientos, creencias y pensamientos de manera efectiva y constructiva; la independencia, la habilidad para autodirigirse en pensamientos y acciones, y sentirse seguro de uno mismo; la empatía, que se refiere a la habilidad para estar alerta y comprender cómo se sienten los demás; la responsabilidad social, referida a la habilidad para identificarse con grupos sociales, amigos, en el trabajo y en la comunidad, y cooperar con otros de manera contributiva y constructiva; las relaciones interpersonales, la habilidad para establecer y mantener relaciones mutuamente satisfactorias; la tolerancia al estrés, que implica la habilidad para manejar de manera constructiva y efectiva nuestras emociones y situaciones estresantes; el control de impulsos, la habilidad para controlar nuestras emociones e impulsos de manera efectiva y constructiva; la prueba de la realidad, la habilidad para validar objetivamente los propios sentimientos; la flexibilidad, la habilidad para adaptar y ajustar las propias emociones, pensamientos y conducta a nuevas situaciones y condiciones; la solución de problemas, la habilidad para resolver problemas intra e interpersonales de manera efectiva; la autorrealización, la habilidad para proponerse metas personales y dirigirse al logro de estas para lograr el máximo potencial propio; el optimismo, la habilidad para mantener una actitud positiva y esperanzadora respecto a la vida aún en situaciones de adversidad; felicidad o bienestar, la habilidad para sentirse contento con unos mismo, con otros y con la vida en general.

A partir de este modelo, se ha estudiado la IE y su relación con diferentes constructos. Parker et al. (2004) estudiaron la asociación entre la IE y el logro académico en estudiantes de entre 14 y 18 años de escuela secundaria en Alabama, EEUU. Los resultados confirman la correlación entre ambas variables. De manera específica, se halló que los estudiantes exitosos puntúan alto en las habilidades de adaptabilidad y manejo del estrés, así como también en la habilidad interpersonal. Por otro lado, se analizó la relación entre la inteligencia emocional y la autoeficacia en profesores de secundaria en Italia. La muestra estuvo conformada por 169 profesores, tanto hombres como mujeres. Los resultados indicaron que, a mayor inteligencia emocional, los profesores demostraban mayor autoeficacia, de modo que tenían un mejor manejo de aula, capacidad para motivar e involucrar a sus alumnos y uso apropiado de estrategias de enseñanza (Di Fabio y Palazzeschi, 2008). 
Así como se ha estudiado el comportamiento de la IE en el ámbito educativo, también ha sido analizada en el ámbito organizacional. En la investigación realizada por Anand (2010), se buscaba analizar la relación entre la IE y las prácticas de liderazgo. La muestra estuvo compuesta por 256 ejecutivos del sector público en Karnataka, India. Se encontró que existe una relación entre ambos constructos. Asimismo, la flexibilidad y la empatía se asocian a la motivación y empoderar el actuar por parte de los ejecutivos hacia sus subordinados. Sobre este estudio, se concluyó que la inteligencia emocional debe ser considerada como una cualidad necesaria en ejecutivos de altos mandos para poder, así, ejercer un liderazgo positivo y efectivo.

Por último, en el ámbito clínico se investigó la relación entre la IE y la alexitimia, que, principalmente, es la dificultad para identificar y describir emociones (Espina, Ortego, Ochoa de Alda Martínez, Alemán, 2001). 734 adultos de un pequeño pueblo de Ontario, Canadá, fueron incluidos en tal estudio. Se reportó una correlación negativa entre los componentes de la inteligencia emocional, tales como el intrapersonal, el interpersonal, la adaptabilidad, el manejo del estrés y el estado del ánimo, y la alexitimia. Los autores señalan que los hallazgos refuerzan la premisa de que altos niveles de inteligencia emocional pueden actuar como un factor para la salud mental y física (Parker, Taylor y Bagby, 2001).

Respecto al modelo, se concluye que aporta una definición bastante completa con la cual se ha podido estudiar el comportamiento de esta variable en los diferentes ámbitos de la psicología: educativo, clínico y organizacional. Así, se confirman y se hallan relaciones entre la IE y el logro académico, alexitimia y liderazgo. De este modo, es posible establecer estos estudios como precedentes para la intervención y prevención, en vista de que la IE actúa como un factor protector.

\subsection{Estilos parentales}

El ámbito familiar es el contexto fundamental en el que se desarrollan las competencias emocionales de los niños y adolescentes, ya que la familia es el núcleo socializador y del aprendizaje social (Goleman, 2011; Olmedo, 2013; Sánchez-Núñez y Latorre, 2012). Por lo tanto, la interacción entre esta y el individuo impacta en el desarrollo general y sobre todo emocional del último. De este modo, es importante considerar la buena crianza, los 
lazos afectivos, el apoyo familiar y la interacción positiva entre padres e hijos como factores cruciales que impactan en la salud mental y el bienestar general de la persona (Goleman, 2011; OMS, 2004; Papalia et al., 2009). La crianza, en particular, resulta indispensable en el desarrollo de la persona. De esta manera, es posible identificar dos niveles de análisis: los estilos educativos o estilos parentales y los hábitos de crianza. Estos últimos son pautas utilizadas por los padres, que, en conjunto, conforman los estilos parentales (EP) (Olmedo, 2013). En consecuencia, los EP se definen como:

“...una constelación de actitudes hacia el hijo que son comunicadas hacia éste y que, tomadas en conjunto, crean un clima emocional en el que se expresan las conductas de los padres. Estas conductas incluyen tanto las conductas específicas dirigidas a metas mediante las cuales realizan sus deberes como padres (referibles como prácticas parentales) y conductas parentales no dirigidas a metas como gestos, cambios en el tono de voz o la expresión espontánea de emoción.” (Darling y Steinberg, 1993, p. 488).

A pesar de que diversos autores proponen diferentes tipos de estilos parentales, se repiten dos dimensiones: el afecto y el control. La primera hace referencia a la cercanía a nivel emocional, el apoyo parental, la cohesión. A su vez, el grado y la calidad de la comunicación también se incluyen en esta dimensión (Oliva, 2006). El control implica las estrategias de socialización parental relacionadas al manejo de la conducta a través de normas, límites y castigos. Además, esta dimensión incluye la exigencia de responsabilidades de los padres a los hijos y el seguimiento y reconocimiento de los comportamientos y actividades de los menores (Oliva, 2006); así como también estrategias de intrusión, constricción y prevención de la conducta autónoma (Gómez, Vallejo, Zapata y Zambrano, 2010). Estas dos dimensiones son equivalentes al cuidado y la sobreprotección, respectivamente.

Así como múltiples autores tienen propuestas de diferentes tipos de estilos parentales, se identifican diversos términos para hacer referencia a los EP. Parker, Tupling y Brown (1979) se refieren a ellos como vínculos parentales. Sobre estos, explican que el vínculo resulta de la interacción de las características del niño, las características del padre o de su sistema de cuidado y las características de la relación entre ambos. Estos vínculos repercuten en las relaciones interpersonales del niño, así como también en la organización de su personalidad (Robles, Oudhof y Mercado, 2016). 
De tal modo, se construye el Instrumento de Vínculos Parentales de Parker et al. (1979) que contempla dos dimensiones: el cuidado y la sobreprotección. Además, brinda una tipología de vínculos parentales (estilos parentales): vínculo óptimo, ausente, constricción cariñosa y control sin afecto (Gómez et al., 2010).

Posteriormente, se reconoció que tal instrumento no capturaba situaciones de abuso físico o sexual, las cuales eran predictores de alguna psicopatología en la etapa adulta (Harris y Brown como se citó en Parker, Roussos, Hadzi-Pavlovic, Mitchell, Wilhelm y Austin, 1997). Por lo tanto, se desarrolló la Escala de Estilos Parentales Disfuncionales de Parker et al. (1997), un instrumento que surge del Parental Bonding Instrument (PBI) o, en español, Instrumento de Vínculos Parentales de Parker et al., 1979. A diferencia del PBI, el cual mide los estilos parentales a través de dos dimensiones: cuidado y sobreprotección, en esta nueva escala se miden tres dimensiones: la sobreprotección, la indiferencia y el abuso. En primer lugar, la dimensión de indiferencia implica la falta de estructuración, control y apoyo. Es probable que los padres que presentan una actitud indiferente trasladen sus responsabilidades hacia otros agentes (familiares o escuela) y que sus hijos demuestren problemas conductuales (Matalinares, Raymundo y Baca, 2016). Por otro lado, la dimensión de sobreprotección está referida al bajo control y la alta exigencia, combinado con una reducida sintonización en referencia a las necesidades de sus hijos. Además, la comunicación no resulta efectiva y suele ser unidireccional, es decir, del padre al hijo (Matalinares et al., 2016). Por último, la dimensión de abuso se relaciona con una crianza estricta, en la que se imponen reglas y existen altas expectativas en cuanto a la obediencia. Un factor indispensable en esta dimensión es el poder que los padres ejercen sobre sus hijos (Matalinares et al., 2016).

Cabe mencionar que este nuevo instrumento se basa, al igual que el PBI, en que los estilos parentales dan la pauta para futuras interacciones sociales, sean estos caracterizados por un vínculo sano o por uno disfuncional. Al respecto, ha quedado en evidencia que los EP son predictores de trastornos o enfermedades psiquiátricas (Matalinares, Raymundo y Baca, 2014). Bowlby, por su parte, propone que la educación anómala, la cual va a predisponer al niño o la niña a algún desorden psiquiátrico y a interacciones disfuncionales sociales y/o emocionales en la edad adulta, es manifestada cuando las figuras parentales no proporcionan el cuidado necesario, son insensibles, 
muestra menosprecio, rechazo o demuestran un control excesivo o sobreprotección (Matalinares et al., 2014; Parker et al., 1997).

Se llevó a cabo una investigación que buscaba relacionar los estilos parentales disfuncionales y el abuso de sustancias en pacientes ambulatorios. La muestra estuvo conformada por 159 pacientes con una edad promedio de 40 años y que, en su mayoría, consumían heroína. Los resultados del estudio indican una relación entre ambas variables, así como altos niveles de indiferencia por parte de la madre (Icick et al., 2013). Por otro lado, se llevó a cabo un estudio en el que se analizaba la relación entre los estilos parentales, temperamento y carácter, y la psicosis. Participaron 78 pacientes con psicosis y 156 sujetos de grupo control. El estudio confirmó que el temperamento y el carácter de los pacientes con psicosis se asociaba con estilos parentales disfuncionales. Además, la búsqueda de novedad y cooperatividad se encuentran asociadas el abuso materno en cuanto a estilos parentales y sintomatología positiva de la psicosis (Mansueto, Palmieri, Faravelli, 2018).

En relación a los estilos parentales, se pone en evidencia el rol indispensable de esta variable en el desarrollo de la persona, ya que estos determinarán el tipo de interacciones sociales y/o emocionales que tendrán en su vida adulta, así como posibles desórdenes psiquiátricos. Teniendo esto en cuenta, sería importante visualizar esta problemática desde la óptica de la prevención y la psicoeducación, con la finalidad de anticiparse a cualquier disfuncionalidad en la vida adulta.

\subsubsection{Estilos parentales en la adolescencia}

En líneas generales, Arranz y Oliva (2010) señalan que los estilos de crianza representan una variable que impacta en el desarrollo psicológico del niño o adolescente. De manera específica, los estilos parentales se relacionan con la madurez emocional y competencia psicosocial, la autoestima, el ajuste emocional y el éxito académico de sus hijos (Paulson y Sputa, 1996; Trishala y Kiran, 2015). Asimismo, se reconoce que los EP contribuyen, además de en el ámbito emocional, también en el cognitivo, específicamente en el desarrollo moral. De este modo, los padres de estilo autoritativo promueven que sus hijos se cuestionen y amplíen su razonamiento (Eisenberg, Morris, McDaniel, y Spinrad, 2004). 
Durante la adolescencia, el sujeto busca la individuación, es decir, volverse autónomo y desarrollar una identidad personal. Los padres, por su parte, deben equilibrar entre brindarles la independencia que buscan los adolescentes y la protección de juicios inmaduros que pueden perjudicarlos. Asimismo, en este periodo, el adolescente pasa mayor tiempo con sus pares y menos con su familia. Sin embargo, se les sigue considerando como una base segura y fuente de apoyo emocional (Papalia et al., 2009). Por ello, resulta importante el rol de los padres en la crianza y el tipo de interacción entre ellos y los adolescentes.

El estilo parental autoritativo repercute positivamente en el desarrollo psicosocial sano (Baumrind, 1991). De este modo, los adolescentes con padres autoritativos se caracterizan por ser competentes socialmente. Por el contrario, los hijos con figuras paternas autoritarias resultan ser obedientes, pero evidencian un pobre autoconcepto. Igualmente, los adolescentes que se desarrollan en un ambiente con padres indulgentes son propensos al abuso de sustancias tóxicas, al bajo rendimiento académico y a las conductas disruptivas (Torío, Peña y Rodriguez, 2008).

Múltiples autores han investigado los EP y su relación con otras variables. En Madrid, se realizó un estudio acerca de la percepción de los hijos respecto a los estilos de crianza materna y paterna. La muestra estuvo conformada por 1182 niños y adolescentes desde 8 hasta 16 años. Así, se concluyó que las niñas perciben mayor sensibilidad a la afectividad, mientras que los niños reconocen más el control y la hostilidad. Por otro lado, se identificó que mientras los niños son más grandes, estos perciben menos afecto, comunicación y supervisión en ambos padres, y reconocen mayor hostilidad (Rodríguez, Del Barrio y Carrasco, 2009).

En Chile, se llevó a cabo una investigación respecto a la relación entre los EP y la calidad de vida familiar. En este estudio se consideró a 109 familias (padres y madres) de niños de 11 a 13 años. Se concluyó que existía una relación significativamente positiva entre las dos variables. Asimismo, se identificó que las estrategias que utilizan los padres de estilo autoritativo están asociadas a una percepción positiva respecto al afecto (Ossa, Navarrete y Jiménez, 2014).

Por último, en Argentina, se hizo un estudio con 219 niños entre 9 y 12 años para conocer si los estilos parentales actuaban como predictores de la creatividad. Los resultados indican que la aceptación por parte de las figuras parentales se considera un 
predictor del proceso creativo. De igual manera, el nivel de disciplina y el control parental impactan en el pensamiento creativo del niño (Krumm, Vargas-Rubilar y Gullón, 2013).

A nivel nacional, se estudió la influencia de los EP en la adicción al internet en una muestra de 2370 adolescentes de tercero a quinto de secundaria de las tres regiones del Perú (costa, sierra y selva), cuyas edades oscilaban entre los 13 y 18 años. Los resultados indicaron que los EP de abuso e indiferencia influyen en la adicción al internet, identificando una mayor incidencia en la costa y en la sierra una mayor percepción de EP disfuncionales (Matalinares et al., 2013).

Asimismo, se evaluó la percepción de los EP y la agresividad en 267 adolescentes de 12 a 17 años de una institución educativa de Lima-este. Los resultados indicaron una asociación entre el EP autoritativo y autoritario con la agresividad reactiva y proactiva. Además, se concluye que la relación entre padres e hijos es de vital importancia para el desarrollo conductual y psicosocial del adolescente (Orihuela, 2017).

Finalmente, en una institución educativa pública se realizó un estudio que relacionaba los estilos educativos parentales y la resiliencia. La muestra estuvo compuesta por 900 alumnos de tercero, cuarto y quinto de secundaria. Se halló una relación significativa entre la resiliencia y el estilo parental inductivo, es decir, aquel en el que los padres explican a sus hijos sobre el establecimiento de normas y se promueve el respeto de estas. Asimismo, se encontró que los estilos negligentes y autoritarios generan altos niveles de depresión (Marquina, 2016).

Durante la adolescencia, las personas se encuentran en la búsqueda de su autonomía y en el desarrollo de su identidad personal. Los estilos parentales van a representar un gran determinante en la consecución de estas dos grandes metas de esta etapa, por lo que los EP deben guiar hacia tal objetivo. Los estudios confirman su relación a diversas variables como la creatividad, la calidad de vida familiar, la resiliencia, las cuales impactan positivamente en el desarrollo del adolescente y, por el contrario, la adicción al internet y la agresividad, que representan conductas de riesgo cuyo impacto entorpecerá el logro de la autonomía y el desarrollo de una identidad personal funcional. 


\subsection{Inteligencia emocional y estilos parentales en los adolescentes}

La literatura confirma una relación entre la inteligencia emocional y los estilos parentales en adolescentes. George et al. (2017) realizaron un estudio en el área rural de Karnataka, India con una muestra de 300 escolares de 13 a 16 años con el objetivo de evaluar la IE, los EP y el rendimiento académico en adolescentes. Esta investigación tuvo una duración de 2 meses en los cuales se aplicaron la encuesta sociodemográfica, el cuestionario de IE con cinco componentes (autoconocimiento, autorregulación, motivación, empatía y habilidades sociales) y el cuestionario de estilos parentales con cuatro tipos (afectivo, sin afecto, óptimo y negligente) a los adolescentes. Los resultados indicaron que la mayoría de los estudiantes puntúan bajo en IE, específicamente en autoconocimiento, motivación y habilidades sociales; moderadamente alto en empatía y alto en autorregulación.

En cuanto a los estilos parentales, se encontró que la mayoría de los padres tenían un EP de control sin afecto. Con relación al éxito académico, se halló que era moderado y que aquellos estudiantes con un alto nivel de autoconocimiento tenían un mejor rendimiento académico. Por otro lado, se evidenció que no existía una relación entre los estilos parentales y la inteligencia emocional, debido, posiblemente, al nivel educativo de los padres (George et al., 2017).

En Pakistán, Batool y Bond (2015) estudiaron la relación entre la inteligencia emocional de padre y la agresión en adolescentes, a través de los estilos parentales como mediadores. La muestra estuvo conformada por 225 estudiantes de 17 a 18 años, los cuales participaron con sus padres. Los cuestionarios de inteligencia emocional y de estilos parentales fueron completados por los padres y el cuestionario de agresión por los adolescentes. Los resultados indican que la IE de los padres está ligada indirectamente con la agresión en sus hijos, la cual es mediada por los EP.

Argyriou et al. (2016) llevaron a cabo un estudio en Grecia, cuyo objetivo fue examinar la relación entre EP y la IE en adolescentes. La muestra estuvo conformada por 127 adolescentes, quienes completaron el cuestionario de EP percibidos y el de IE. Los resultados indican que los estilos parentales se relacionan con la inteligencia emocional. Asimismo, esta última se relacionó positivamente con el estilo autoritativo, pero negativamente con el estilo autoritario. No hubo evidencia significativa para la relación entre el estilo permisivo y la IE. Por lo tanto, se concluye que existe un vínculo entre los EP positivos y el desarrollo emocional del adolescente. 
Se evidencia el aporte de estos estudios a la relación entre los estilos parentales y la inteligencia emocional. Sin embargo, no representan una realidad próxima a la nacional. Esto deja en evidencia la necesidad de replicar estas investigaciones en la realidad peruana y, a su vez, brindar un mayor soporte empírico con respecto a las variables de estudio. 


\section{CAPÍTULO III: OBJETIVOS, HIPÓTESIS Y DEFINICIÓN DE VARIABLES}

\subsection{Objetivo}

El objetivo de la presente investigación es relacionar los estilos parentales disfuncionales y la inteligencia emocional de los adolescentes de 13 a 17 años de instituciones educativas particulares de la ciudad de Lima.

\subsection{Hipótesis}

Las dimensiones de los estilos parentales disfuncionales, abuso, sobreprotección e indiferencia, se relacionan negativamente con las dimensiones de la inteligencia emocional, intrapersonal, interpersonal, de adaptabilidad, manejo del estrés y estado de ánimo en general.

\subsection{Definición de variables}

Una de las variables a estudiar es la inteligencia emocional, la cual se define, conceptualmente, como un conjunto de competencias sociales y emocionales, habilidades y facilitadores que se interrelacionan y determinan cuán efectivamente uno se comprende a sí mismo y se expresa, comprende y se identifica con los demás, y afronta las demandas del día a día (Bar-On, 2006). De manera operacional, se define como los puntajes obtenidos en el Inventario de Inteligencia Emocional de BarOn ICE: NA, en niños y adolescentes, adaptado en Perú por Ugarriza y Pajares (2005).

La otra variable analizada son los estilos parentales, los cuales se definen, conceptualmente, como "una constelación de actitudes hacia el hijo que son comunicadas hacia éste y que, tomadas en conjunto, crean un clima emocional en el que se expresan las conductas de los padres" (Darling y Steinberg, 1993, p. 488). Operacionalmente, se define como los puntajes obtenidos en la Escala de estilos parentales disfuncionales de 
Parker et al. (1997), adaptada en Perú por Matalinares et al. (2016), la cual considera las dimensiones de abuso, indiferencia y sobreprotección. 


\section{CAPÍTULO IV: MÉTODO}

\subsection{Tipo y diseño de investigación}

La presente investigación tiene como finalidad relacionar los estilos parentales y la inteligencia emocional de los adolescentes de 13 a 17 años de instituciones educativas particulares de la ciudad de Lima. Por tanto, es un estudio cuantitativo, de tipo correlacional, puesto que se busca conocer la relación entre variables, midiéndolas, cuantificando y analizando dicha relación (Hernández, Fernández y Baptista, 2014).

Dado que se busca relacionar estas dos variables: estilos parentales e inteligencia emocional, el diseño de investigación es no experimental de tipo transeccional correlacional. Esto implica que se busca determinar la relación entre variables en un momento determinado, sin manipular el comportamiento de estas (Field, 2009; Hernández et al., 2014).

\subsection{Participantes}

La población estudiada estuvo compuesta por adolescentes de ambos sexos, que, durante el estudio, vivían en la ciudad de Lima y estaban matriculados en instituciones educativas particulares. Es decir, que estaban cursando entre 1ero y 5to de secundaria o algún ciclo universitario. Asimismo, no se encontraban participando en un proceso psicoterapéutico o farmacológico.

No fueron incluidos en la muestra, aquellas personas que eran menores de 13 años y mayores de 17 años, sujetos que no desearon formar parte del estudio de manera voluntaria y quienes no completaron los cuestionarios al 100\%. Asimismo, fueron excluidos aquellos estudiantes de instituciones estatales, que estuvieran en un proceso psicoterapéutico o que se encontraban en tratamiento farmacológico.

Los evaluados fueron seleccionados a través de un muestreo no probabilístico, por conveniencia, ya que se seleccionaron aquellos casos a los que se tenía acceso y se encontraban disponibles (Hernández et al., 2014). 
Con la finalidad de calcular el tamaño de la muestra, se hizo uso del programa G*Power (versión 3.1.9.2) de Buchner, Erdfelder y Lang (2014). Para el cálculo, se consideró un tamaño del efecto de .28, reportado por Argyriou et al. (2016), quienes investigaron la relación entre las variables a estudiar en la presente investigación. Se utilizó una potencia de .80, valor mínimo recomendado que indica un $80 \%$ de probabilidad de detectar un efecto considerable entre las variables de estudio (Field, 2009) y un nivel de significación de .05, el cual es considerado el valor mínimo para poder generalizar los resultados (Field, 2009). De este modo, se estima un tamaño de la muestra de 77 adolescentes de 13 a 17 años de instituciones educativas particulares de la ciudad de Lima que cumplan con las características esperadas.

La muestra final estuvo conformada por adolescentes entre 13 y 17 años de colegios e instituciones de educación superior particulares de la ciudad de Lima. La muestra estuvo compuesta por 77 adolescentes, tras la eliminación de participantes que no pertenecían a instituciones educativas particulares, que estuvieran recibiendo tratamiento psicológico o farmacológico, o que no hayan completado la encuesta sociodemográfica o las pruebas al $100 \%$.

En relación a las características de la muestra, la edad promedio de los adolescentes (62.3\% femenino) fue de 15 años, cuya mayoría se encontraba cursando el cuarto año $(31.2 \%)$, quinto año $(23.4 \%)$ y tercer año de secundaria $(22.1 \%)$, más que a los primeros grados, como primero y segundo año de secundaria (7.8\% y $5.2 \%$ respectivamente) o estudios superiores (10.4\%). Por otro lado, la mayoría de los adolescentes incluidos en el estudio viven con sus padres (68.8\%). Asimismo, con respecto al estado civil de las madres y los padres de los sujetos, la mayoría se encuentra casado (74\% y $75.3 \%$, respectivamente). Estas y otras características relevantes de la muestra se encuentran caracterizadas en las Tablas 4.1 y 4.2 :

Tabla 4.1

Distribución de la muestra según edad, cantidad de hermanos y posición ordinal $(N=77)$

\begin{tabular}{llcc}
\hline & Características & $\mathrm{n}$ & $\%$ \\
\hline Edad & & 7 & \\
& 13 & 12 & 9.1 \\
& 14 & 23 & 15.6 \\
15 & & & (continúa)
\end{tabular}


(continuación)

\begin{tabular}{ccc}
\hline 16 & 20 & 26 \\
17 & 15 & 19.5 \\
Cantidad de hermanos & 10 & \\
0 & 25 & 32.5 \\
1 & 21 & 27.3 \\
2 & 14 & 18.2 \\
3 & 2 & 2.6 \\
4 & 5 & 6.5 \\
$>4$ & & \\
0 & 15 & 19.5 \\
1 & 20 & 26 \\
2 & 21 & 27.3 \\
3 & 11 & 14.3 \\
4 & 7 & 9.1 \\
$>4$ & 3 & 3.9 \\
\hline
\end{tabular}

Tabla 4.2

Distribución de la muestra según grado, sexo, con quiénes vive y estado civil de los padres $(N=77)$

\begin{tabular}{llcc}
\hline \multicolumn{1}{c}{ Características } & $\mathrm{n}$ & $\%$ \\
\hline Grado & & \\
& Primero de secundaria & 6 & 7.8 \\
Segundo de secundaria & 4 & 5.2 \\
Tercero de secundaria & 17 & 22.1 \\
Cuarto de secundaria & 24 & 31.2 \\
Quinto de secundaria & 18 & 23.4 \\
Estudios superiores & 8 & 10.4 \\
Sexo & & \\
Femenino & 48 & 62.3 \\
Masculino & 29 & 37.7 \\
Con quiénes vive & & \\
$\quad$ Madre & 13 & 16.9 \\
$\quad$ Padre & 1 & 1.3 \\
Ambos padres & 53 & 68.8 \\
Madre y otros & 3 & 3.9 \\
Ambos padres y otros & 7 & 9.1 \\
Estado civil de la madre & & \\
Soltera & 6 & 7.8 \\
Casada & 57 & 74 \\
Divorciada & 5 & 6.5 \\
Separada & 9 & 11.7 \\
Estado civil del padre & & 9.1 \\
Soltero & 7 & 75.3 \\
Casado & 58 & 6.5 \\
Divoriado & 5 & 9.1 \\
Separado & 7 & \\
\end{tabular}




\subsection{Técnicas de recolección de datos}

\subsubsection{Encuesta sociodemográfica para los adolescentes}

Este instrumento fue elaborado específicamente para esta investigación. Está conformado por cinco preguntas con formato de respuesta abierta que recogen información sobre edad, colegio, grado, número de hermanos y posición ordinal. Además, se plantean seis preguntas con formato de respuesta cerrada sobre el sexo, gestión del colegio (pública o privada), participación actual en un proceso psicoterapéutico o tratamiento farmacológico, con quiénes vive el o la adolescente, el estado civil de los padres y si el (la) evaluado (a) tiene hermanos.

\subsubsection{Escala de Estilos Parentales Disfuncionales}

Fue diseñada por Parker et al. (1997), y adaptada al Perú por Matalinares et al. (2016) en una muestra de 2370 adolescentes de 13 a 19 años de 14 ciudades representativas de la costa, la sierra y la selva del país. La Escala de Estilos de Parentales Disfuncionales, en el fondo, posee dos escalas que evalúan el nivel de los estilos parentales disfuncionales: estilos parentales del padre y estilos parentales de la madre. Estas escalas poseen tres dimensiones: indiferencia, abuso y sobreprotección (Matalinares et al., 2016).

La prueba consta de 14 ítems que deben contestarse en relación al padre, por un lado, y a la madre por el otro. Estos se distribuyen, en la escala del padre, en las tres dimensiones mencionadas de la siguiente manera: la dimensión de abuso contiene a los ítems 1, 2, 3, 4, 6, 8 y 9; la de sobreprotección es medida por los ítems 5 y 14; y, por último, la de indiferencia por los ítems 7, 10, 11, 12 y 13. Por otro lado, en cuanto a la escala de la madre, los ítems se distribuyen en las tres dimensiones del siguiente modo: los ítems 1, 3, 4, 6, 8 y 9 correspondientes a la dimensión de abuso; la dimensión de sobreprotección está medida por los ítems 2, 5 y 14; y, finalmente, los ítems 7, 10, 11, 12 y 13 miden la dimensión de indiferencia (Matalinares et al., 2016).

Está dirigida a adolescentes de 13 a 19 años y la duración de la escala es de 15 minutos aproximadamente (Matalinares et al., 2016).

La evaluación utiliza la escala tipo Likert de 4 opciones que van desde 0 (nunca), 1 (a veces), 2 (muchas veces) y 3 (siempre). De este modo, se suman los puntajes por cada dimensión, así como el total de todos los ítems para obtener el puntaje directo, el cual deberá ser transformado en percentil para así, determinar si es que cada dimensión 
(abuso, indiferencia y sobre protección) corresponde a un nivel bajo, medio o alto. El mismo procedimiento se sigue para el total de las tres dimensiones de la escala del padre y de la madre, por separado, y determinar si responde a un estilo parental disfuncional alto, medio o bajo. Por tanto, del percentil 1 al 10 es considerado como bajo, del 15 al 85 como medio y del 90 al 99 como alto. (Matalinares et al., 2016). Para la presente investigación se utilizaron los puntajes directos, la interpretación de estos se grafica a continuación en la Tabla 4.3 y 4.4 .

Tabla 4.3

Puntajes directos y categorías diagnósticas de la escala de estilos parentales disfuncionales del padre

\begin{tabular}{lcccc}
\hline \multirow{2}{*}{$\begin{array}{l}\text { Categoría } \\
\text { diagnóstica }\end{array}$} & \multicolumn{2}{c}{ Puntajes directos de la escala de estilos parentales } & \multirow{2}{*}{ Escala Total } \\
\cline { 2 - 4 } & Abuso & Indiferencia & Sobreprotección & \\
\hline Alto & $9-24$ & $4-12$ & $4-6$ & $19-24$ \\
Medio & $2-8$ & $0-3$ & $0-3$ & $3-13$ \\
Bajo & $0-1$ & - & - & $0-2$ \\
\hline
\end{tabular}

Tabla 4.4

Puntajes directos y categorías diagnósticas de la escala de estilos parentales disfuncionales de la madre

\begin{tabular}{lcccc}
\hline \multirow{2}{*}{$\begin{array}{l}\text { Categoría } \\
\text { diagnóstica }\end{array}$} & \multicolumn{2}{c}{ Puntajes directos de la escala de estilos parentales de } & \multirow{2}{*}{ Escala Total } \\
\cline { 2 - 4 } & Abuso & Indiferencia & Sobreprotección & \\
\hline Alto & $5-18$ & $9-18$ & $4-6$ & $21-28$ \\
Medio & $0-4$ & $2-8$ & $0-3$ & $3-13$ \\
Bajo & - & $0-1$ & - & $0-2$ \\
\hline
\end{tabular}

En lo referido a las evidencias de confiabilidad, con la finalidad de realizar un análisis de consistencia interna, se utilizó el coeficiente alfa de Cronbach por cada escala. En cuanto a los estilos parentales del padre, se obtuvo un coeficiente que oscilaba entre .77 y .85 , lo cual indica un nivel entre bajo y moderado. Por otro lado, en la escala de estilos parentales de la madre, se halló que el coeficiente del alfa de Cronbach se encontraba entre .74 y .80 , que también indica un nivel entre bajo y moderado (Matalinares et al., 2016). En ambas escalas, la mayoría de ítems correlaciones ítems-test se encuentran por encima de .20 , excepto el ítem 1 . Es por ello que se eliminó tal ítem en 
ambas escalas debido al bajo índice de discriminación: .01 en la del padre y .06 en la de la madre (Matalinares et al., 2016).

Por otro lado, en relación a las evidencias de validez, se realizó un análisis confirmatorio, utilizando los indicadores de bondad de ajuste: Chi-cuadrado; índice de ajuste nomado del Chi-cuadrado (X2); raíz cuadrada media de error de aproximación (RMSEA, Root mean square error of approximation); índice de ajuste nomado (NFI, Normed-fit index); y el índice de ajuste comparativo de Bentler (CFI, Comparative fit index) (Matalinares et al., 2016). De este modo, los resultados de los índices mencionados fueron insatisfactorios en ambas sub-escalas (padre y madre). Así, el modelo de los tres factores de Parker et al. (1997) es inapropiado para el conjunto de ítems del instrumento (Matalinares et al., 2016).

Tabla 4.5

Índices de ajuste del análisis factorial confirmatorio (modelo de 3 factores)

\begin{tabular}{lcccccc}
\hline & $\begin{array}{c}\text { Chi-cuadrado } \\
(X 2)\end{array}$ & $\mathrm{gl}$ & $X 2 / \mathrm{df}$ & RMSEA & NFI & CFI \\
\hline $\begin{array}{l}\text { Escala: } \\
\text { Padre }\end{array}$ & $2,545.0493 * *$ & 77 & 33.05 & .12 & .49 & .50 \\
$\begin{array}{l}\text { Escala: } \\
\text { Madre }\end{array}$ & $950.887 * *$ & 74 & 12.35 & .07 & .77 & .78 \\
**p<0.01 & & & & & & \\
$\begin{array}{l}\text { Nota: Fuente: Matalinares, M., Raymundo, O. y Baca, D. (2016). Escala de Estilos Parentales } \\
\text { Disfuncionales-MOPS-Perú [Manual]. Instrumento no publicado. }\end{array}$
\end{tabular}

Dado los resultados del análisis confirmatorio (Tabla 4.5), se realizó un análisis factorial exploratorio para identificar el mejor modelo que explique la Escala de Estilos Parentales Disfuncionales. Para ello, se analizó el valor del determinante, la medida de adecuación de muestreo KMO y el test de esfericidad de Bartlet. Los resultados, que se encuentran en la Tabla 4.6, indicaron que, para ambas escalas, del padre y de la madre, el determinante es próximo a 0, la medida de adecuación de muestreo KMO se aproxima a $1.0 \mathrm{y}$ el test de esfericidad de Bartlet es estadísticamente significativo (Matalinares et al., 2016). 
Tabla 4.6

Estimadores para el uso del análisis factorial exploratorio

\begin{tabular}{lccc}
\hline & Determinante & $\begin{array}{c}\text { Medida de } \\
\text { adecuación de } \\
\text { muestreo KMO }\end{array}$ & $\begin{array}{c}\text { Test de esfericidad } \\
\text { de Bartlet }\end{array}$ \\
\hline Escala: Padre & .02 & .92 & $9,942.278^{* *}$ \\
Escala: Madre & .04 & .88 & $7,592.001^{* *}$ \\
\hline
\end{tabular}

N*p<.01 Disfuncionales-MOPS-Perú [Manual]. Instrumento no publicado.

En el análisis factorial exploratorio de las dimensiones se hizo uso del método de extracción de ejes principales. Con ello, se pudo identificar que el modelo de tres factores resultaba ser el más apropiado, en vista de que explicaba el $53.81 \%$ de la varianza total en la escala del padre y el $49.26 \%$ en la escala de la madre. El método de rotación ortogonal, de tipo varimax fue utilizado también (Matalinares et al., 2016).

Por último, se obtuvo la estructura factorial del MOPS. En la tabla 4.7 se presenta tal estructura, indicando los factores y sus respectivos ítems, así como las cargas factoriales de los mismos. Dado que en casi todos los casos los resultados se aproximan a .50 o más, entonces los ítems propician la clara definición e interpretación de los factores (Matalinares et al., 2016).

Tabla 4.7

Estructura factorial de la Escala de Estilos Parentales Disfuncionales

\begin{tabular}{|c|c|c|c|c|c|c|c|}
\hline \multicolumn{4}{|c|}{ Sub-escala de estilos parentales del padre } & \multicolumn{4}{|c|}{ Sub-escala de estilos parentales de la madre } \\
\hline Ítems & Abuso & Sobreprotección & Indiferencia & Ítems & Abuso & Sobreprotección & Indiferencia \\
\hline 2 & .629 & & & 2 & .430 & & \\
\hline 3 & 665 & & & 3 & & 711 & \\
\hline 4 & .593 & & & 4 & 619 & & \\
\hline 5 & .366 & & & 5 & .704 & & \\
\hline 6 & & .334 & & 6 & & .634 & \\
\hline 7 & .526 & & & 7 & 209 & & \\
\hline 8 & & & .813 & 8 & & & .787 \\
\hline 9 & .606 & & & 9 & .505 & & \\
\hline 10 & .355 & & & 10 & .719 & & \\
\hline 11 & & & .331 & 11 & & & .250 \\
\hline
\end{tabular}

(continúa) 


\begin{tabular}{|c|c|c|c|c|c|}
\hline 12 & & .224 & 12 & & .308 \\
\hline 13 & & .737 & 13 & & .804 \\
\hline 14 & & .387 & 14 & & .420 \\
\hline 15 & .429 & & 15 & .480 & \\
\hline
\end{tabular}

Nota: Fuente: Matalinares, M., Raymundo, O. y Baca, D. (2016). Escala de Estilos Parentales Disfuncionales-MOPS-Perú [Manual]. Instrumento no publicado.

\subsubsection{ICE NA Inventario de la Inteligencia Emocional de BarOn (I-CE)}

Fue adaptado en una muestra peruana de 3374 niños y adolescentes de edades entre los 7 y 18 años por Ugarriza y Pajares (2005). El Inventario de la Inteligencia Emocional de BarOn evalúa las habilidades sociales y emocionales de niños y adolescentes desde los 7 a los 18 años. La prueba consta de una versión completa y otra abreviada, la cuales tienen una duración de 20-25 minutos y 10-15 minutos, respectivamente.

El BarOn ICE: NA, de versión completa, cuenta con 60 ítems, los cuales se organizan en 5 dimensiones: intrapersonal, interpersonal, manejo del estrés, adaptabilidad y ánimo general. Asimismo, también se incluye la dimensión de impresión positiva (Ugarriza y Pajares, 2005). Los ítems se distribuyen de la siguiente manera: los ítems 7, 17, 28, 31, 43 y 53 corresponden a la dimensión intrapersonal; los ítems 2, 5, 10, 14, 20, 24, 36, 41, 45, 51, 55 y 59 miden la dimensión interpersonal; la dimensión de manejo del estrés está medida por los ítems 3, 6, 11, 15, 21, 26, 35, 39, 46, 49, 54 y 58; en la de adaptabilidad están contenidos los ítems 12, 16, 22, 25, 30, 34, 38, 44, 48 y 57; los ítems 1, 4, 9, 13, 19, 23, 29, 32, 37, 40, 47, 50, 56 y 60 miden la dimensión de ánimo general; y por últimos los ítems 8, 18, 27, 33, 42 y 52 que miden la impresión positiva (Ugarriza y Pajares, 2005).

Este inventario utiliza la escala tipo Likert de 4 opciones que van desde 1 (muy rara vez), 2 (rara vez), 3 (a menudo) y 4 (mиу a menudo). Los puntajes permiten identificar el nivel de inteligencia emocional y social a través de la suma total de la escala y, consiguiente conversión a puntajes estándares. Con la finalidad de llegar a este resultado, se debe tener en cuenta los ítems que tienen el puntaje invertido (Ugarriza y Pajares, 2005). La Tabla 4.7 muestra la clasificación de los coeficientes emocionales, que resultan de la conversión de puntajes. 
Tabla 4.8

Coeficientes emocionales e interpretaciones

\begin{tabular}{ll}
\hline Rangos & \multicolumn{1}{c}{ Pautas de interpretación } \\
\hline 130 y más & Marcadamente alta. Capacidad emocional y social atípicamente bien desarrollada. \\
120 a 129 & Muy alta. Extremadamente capacidad emocional y social bien desarrollada. \\
110 a 119 & Alta capacidad emocional y social bien desarrollada. \\
90 a 109 & Promedio. Capacidad emocional y social adecuada. \\
80 a 89 & Baja. Capacidad emocional y social subdesarrollada. Necesita mejorarse en algo. \\
70 a 79 & $\begin{array}{l}\text { Muy baja. Capacidad emocional y social extremadamente subdesarrollada que } \\
\text { necesita mejorarse considerablemente. }\end{array}$ \\
69 y menos & Marcadamente baja. Capacidad emocional deficiente y atípica. \\
\hline $\begin{array}{l}\text { Nota: Fuente: Ugarriza, N., y Pajares, L. (2005). “Adaptación y estandarización del inventario de } \\
\text { Inteligencia Emocional de BarOn ICE: NA, en niños y adolescentes" [Instrumento de medición]. Lima }\end{array}$
\end{tabular}

Respecto a las propiedades psicométricas, se estudiaron las evidencias de confiabilidad, por medio del análisis de la consistencia interna del instrumento, calculado a través del alfa de Cronbach, con la finalidad de revisar que el conjunto de ítems de cada escala midiera el constructo de manera consistente. En los varones de 13 a 15 años, valores se encuentran entre .46 y .87; y en los de 16 a 18 años, se encuentran entre .56 y .88. Por otro lado, en las mujeres de 13 a 15 años, los valores oscilan entre 47 y .87; y en las de 16 a 18 años de .58 a .87 . En este análisis no se incluyeron el índice de inconsistencia ni la escala de impresión positiva debido a la manera en que se han calculado. Los resultados fueron satisfactorios a pesar de que algunas escalas tienen pocos ítems (Ugarriza y Pajares, 2005).

Además, se calculó la media de las correlaciones inter-ítems para confirmar que los ítems de cada escala midieran de manera consistente el mismo constructo. Las correlaciones obtenidas refuerzan el soporte para la consistencia interna de las escalas, las cuales aumentan según la edad (Ugarriza y Pajares, 2005).

Con respecto a las evidencias de validez, se estudió la estructura interna del inventario. Para ello, se analizaron los 40 ítems de las escalas interpersonal, intrapersonal, manejo del estrés y adaptabilidad, las cuales corresponden a las escalas utilizadas para medir la inteligencia emocional total. Por lo tanto, el análisis factorial realizado con los componentes principales confirmó las cuatro dimensiones del inventario, las cuales 
explican en un $28.05 \%$ el constructo que se buscaba medir. Esta información fue proporcionada directamente por las autoras de la adaptación del instrumento (Tabla 4.8).

Tabla 4.9

Pesos de los ítems en el Análisis Factorial Exploratorio (4 factores) del BarOn ICE:

NA - Forma Larga

\begin{tabular}{|c|c|c|c|c|}
\hline ÍTEMS & 1 & 2 & 3 & 4 \\
\hline 30 Puedo dar buenas respuestas a preguntas difíciles & .643 & & & \\
\hline $\begin{array}{l}38 \text { Puedo usar fácilmente diversos modos de resolver } \\
\text { problemas }\end{array}$ & .605 & & & \\
\hline $\begin{array}{l}34 \text { Puedo tener muchas maneras de responder una } \\
\text { pregunta difícil, cuando yo quiero }\end{array}$ & .604 & & & \\
\hline 22 Puedo comprender preguntas difíciles & .597 & & & \\
\hline 48 Soy bueno (a) resolviendo problemas & .575 & & & \\
\hline $\begin{array}{l}44 \text { Cuando respondo preguntas difíciles trato de pensar en } \\
\text { muchas soluciones }\end{array}$ & .445 & & & \\
\hline $\begin{array}{l}12 \text { Intento usar diferentes formas de responder las } \\
\text { preguntas difíciles }\end{array}$ & .438 & & & \\
\hline $\begin{array}{l}25 \text { No me doy por vencido (a) ante un problema hasta que } \\
\text { lo resuelvo }\end{array}$ & .418 & & & \\
\hline $\begin{array}{l}57 \text { Aún cuando las cosas sean difíciles, no me doy por } \\
\text { vencido }\end{array}$ & .394 & & & \\
\hline 16 Es fácil para mí comprender las cosas nuevas & .328 & & & \\
\hline 11 Sé cómo mantenerme tranquilo & .264 & & & \\
\hline 39 Demoro en molestarme & .202 & & & \\
\hline 35 Me disgusto fácilmente & & .664 & & \\
\hline 54 Me molesto fácilmente & & .655 & & \\
\hline 26 Tengo mal genio & & .570 & & \\
\hline 58 Cuando me molesto actúo sin pensar & & .569 & & \\
\hline $\begin{array}{l}46 \text { Cuando estoy molesto (a) con alguien, me siento } \\
\text { molesto (a) por mucho tiempo }\end{array}$ & & .542 & & \\
\hline 15 Me molesto demasiado de cualquier cosa & & .520 & & \\
\hline 21 Peleo con la gente & & .496 & & \\
\hline 49 Para mí es difícil esperar mi turno & & .437 & & \\
\hline 3 Puedo mantener la calma cuando estoy molesto & & .260 & & \\
\hline 53 Me es difícil decirle a los demás mis sentimientos & & .260 & & \\
\hline 6 Me es difícil controlar mi cólera & & .230 & & \\
\hline $\begin{array}{l}45 \text { Me siento mal cuando las personas son heridas en sus } \\
\text { sentimientos }\end{array}$ & & & .590 & \\
\hline 55 Puedo darme cuenta cuando mi amigo se siente triste & & & .556 & \\
\hline 5 Me importa lo que les sucede a las personas & & & .538 & \\
\hline 36 Me agrada hacer las cosas para los demás & & & .504 & \\
\hline $\begin{array}{l}59 \text { Sé cuando la gente está molesta aún cuando no dicen } \\
\text { nada }\end{array}$ & & & .464 & \\
\hline 51 Me agradan mis amigos & & & .449 & \\
\hline 20 Tener amigos es importante & & & .429 & \\
\hline $\begin{array}{l}2 \text { Soy muy bueno (a) para comprender como la gente se } \\
\text { siente }\end{array}$ & & & .410 & \\
\hline 10 Sé como se sienten las personas & & & .399 & \\
\hline 24 Intento no herir los sentimientos de las personas & & & .372 & \\
\hline 41 Hago amigos fácilmente & & & .351 & \\
\hline 14 Soy capaz de respetar a los demás & & & .345 & \\
\hline
\end{tabular}

(continúa) 
(continuación)

17 Puedo hablar fácilmente sobre mis sentimientos $\quad .707$

43 Para mí es fácil decirle a las personas cómo me siento $\quad .667$

31 Puedo fácilmente describir mis sentimientos $\quad .636$

7 Es fácil decirle a la gente cómo me siento $\quad .587$

28 Es difícil hablar sobre mis sentimientos más íntimos $\quad-.275$

$\begin{array}{lllll}\text { Eigenvalue } & 3.21 & 2.92 & 2.88 & 2.21\end{array}$

Nota: Fuente: Información proporcionada directamente por las autoras

A su vez, se analizaron las fuentes de validez con otros criterios externos. De este modo, se estudiaron las evidencias de validez concurrente del ICE: NA con la Escala de Depresión de Reynolds para Niños y Adolescentes; y, por otro lado, las evidencias de validez discriminante con el I-CE de BarOn para Adultos. En ambos se obtuvieron resultados satisfactorios (Ugarriza y Pajares, 2005).

\subsection{Procedimiento de recolección de datos}

Como paso previo, se contactó, vía correo electrónico, a los autores de las adaptaciones de las pruebas a utilizar, con la finalidad de autorizar el uso de estas en la presente investigación.

Para comenzar, se divulgó la convocatoria para participar en la presente investigación, a través de la red social de Facebook. En esta, se especificó el tema de estudio, el objetivo, las pruebas a aplicar y la población objetivo. Asimismo, se especificó que era voluntario y que se respetaría la confidencialidad. Asimismo, cabe recalcar que se utilizó este medio y un lenguaje coloquial debido a las características de la muestra. De esta manera, se fueron realizando las coordinaciones con quienes estaban dispuestos a formar parte del estudio. En las fechas acordadas se les entregó el consentimiento informado para los padres, la encuesta sociodemográfica y dos pruebas: Escala de Estilos Parentales Disfuncionales (MOPS) y el Inventario de la Inteligencia Emocional de BarOn (ICE), así como una breve explicación de manera oral sobre la investigación y las indicaciones para la resolución de las pruebas y la encuesta. De igual modo, se les reiteró acerca de la confidencialidad y la importancia de la sinceridad en sus respuestas. Cabe resaltar que también se consideró el asentimiento de los adolescentes respecto a la participación en el presente estudio, el cual fue expresado de manera oral por los mismos. Los adolescentes o padres de estos notificaron a la evaluadora cuando los documentos 
estuvieron completos para recogerlos. En las fechas de devolución se les otorgaba la copia del consentimiento. La duración de la aplicación fue de aproximadamente 20 minutos en total. El consentimiento informado, la encuesta sociodemográfica, y las dos pruebas se encuentran adjuntas en los anexos 1, 2, 3 y 4 , respectivamente.

Esta recolección de datos tomó cuatro semanas aproximadamente, teniendo en cuenta cualquier imprevisto que pudiera presentarse. 


\section{CAPÍTULO V: RESULTADOS}

En primer lugar, se exponen los resultados descriptivos de las variables de estudio en la muestra. Posteriormente, se presentan los resultados inferenciales, es decir las correlaciones entre las variables estudiadas (EP e IE).

\subsection{Estadísticos descriptivos}

Los estadísticos descriptivos fueron calculados para las variables inteligencia emocional y estilos parentales. De este modo, también se calculó los valores mínimos y máximos, la media aritmética, la desviación estándar, la asimetría y la curtosis. Los resultados referidos a los estilos parentales se muestran en la Tabla 5.1.

En cuanto a los estilos parentales del padre, el reporte de la media más alta corresponde a la sub escala de abuso (2.86) y la más baja a la sub escala de sobreprotección (.78). En lo referido a los estilos parentales de la madre, la media más alta corresponde a la sub escala de abuso (2.11), mientras que la más baja de la sub escala de indiferencia (1.34).

En relación a la asimetría y curtosis, se identifica una asimetría positiva $(>0)$ en todas las dimensiones, es decir que se agrupan más valores por debajo de la media. Además, se halló una curva leptocúrtica $(>0)$, lo cual indica una distribución elevada (Hernández-Sampieri y Mendoza, 2018).

Tabla 5.1

Características de las dimensiones de estilos parentales disfuncionales

\begin{tabular}{lcccccc}
\hline & Mín. & Máx. & M & DE & Asimetría & Curtosis \\
\hline $\begin{array}{l}\text { Abuso del padre } \\
\begin{array}{l}\text { Sobreprotección } \\
\text { del padre }\end{array}\end{array}$ & 0 & 13 & 2.86 & 2.49 & 1.25 & 2.51 \\
$\begin{array}{l}\text { Indiferencia del } \\
\text { padre }\end{array}$ & 0 & 4.5 & 0.78 & .94 & 1.50 & 2.66 \\
$\begin{array}{l}\text { Abuso de la } \\
\text { madre }\end{array}$ & 0 & 6.4 & 1.68 & 1.71 & 1.14 & 0.54 \\
\hline
\end{tabular}

(continúa) 
(continuación)

\begin{tabular}{lcccccc}
\hline $\begin{array}{l}\text { Sobreprotección } \\
\text { de la madre }\end{array}$ & 0 & 7 & 1.99 & 1.60 & .88 & 0.43 \\
$\begin{array}{l}\text { Indiferencia de la } \\
\text { madre }\end{array}$ & 0 & 7 & 1.34 & 1.37 & 1.45 & 2.95 \\
$\begin{array}{l}\text { Estilos parentales } \\
\text { del padre }\end{array}$ & 0 & 21 & 5.33 & 4.59 & 1.45 & 2.14 \\
$\begin{array}{l}\text { Estilos parentales } \\
\text { de la madre }\end{array}$ & 0 & 19 & 5.44 & 4.43 & 1.18 & 1.04 \\
$\mathrm{~N}=77$ & & & & &
\end{tabular}

Del mismo modo, se obtuvieron los estadísticos descriptivos para la variable de inteligencia emocional, los cuales se muestran en la Tabla 5.2.

Se observa que la media más alta corresponde a la dimensión de estado de ánimo (43.61) y la más baja a la dimensión intrapersonal (13.49). Por otro lado, se evidencia una asimetría negativa en todas las dimensiones $(<0)$, lo que se interpreta como la concentración de datos por encima de la media. Respecto a la curtosis, en las dimensiones intrapersonal y de manejo del estrés, se identifica una curva platicúrtica $(<0)$, es decir una distribución predominantemente plana, mientras que, en las dimensiones interpersonal, de adaptabilidad y de estado del ánimo prevalece una curva leptocúrtica (>0), lo cual indica una distribución elevada (Hernández-Sampieri y Mendoza, 2018).

Tabla 5.2

Características de las dimensiones de inteligencia emocional

\begin{tabular}{lcccccc}
\hline & Mín. & Máx. & M & DE & Asimetría & Curtosis \\
\hline Intrapersonal & 6 & 24 & 13.49 & 4.13 & -.05 & -0.05 \\
Interpersonal & 19 & 48 & 39.13 & 5.43 & -.95 & 1.85 \\
Adaptabilidad & 19 & 40 & 29.49 & 4.29 & -.05 & 0.25 \\
Manejo del estrés & 19 & 46 & 34.06 & 6.42 & -.07 & -0.33 \\
Estado de ánimo & 20 & 56 & 43.61 & 7.56 & -.77 & 0.47 \\
\hline $\mathrm{N}=77$ & & & & & &
\end{tabular}

Se realizó la prueba de normalidad de Shapiro-Wilk (Tablas 5.3 y 5.4), dado que es considerada como una de las pruebas más potentes para esta finalidad (Moni, 2015; Saculinggan y Balase, 2013), para comprobar si los puntajes de las variables (IE y EP) se distribuyen normalmente. El objetivo de este análisis apunta a comprobar uno de los supuestos necesarios para decidir la utilización del coeficiente de correlación de Pearson o el coeficiente por rangos de Spearman, prueba paramétrica y no paramétrica, respectivamente (Alarcón, 2013). 
En cuanto a la variable de inteligencia emocional, respecto a las dimensiones intrapersonal $(\mathrm{p}=.06)$, de adaptabilidad $(\mathrm{p}=.30)$ y manejo del estrés $(\mathrm{p}=.23)$ se puede concluir que la distribución muestral no corresponde a una distribución normal ( $p>.05)$. Por otro lado, las dimensiones, interpersonal $(\mathrm{p}<.001)$ y de estado del ánimo $(\mathrm{p}=.01)$, indican que la distribución muestral no se asemeja a una distribución muestral normal.

En relación a la variable de estilos parentales, se concluye que la distribución muestral de ninguna de las dimensiones, tanto del padre como de la madre, desde abuso hasta indiferencia, provienen de una distribución normal $(p<.001)$.

Tabla 5.3

Prueba de normalidad para las dimensiones de la variable de inteligencia emocional según Shapiro-Wilk

\begin{tabular}{lcc}
\hline & Estadístico & Sig. \\
\hline Intrapersonal & .97 & .06 \\
Interpersonal & .94 & $<.001$ \\
Adaptabilidad & .98 & .30 \\
Manejo del estrés & .98 & .23 \\
Estado de ánimo & .96 & .01 \\
\hline gl=77 & &
\end{tabular}

Tabla 5.4

Prueba de normalidad para las dimensiones de la variable de estilos parentales disfuncionales según Shapiro-Wilk

\begin{tabular}{lcc}
\hline & Estadístico & Sig. \\
\hline Abuso del padre & .90 & $<.001$ \\
Sobreprotección del padre & .77 & $<.001$ \\
Indiferencia del padre & .83 & $<.001$ \\
Abuso de la madre & .81 & $<.001$ \\
Sobreprotección de la madre & .88 & $<.001$ \\
Indiferencia de la madre & .83 & $<.001$ \\
\hline gl=77 & &
\end{tabular}

Asimismo, se llevaron a cabo los respectivos gráficos de dispersión para cada dimensión. Estos se encuentran en el anexo 6.

Dado lo expuesto, resulta pertinente utilizar pruebas no paramétricas, como lo es el coeficiente por rangos de Spearman (Field, 2009), debido a que el supuesto de normalidad no se cumple en las variables a estudiar, ni las variables, en su totalidad, presentan una relación lineal. 


\subsection{Estadísticos inferenciales}

Se analizó la relación entre los puntajes de las dimensiones de estilos parentales, tanto de la madre como del padre, y aquellos de las dimensiones de inteligencia emocional, haciendo uso del coeficiente de correlación Rho de Spearman ( $r s)$. Los resultados de la correlación entre las dimensiones de los estilos parentales del padre y las dimensiones de la inteligencia emocional se encuentran en la Tabla 5.5.

Es posible identificar una relación negativa y estadísticamente significativa entre la dimensión intrapersonal y el grado de abuso del padre $\left(r_{s}=-.22\right)$. Al mismo tiempo esta última dimensión del padre demuestra una relación negativa y estadísticamente significativa con las dimensiones de manejo del estrés $\left(r_{s}=-.28\right)$ y el estado de ánimo $\left(r_{s}\right.$ $=-.23)$ del adolescente.

Por otro lado, en cuanto a la dimensión de sobreprotección del padre, se identifica una relación negativa y estadísticamente significativa con la dimensión intrapersonal $\left(r_{s}\right.$ $=-.37)$, de manejo del estrés $\left(r_{s}=-.28\right)$ y del estado de ánimo $\left(r_{s}=-.23\right)$.

Por último, en referencia a la dimensión de indiferencia del padre, es posible observar una relación negativa y estadísticamente significativa entre la dimensión intrapersonal $\left(r_{s}=-.20\right)$ y de manejo del estrés $\left(r_{s}=-.27\right)$ del adolescente.

\section{Tabla 5.5}

Correlación entre las dimensiones de estilos parentales disfuncionales del padre y las dimensiones de la inteligencia emocional

\begin{tabular}{lccc}
\hline & Abuso del padre & $\begin{array}{c}\text { Sobreprotección del } \\
\text { padre }\end{array}$ & $\begin{array}{c}\text { Indiferencia del } \\
\text { padre }\end{array}$ \\
\hline Intrapersonal & $r_{s}$ & $r_{s}$ & $r_{s}$ \\
Interpersonal & $-.22 *$ & $-.37 * *$ & $-.20^{*}$ \\
Adaptabilidad & -.09 & -.01 & -.02 \\
Manejo del estrés & -.03 & -.09 & -.11 \\
Estado del ánimo & $-.28^{* *}$ & $-.28^{* *}$ & $-.27 *$ \\
${ }^{*} p<.05 ; * * p<.01$ & $-.23 *$ & $-.23^{*}$ & -.01 \\
\hline
\end{tabular}

Del mismo modo, se hizo la correlación entre las dimensiones de estilos parentales de la madre y las dimensiones de la inteligencia emocional. Estos resultados se grafican en la Tabla 5.6. 
En cuanto a la escala de la madre, se observa una relación negativa y estadísticamente significativa entre la dimensión intrapersonal y el grado de abuso de la madre $\left(r_{s}=-.32\right)$. Al mismo tiempo esta última dimensión de la madre demuestra una relación negativa y estadísticamente significativa con las dimensiones de manejo del estrés $\left(r_{s}=-.27\right)$ y el estado de ánimo $\left(r_{s}=-.22\right)$ del adolescente.

Por otro lado, en cuanto a la dimensión de sobreprotección de la madre, se identifica una relación negativa y estadísticamente significativa con la dimensión intrapersonal $\left(r_{s}=-.37\right)$, de manejo del estrés $\left(r_{s}=-.31\right)$ y del estado de ánimo $\left(r_{s}=-.27\right)$.

Por último, en referencia a la dimensión de indiferencia de la madre, es posible observar una relación negativa y estadísticamente significativa entre la dimensión intrapersonal $\left(r_{s}=-.25\right)$, adaptabilidad $\left(r_{s}=-.21\right)$ y de manejo del estrés $\left(r_{s}=-.34\right)$ del adolescente.

Con respecto al tamaño del efecto, los coeficientes de correlación son utilizados, a su vez, como una medida estandarizada para analizar el tamaño del efecto. De este modo, si el valor del coeficiente es \pm .1 , el tamaño del efecto es pequeño; si es \pm .3 , representa un efecto mediano y si es \pm .5 corresponde a un efecto grande (Field, 2009). En cuanto a la escala de la madre, los valores oscilan entre -.21 y -.37, lo cual indicaría un tamaño del efecto pequeño a moderado. Por otro lado, en la escala del padre, los valores se encuentran entre -.20 y -.37, lo que indicaría, también, un tamaño del efecto pequeño a moderado.

Tabla 5.6

Correlación entre las dimensiones de estilos parentales disfuncionales de la madre y las dimensiones de la inteligencia emocional

\begin{tabular}{llcc}
\hline & $\begin{array}{c}\text { Abuso de la } \\
\text { madre }\end{array}$ & $\begin{array}{c}\text { Sobreprotección de } \\
\text { la madre }\end{array}$ & $\begin{array}{c}\text { Indiferencia de la } \\
\text { madre }\end{array}$ \\
\hline Intrapersonal & $r_{s}$ & $r_{s}$ & $r_{s}$ \\
Interpersonal & $-.32^{* *}$ & $-.37^{* *}$ & $-.25^{*}$ \\
Adaptabilidad & -.15 & -.15 & -.11 \\
Manejo del estrés & -.04 & -.03 & $-.21^{*}$ \\
Estado del ánimo & $-.27 * *$ & $-.31 * *$ & $-.34^{* *}$ \\
$* p<.05 ; * p<.01$ & $-.22^{*}$ & $-.27^{* *}$ & -.17 \\
\hline
\end{tabular}




\section{CAPÍTULO VI: DISCUSIÓN}

El objetivo de la presente investigación fue relacionar las dimensiones de los estilos parentales de abuso, indiferencia y sobreprotección, tanto del padre como de la madre, con las dimensiones de la inteligencia emocional: intrapersonal, interpersonal, adaptabilidad, manejo del estrés y estado del ánimo en 77 adolescentes de 13 a 17 años de instituciones educativas privadas de la ciudad de Lima.

En relación a los resultados del análisis descriptivo, la mayoría de los adolescentes que participaron en este estudio viven con sus padres y estos son, en su mayoría, casados. En cuanto a los estilos parentales, se identificó que, en general, estos son percibidos por los adolescentes como medianamente disfuncionales. De manera específica, los adolescentes perciben un nivel moderadamente disfuncional de abuso e indiferencia, tanto de los padres como de las madres. Esto quiere decir un patrón de crianza en el que las reglas se imponen y se espera una obediencia estricta, además del poder ejercido por los padres sobre los hijos. Asimismo, identifican una moderada ausencia de exigencias y de cumplimiento de responsabilidades, acompañadas de la falta de estructuración, control y apoyo por parte de los padres (Matalinares et al., 2016). Coinciden, además, en que no perciben niveles disfuncionales de sobreprotección de ambos padres. Esto implica que reconocen a sus padres como sensibles a sus necesidades, muestran niveles de firmeza adecuados y esperan acciones maduras de sus hijos (Matalinares et al., 2016).

Por otro lado, en referencia a la inteligencia emocional, los adolescentes muestran un nivel por encima del promedio en cuanto a su manejo interpersonal, su adaptabilidad y su estado de ánimo. Por tanto, son capaces de entablar relaciones interpersonales satisfactorias caracterizadas por empatía, cercanía emocional e intimidad; hacen frente a los problemas con soluciones efectivas y demuestran un ajuste adecuado de emociones, pensamientos y conductas a las situaciones cambiantes del entorno; finalmente, evidencian un estado de satisfacción con la vida y con sí mismos, así como mantienen una actitud positiva, a pesar de la adversidad (Ugarriza y Pajares, 2005). Sin embargo, sus niveles de tolerancia y capacidad para soportar y enfrentar asertiva y efectivamente situaciones estresantes y emociones fuertes, así como controlar impulsos, se evidencian 
por debajo de lo esperado. Asimismo, se ve disminuidas su capacidad para el reconocimiento, comprensión y expresión asertiva de emociones, su capacidad para proponerse y lograr metas personales, y su autoconcepto.

Cabe resaltar que los adolescentes se encuentran en búsqueda de la individuación, lo cual implica el volverse autónomos y desarrollar la identidad personal. De tal manera, los padres deben apoyar y contribuir con este proceso, brindándoles la independencia y restringiendo mensajes inmaduros o críticos que puedan perjudicar tal búsqueda (Papalia et al., 2009). De acuerdo a los resultados, si los padres ejercen estos tres tipos de estilos parentales disfuncionales, limitarían el desarrollo del adolescente, impactando en la consecución de su autonomía e identidad personal.

En cuanto a la relación entre las dimensiones de los estilos parentales y las dimensiones de la inteligencia emocional, se acepta la hipótesis planteada, debido a que se encuentra una relación estadísticamente significativa, de tipo negativa, entre ciertas dimensiones de ambas variables. Por tanto, se interpreta que, mientras los estilos parentales sean más disfuncionales, siendo estos el abuso, la sobreprotección y la indiferencia, el adolescente demostrará un menor grado de inteligencia emocional, principalmente en las habilidades intrapersonal, manejo del estrés, adaptabilidad y estado del ánimo. Esto concuerda con lo encontrado por Argyriou et al. (2016), quienes concluyeron que existe una relación negativa entre el estilo parental autoritario, es decir que su nivel de involucramiento con los hijos es bajo, sin embargo, el grado de control y exigencia son muy altos, pudiendo identificarse un poder, proveniente de los padres, sobre los hijos (Baumrind, 1966), y la inteligencia emocional disminuida. No obstante, los resultados del presente estudio difieren de lo hallado por George et al. (2017), quienes no encontraron una relación entre los estilos parentales y la inteligencia emocional, lo cual se debe, posiblemente, al nivel educativo de los padres de dicho estudio.

De manera específica, tanto por parte del padre como de la madre, se identifica que, a mayores niveles de abuso y sobreprotección, mayores dificultades evidencian los adolescentes en cuanto a su desarrollo intrapersonal, el manejo del estrés y el estado de ánimo. Por tanto, un estilo de crianza en el que predomina la estructura, las reglas y las altas expectativas de obediencia, así como también el poder que los padres ejercen sobre los hijos y el uso de medidas punitivas (Matalinares et al., 2016), produce en los adolescentes una comprensión y expresión pobre de las propias emociones y de ellos 
mismos; dificultades en el manejo, cambio y resolución de problemas intra e interpersonales; y un bajo nivel de optimismo y apreciación positiva de los hechos cotidianos (Ugarriza y Pajares, 2005). Estas mismas consecuencias a nivel de inteligencia emocional se observan ante un estilo parental disfuncional en el que predomina la sobreprotección, es decir que los padres ejercen un bajo control, pero una alta exigencia, la cual no responde a las necesidades de los adolescentes. A ello, se le suma una comunicación de tipo poco efectiva y unidireccional, del padre hacia el hijo (Matalinares et al., 2016). Estudios previos confirman que un estilo parental autoritario, el cual se asemeja al estilo parental disfuncional de abuso, conlleva a que los adolescentes sean obedientes, pero con un pobre autoconcepto (Torío et al., 2008).

Por otro lado, ante un alto grado de indiferencia de la madre, es decir que, en su estilo parental, carecen de estructuración, control y apoyo, presentando una actitud indiferente y trasladan sus responsabilidades a otros agentes (Matalinares et al., 2016), los adolescentes presentan dificultades en lo que se refiere a la capacidad para comprender y expresar sus propias emociones; manejar y controlar las propias emociones para usarlas de manera efectiva ante las situaciones de cambio; y en el manejo de estados emocionales de gran intensidad en situaciones o eventos estresantes. En relación a los padres, el grado de indiferencia impacta en los adolescentes, generando una pobre comprensión de sí mismos y sus emociones y dificultades en la manera en cómo manejan, cambian y resuelven diversas situaciones o conflictos, tanto intra como interpersonales.

Por otro lado, dada la relación encontrada entre las dimensiones de inteligencia emocional y estilos parentales, se confirma la importancia de la familia, siendo esta el núcleo socializador de la persona (Goleman, 2011; Olmedo, 2013; Sánchez-Núñez y Latorre, 2012), en el desarrollo general y, sobre todo, emocional del individuo. De este modo, en el presente estudio se halló que los vínculos parentales disfuncionales se asocian negativamente con las habilidades y competencias emocionales de los adolescentes. Ello, reafirma la literatura, que indica que la buena crianza, los lazos afectivos, el apoyo familiar y la interacción entre padres e hijos actúa como predictor de la salud mental y el bienestar general de la persona (OMS, 2004; Papalia et al, 2009; Goleman, 2011).

A pesar de que estos resultados contribuyen al entendimiento de la relación entre los estilos parentales y la inteligencia emocional, es importante mencionar que el estudio 
presenta algunas limitaciones. En primer lugar, se identifica una restricción en la capacidad de generalización, dado que se utiliza un muestreo no probabilístico, debido a la dificultad existente para acceder a la población; principalmente por ser menores de edad. A su vez, el tamaño de la muestra, al ser pequeño, limita la capacidad de generalizar los resultados a toda la población adolescente. De este modo, solo podrán generalizarse los resultados a grupos humanos con las mismas características de la muestra.

Por otro lado, otra posible limitación es la deseabilidad social, por parte de los adolescentes, al responder los cuestionarios. Así, se recibieron comentarios, al finalizar las pruebas, relacionados a la manera en la cual estaban redactados los ítems, siendo estos percibidos como "muy directos" por los participantes. Por tanto, es importante tener en consideración esta limitación, puesto que las respuestas podrían mostrar una tendencia hacia aquello socialmente aceptado o esperado, aún más en esta población (adolescentes), quienes están en proceso de desarrollar su identidad (Lemos, 2005).

No obstante, los hallazgos representan un aporte empírico para complementar la comprensión de la relación entre los estilos parentales y la inteligencia emocional. Es posible identificar estudios que exploran cada una de estas variables y su relación con otras como el ajuste psicosocial (Salguero, Fernández-Berrocal, Ruiz-Aranda, Castillo y Palomera, 2011), el éxito académico (Parker et al., 2004), clima familiar (Sánchez-Núñez y Latorre, 2012), satisfacción general de vida (Palmer et al., 2002), entre otras. Sin embargo, existen pocas investigaciones que relacionan los EP y la IE, menos en el contexto peruano. Por ello, el presente estudio representa una de las primeras aproximaciones de la relación entre los estilos parentales y la inteligencia emocional en los adolescentes de la ciudad de Lima.

Asimismo, esta investigación, en específico sus resultados, contribuyen de manera práctica en la estructuración y planificación de programas de intervención, tanto en el área de la inteligencia emocional como de los estilos parentales. De tal modo, se pueden abordar temáticas relacionadas a las dimensiones de manejo del estrés, adaptabilidad, estado del ánimo e intrapersonal. Por otro lado, en cuanto a los estilos parentales, se puede intervenir promoviendo prácticas de crianza más asertivas y efectivas como la disciplina positiva, la cual, para disciplinar, no hace uso del castigo, sino del respeto mutuo (Nelsen y Lott, 2005). 


\section{CONCLUSIONES}

A continuación, se muestran las conclusiones de la presente investigación:

- Las dimensiones de los estilos parentales disfuncionales evidencian una relación estadísticamente significativa, de tipo negativa, con las dimensiones de la inteligencia emocional.

- En general, se halló un tamaño del efecto de pequeño a moderado, puesto que los coeficientes de correlación, usados también como medida del tamaño del efecto correspondían al criterio de \pm .1 .

- Los estilos parentales percibidos por los adolescentes fueron medianamente disfuncionales, tanto del padre como de la madre. Aun así, se evidencia una relación significativa con la inteligencia emocional de los adolescentes.

- Se halló que, tanto en padres como en madres, a mayores niveles de abuso y sobreprotección, menor capacidad para manejarse de manera intrapersonal, afrontar situaciones estresantes y expresar una percepción optimista de los eventos cotidianos o experiencias.

- Se identifica, por parte del padre, que, a mayor grado de indiferencia en su estilo de crianza, mayores dificultades puede presentar el adolescente en su competencia intrapersonal y de manejo del estrés.

- Por parte de la madre, cuando el grado de indiferencia es mayor, se presentan mayores consecuencias negativas para el adolescente, viéndose comprometida su competencia intrapersonal, su capacidad de adaptabilidad ante situaciones nuevas o de cambio y su habilidad para manejar sus estados emocionales en situaciones de estrés. 


\section{RECOMENDACIONES}

En vista de los resultados del presente estudio y con la finalidad de mejorar futuras, se formulan las siguientes recomendaciones:

- Para próximas investigaciones sobre la relación entre ambas variables, contemplar una muestra más numerosa, con la finalidad de lograr una mayor generalización de los hallazgos.

- Estudiar la relación entre los estilos parentales y la inteligencia emocional en otros contextos del país, puesto que en la presente investigación se focalizó en adolescentes que asistieran a instituciones educativas particulares. De este modo, sería posible realizar una comparación entre ambos tipos de contextos y llegar a una mejor compresión del comportamiento de estas variables.

- En relación a los padres, llevar a cabo talleres vivenciales de disciplina positiva, la cual se basa en el respeto mutuo en la crianza de los hijos. De este modo, se afirma la autoestima de los adolescentes (Nelsen y Lott, 2005), uno de los aspectos esenciales para que este pueda comprender y expresar las propias emociones y a uno mismo (intrapersonal). A su vez, estos talleres contribuyen a mejorar los estilos de crianza disfuncionales utilizados por los padres basados en indiferencia, sobreprotección y abuso.

- En cuanto a los adolescentes, se observó que poseen dificultades para manejar y controlar sus emociones de acuerdo a las diversas situaciones (adaptabilidad), para manejar, cambiar y resolver problemas intra e interpersonales (manejo del estrés), así como también para el reconocimiento, comprensión y expresión asertiva de emociones y su capacidad para proponerse y lograr metas, y su autoconcepto (intrapersonal). Para ello, brindarles herramientas y estrategias a los adolescentes, a manera de dinámicas grupales, enfocadas en afrontar las dificultades mencionadas. Asimismo, el trabajo en grupo contribuye al fortalecimiento del componente interpersonal en los adolescentes, haciendo énfasis en la empatía al realizar las sesiones. Resulta importante, a su vez, realizar 
un seguimiento individual enfocado en el desarrollo del área intrapersonal, de acuerdo a las necesidades y características de cada adolescente. 


\section{REFERENCIAS}

Alarcón, R. (2013). Métodos y diseños de investigación del comportamiento. Lima: Universitaria.

Anand, R. (2010). Emotional Intelligence and Its Relationship with Leadership Practices. International Journal of Business and Management, 5(2), 65-76. Recuperado de https://gr8synergy.com/nimpathways/wp-content/uploads/2016/04/4359-156001-PB.pdf

Argyriou, E., Bakoyannis, G., \& Tantaros, S. (2016). Parenting styles and trait emotional intelligence in adolescence. Scandinavian Journal of Psychology, 57(1), 42-49. https://doi.org/10.1111/sjop.12266

Arranz, E. y Oliva, A. (2010). Desarrollo psicológico en las nuevas estructuras familiares. Madrid: Pirámide.

Bar-On, R. (2006). The Bar-On model of emotional-social intelligence (ESI). Psicothema, 18, 13-25. Recuperado de http://www.psicothema.com/pdf/3271.pdf

Bar-On. R. (2013). The 15 factors of the Bar-On model. Recuperado de http://www.reuvenbaron.org/wp/the-5-meta-factors-and-15-sub-factors-of-thebar-on-model/

Batool, S., \& Bond, R. (2015). Mediational role of parenting styles in emotional intelligence of parents and aggression among adolescents. International Journal of Psychology, 50(3), 240-244. https://doi.org/10.1002/ijop.12111

Baumrind, D. (1966). Effects of Authoritative Parental Control on Child Behavior. Child Development, 37(4), 887. doi:10.2307/1126611

Baumrind, D. (1971). Current patterns of parental authority. Developmental Psychology Monograph, 4(1), 1-103. Recuperado de http://dx.doi.org/10.1037/h0030372

Baumrind, D. (1991). The Influence of Parenting Style on Adolescent Competence and Substance Use. The Journal of Early Adolescence, 11(1), 56-95. doi:10.1177/0272431691111004 
Becerra, S., Roldán, W. y Aguirre, M. (2008). Adaptación del cuestionario de crianza parental (pcri-m) en Canto Grande. Pensamiento Psicológico, 4(11), 135-150. Recuperado

de http://revistas.javerianacali.edu.co/index.php/pensamientopsicologico/article/vie $\mathrm{w} / 84$

Brackett, M. A., \& Mayer, J. D. (2003). Convergent, discriminant, and incremental validity of competing measures of emotional intelligence. Personality and Social Psychology Bulletin, 29(9), 1147-1158. https://doi.org/10.1177/0146167203254596

Brackett, M., Rivers, S., Shiffman, S., Lerner, N., \& Salovey, P. (2006). Relating emotional abilities to social functioning: A comparison of self-report and performance measures of emotional intelligence. Journal of Personality and Social Psychology, 91(4), 780. http://dx.doi.org/10.1037/0022-3514.91.4.780

Brackett, M., Warner, R., \& Bosco, J. (2005). Emotional intelligence and relationship quality among couples. Personal Relationships, 12(2), 197-212. https://doi.org/10.1111/j.1350-4126.2005.00111.x

Bronfenbrenner, U. (1987). La ecología del desarrollo humano: experimentos en entornos naturales y diseñados. Barcelona: Paidós.

Buchner, A., Erdfelder, E., Faul, F., \& Lang, A. G. (2014). G* Power (versión 3.1. 9.2). [Software de computación]. Recuperado de http://www.gpower.hhu.de

Ciarrochi, J., Deane, F. P., \& Anderson, S. (2002). Emotional intelligence moderates the relationship between stress and mental health. Personality and Individual Differences, 32(2), 197-209. https://doi.org/10.1016/S0191-8869(01)00012-5

Darling, N., \& Steinberg, L. (1993). Parenting style as context: An integrative model. Psychological Bulletin, 113(3), 487-496.

Di Fabio, A., \& Palazzeschi, L. (2008). Emotional intelligence and self-efficacy in a sample of italian hig school teachers. Social Behavior and Personality, 36(3), 315-326. https://doi.org/10.2224/sbp.2008.36.3.315 
Eisenberg, N., Morris, A. S., McDaniel, B., \& Spinrad, T. L. (2004). Moral cognitions and prosocial responding in adolescence. Handbook of Adolescent Psychology, 2, 155-188. Recuperado de https://books.google.com.pe/

Esnaola, I., Revuelta, L., Ros, I., \& Sarasa, M. (2017). The development of emotional intelligence in adolescence. Annals of Psychology, 33(2), 327-333. Recuperado de http://revistas.um.es/analesps/article/view/analesps.33.2.251831/210691

Espina, A., Ortego, M. A., Ochoa de Alda Martínez, I., \& Alemán, A. (2001). Alexithymia, family and eating disorders. Annals of Psychology, 17(1), 139-149. Recuperado de https://revistas.um.es/analesps/article/view/29141

Estévez, E. (2013). Los problemas en la adolescencia. Madrid: Síntesis

Extremera, N. y Fernández-Berrocal, P. (2004). El papel de la inteligencia emocional en el alumnado: evidencias empíricas. Revista Electrónica de Investigación Educativa, 6(2), 1-17. Recuperado de https://dialnet.unirioja.es/servlet/articulo?codigo=1068423

Extremera, N., Fernández-Berrocal, P., Ruiz-Aranda, D. y Cabello, R. (2006). Inteligencia emocional, estilos de respuesta y depresión. Ansiedad y Estrés, 12(23), 191-205. Recuperado de https://www.researchgate.net/profile/Pablo_FernandezBerrocal/publication/230886989_Emotional_Intelligence_responses_styles_and _depression/links/00b7d52e57d24d208d000000.pdf

Field, A. (2009). Discovering statistics using SPSS. Londres: Sage Publications.

Florenzano, R. (2002). El adolescente y sus conductas de riesgo. Santiago de Chile: Universidad Católica de Chile.

Flores, E. (2016). Propiedades psicométricas del Inventario de Inteligencia Emocional de BarOn Ice: Na en estudiantes de educación secundaria de algunas Instituciones Educativas Privadas del Distrito de Trujillo. (Tesis de Licenciatura). Universidad César Vallejo, Trujillo. Recuperado de http://repositorio.ucv.edu.pe/bitstream/handle/UCV/321/flores_ve.pdf?sequence $=1 \&$ is Allowed $=\mathrm{y}$ 
Galambos, N. L., Barker, E. T., \& Almeida, D. M. (2003). Parents do matter: Trajectories of change in externalizing and internalizing problems in early adolescence. Child Development, 74(2), 578-594. https://doi.org/10.1111/1467-8624.7402017

García-Fernández, M. y Giménez-Mas, S. (2010). La inteligencia emocional y sus principales modelos: propuesta de un modelo integrador. Espiral. Cuadernos del Profesorado, 3(6), 43-52. Recuperado de http://ojs.ual.es/ojs/index.php/ESPIRAL/article/view/909/828

George, J. (2000). Emotions and leadership: The role of emotional intelligence. Human Relations, 53(8), 1027-1055. https://doi.org/10.1177/0018726700538001

George, N., Shanbhag, D., George, M., Shaju, A., Johnson, R., Mathew, P., ... \& Goud, R. (2017). A study of emotional intelligence and perceived parenting styles among adolescents in a rural area in Karnataka. Journal of Family Medicine and Primary Care, 6(4), 848. https://doi.org/10.4103/jfmpc.jfmpc_100_17

Goleman, D. (2011). Inteligencia emocional. Barcelona: Kairós.

Gómez, Y., Vallejo, V. J., Villada, J. y Zambrano-Cruz, R. (2010). Propiedades psicométricas del instrumento de Lazos Parentales (Parental Bonding Instrument, PBI) en la población de Medellín, Colombia. Pensando Psicología, 6(11), 65-73.

Graber, J. A., \& Sontag, L. M. (2009). Internalizing problems during adolescence. En R. M. Lerner \& L. Steinberg (Eds.), Handbook of adolescent psychology: Individual bases of adolescent development (pp. 587-626) https://doi.org/10.1002/9780471726746.ch19

Harwood, R., Leyendecker, B., Carlson, V., Asencio, M., \& Miller, A. (2002) Parenting among Latino Families in the U.S. En Bornstein (Ed.) Handbook of Parenting Vol.4. (pp. 21-46). Recuperado de https://books.google.com.pe/

Hernández, R., Fernández, C. y Baptista, P. (2014). Metodología de la Investigación (6 ${ }^{\mathrm{a}}$ ed.). México: McGraw-Hill.

Hernández-Sampieri, R. y Mendoza, C. (2018). Metodología de la investigación: Las rutas cuantitativa, cualitativa y mixta. McGraw-Hill: México.

Icick, R., Lauer, S., Romo, L., Dupuy, G., Lépine, J.-P., \& Vorspan, F. (2013). Dysfunctional parental styles perceived during childhood in outpatients with 
substance use disorders. Psychiatry Research, 210(2), 522-528. https://doi.org/10.1016/j.psychres.2013.06.041

Iglesias, B. y Romero, E. (2009). Estilos parentales percibidos, psicopatología y personalidad en la adolescencia. Revista de Psicopatología y Psicología Clínica, 14(2), 63-77. Recuperado de http://e-spacio.uned.es/fez/view/bibliuned:Psicopat2009-14-2-0001

Instituto Nacional de Estadística e Informática [INEI]. (2014). Una mirada a Lima Metropolitana. Recuperado de http://www.inei.gob.pe/media/MenuRecursivo/publicaciones_digitales/Est/Lib1 168/libro.pdf

Instituto Nacional de Salud Mental Honorio Delgado - Hideyo Noguchi [INSM]. (2012). Uno de cada ocho niños o adolescentes presentarán algún problema de salud mental. Recuperado de http://www.insm.gob.pe/oficinas/comunicaciones/notasdeprensa/2012/011.html

Irarrázaval, M., Prieto, F. y Armijo, J. (2016). Prevención e intervenciones tempranas en salud mental: una perspectiva internacional. Acta Bioethica, 22(1), 37-50. http://dx.doi.org/10.4067/S1726-569X2016000100005

Krumm, G., Vargas-Rubilar, J. y Gullón, S. (2013). Estilos parentales y creatividad en niños escolarizados. $\quad$ Psicoperspectivas, 12(1), 161-182. http://dx.doi.org/10.5027/psicoperspectivas-Vol12-Issue1-fulltext-223

Lam, L., \& Kirby, S. (2002). Is emotional intelligence an advantage? An exploration of the impact of emotional and general intelligence on individual performance. The Journal of Social Psychology, 142(1), 133-143. https://doi.org/10.1080/00224540209603891

Lemos, V. (2005). Construcción y validación de una escala para la evaluación de la deseabilidad social infantil (EDESI). Interdisciplinaria, 22(1), 77-96. Recuperado de http://www.redalyc.org/articulo.oa?id=18022104

Levin, E. (2011). Baumrind's parenting styles. En S. Goldstein \& J. A. Naglieri (Eds.), Encyclopedia of child behavior and development (pp. 213-215). Nueva York: Springer. http://doi.org/10.1007/978-0-387-79061-9_293 
Lopes, P. N., Salovey, P., Côté, S., Beers, M., \& Petty, R. E. (2005). Emotion Regulation Abilities and the Quality of Social Interaction. Emotion, 5(1), 113-118. http://dx.doi.org.ezproxy.ulima.edu.pe/10.1037/1528-3542.5.1.113

Lopes, P., Brackett, M., Nezlek, J., Schütz, A., Sellin, I., \& Salovey, P. (2004). Emotional intelligence and social interaction. Personality and Social Psychology Bulletin, 30(8), 1018-1034. https://doi.org/10.1177/0146167204264762

Mansueto, G., Palmieri, S., \& Faravelli, C. (2018). Parental style and Cloninger's model in psychosis. Psychiatry Research, 269, 221-228. https://doi.org/10.1016/j.psychres.2018.08.066

Marquina, R. (2016). Estilos educativos parentales y resiliencia en adolescentes de la institución educativa pública "Colegio Mayor Secundario Presidente del Perú" (tesis doctoral). Universidad San Martín de Porres, Lima. Recuperado de http://www.repositorioacademico.usmp.edu.pe/bitstream/usmp/2186/1/marquina _lrj.pdf

Más del 60\% de los pacientes de los servicios de Salud Mental son menores de 18 años. (25 de junio de 2019). El Comercio. Recuperado de https://elcomercio.pe/peru/60-pacientes-servicios-salud-mental-son-menores-18anos-noticia-649085-noticia/?ref=ecr

Matalinares, M., Arenas, C., Chocano, A., Muratta, R., Pareja, C., Díaz, G., ... Chávez, J. (2005). Inteligencia emocional y autoconcepto en colegiales de Lima Metropolitana. Revista de Investigación en Psicología, 8(2), 41-55. Recuperado de

http://repositorio.minedu.gob.pe/bitstream/handle/123456789/265/139.\%20Inteli gencia $\% 20$ emocional $\% 20 \mathrm{y} \% 20$ autoconcepto $\% 20$ en $\% 20$ colegiales $\% 20 \mathrm{de} \% 20 \mathrm{Li}$ ma\%20Metropolitana.pdf?sequence=1\&isAllowed=y

Matalinares, M., Díaz, G., Raymundo, O., Baca, D., Fernández, E., Uceda, J., ... Díaz, A. (2013). Influencia de los estilos parentales en la adicción al internet en alumnos de secundaria del Perú. Revista de Investigación en Psicología, 16(2), 195-220. https://doi.org/10.15381/rinvp.v16i2.6554 
Matalinares, M., Raymundo, O. y Baca, D. (2014). Propiedades psicométricas de la Escala de Estilos Parentales (MOPS). Persona, 17, 95-121. https://doi.org/10.26439/persona2014.n017.291

Matalinares, M., Raymundo, O. y Baca, D. (2016). Escala de Estilos Parentales Disfuncionales-MOPS-Perú [Manual]. Instrumento no publicado.

Mayer, J., \& Salovey, P. (1997). What is emotional intelligence? En P. Salovey \& D. Sluyter (Eds.), Emotional development, emotional literacy, and emotional intelligence. New York; NY: Basic Books. Recuperado de http://www.insightsonindia.com/wp-content/uploads/2013/09/emotionalintelligence.pdf

Moni, M. (2015). A comparison of power of normality tests: Shapiro-Wilk, KolmogorovSmirnov, Lilliefors, Anderson-Darling and Jarque-Bera Tests (Tesis de Licenciatura). Universidad de Dhaka, Bangladesh. Recuperado de http://www.stataids.com/wp-content/uploads/2016/01/A-Comparison-ofPowerof-Normality-Tests.pdf

Morris, A., Silk, J., Steinberg, L., Sessa, F., Avenevoli, S., \& Essex, M. (2002). Temperamental vulnerability and negative parenting as interacting of child adjustment. Journal of Marriage and Family, 64, 461-471. https://doi.org/10.1111/j.1741-3737.2002.00461.x

Moscatelli, S., \& Rubini, M. (2009). Parenting styles in adolescence: The role of warmth, strictnedd, and psychological autonomy granting in influencing collective selfesteemand expectations for the future. En P. Krause \& T. Dailey (Eds.), Handbook of Parenting: Styles, Stresses and Strategies. Nueva York: Nova Science Publishers, Inc.

Nelsen, J., \& Lott, J. (2005). Disciplina Positiva para Adolescentes. Nueva York: Random House.

Oliva, A. (2006). Relaciones familiares y desarrollo adolescente. Anuario de Psicología/The UB Journal of Psychology,37(3), 209-224. Recuperado de https://www.raco.cat/index.php/AnuarioPsicologia/article/view/61838/82584 
Oliva, A., Parra, A. y Arranz, E. (2008). Estilos relacionales parentales y ajuste del adolescente. Infancia y Aprendizaje, 31, 93-106. https://doi.org/10.1174/021037008783487093

Olmedo, M. (2013). Guía de prevención y tratamiento de problemas en la adolescencia. Madrid: Síntesis.

Organización Mundial de la Salud [OMS]. (2004). Prevención de los Trastornos Mentales: intervenciones efectivas y opciones de políticas. Recuperado de http://www.who.int/mental_health/evidence/Prevention_of_mental_disorders_sp anish_version.pdf

Orihuela, D. (2017). Percepción de estilos parentales y agresividad en estudiantes de 2do a 5to grado de secundaria de una Institución Educativa de Lima-Este, 2016 (tesis para licenciatura). Universidad Peruana Unión, Lima. Recuperado de https://repositorio.upeu.edu.pe/bitstream/handle/UPEU/408/Danny_Tesis_bachil ler_2017.pdf?sequence $=1 \&$ isAllowed $=y$

Ossa, C., Navarrete, L. y Jiménez, A. (2014). Estilos parentales y calidad de vida familiar en padres y madres de adolescentes de un establecimiento educacional de la ciudad de Chillán (Chile). Investigación \& Desarrollo, 22(1), 19-37. Recuperado de http://www.redalyc.org/articulo.oa?id=26831411002

Palmer, B., Donaldson, C., \& Stough, C. (2002). Emotional intelligence and life satisfaction. Personality and Individual Differences, 33(7), 1091-1100. https://doi.org/10.1016/S0191-8869(01)00215-X

Papalia, D., Wendkos, S. y Duskin, R. (2009). Psicología del desarrollo: de la infancia a la adolescencia. México: McGraw-Hill.

Papalia, D., Wendkos, S. y Duskin, R. (2010). Desarrollo humano. México: Mc Graw Hill.

Parker, G., Roussos, J., Hadzi-Pavlovic, D., Mitchell, P., Wilhelm, K., \& Austin, M.P. (1997). The development of a refined measure of dysfunctional parenting ans assessment of its relevance in patients with affective disorder. Psychological Medicine, 27(5), 1193-1203. http://doi:10.1017/s003329179700545x 
Parker, G., Tupling, H., \& Brown, L. B. (1979). A parental bonding instrument. British Journal of Medical Psychology, 52(1), 1-10. http://doi:10.1111/j.20448341.1979.tb02487.x

Parker, J., Creque, R., Barnhart, D., Harris, J., Majeski, S., Wood, L., ... Hogan, M. (2004). Academic achievement in high school: does emotional intelligence matter? Personality and Individual Differences, 37(7), 1321-1330. https://doi.org/10.1016/j.paid.2004.01.002

Parker, J., Summerfeldt, L., Hogan, M., \& Majeski, S. (2004). Emotional intelligence and academic success: Examining the transition from high school to university. Personality and Individual Differences, 36(1), 163-172. http://doi:10.1016/s0191-8869(03)00076-x

Parker, J., Taylor, G., \& Bagby, R. (2001). The relationship between emotional intelligence and alexithymia. Personality and Individual Differences, 30(1), 107115. https://doi.org/10.1016/S0191-8869(00)00014-3

Parra, A., Oliva, A., \& Reina, M. D. C. (2015). Family relationships from adolescence to emerging adulthood: A longitudinal study. Journal of Family Issues, 36(14), 2002-2020. https://doi.org/10.1177/0192513X13507570

Paulson, S., \& Sputa, C. (1996). Patterns of parenting during adolescence: Perceptions of adolescents and parents. Adolescence, 31(122), 369-382. Recuperado de https://search.proquest.com/docview/195933590?pq-origsite=gscholar

Ramírez-Lucas, A., Ferrando, M. y Sainz, A. (2015). ¿Influyen los Estilos Parentales y la Inteligencia Emocional de los Padres en el Desarrollo Emocional de sus Hijos Escolarizados en $2^{\circ}$ Ciclo de Educación Infantil? Acción Psicológica, 12(1), 6578. http://dx.doi.org/10.5944/ap.12.1.14314

Ramos, D., Enríquez, A. y Recondo, P. (2012). Inteligencia emocional plena: Mindfulness y la gestión eficaz de las emociones. Barcelona: Kairós.

Robles, E., Oudhof, H., \& Mercado, A. (2016). Validity and reliability of the Parental Bonding Instrument (PBI) in a sample of Mexican males. Psicogente, 19(35), 1424. http://dx.doi.org/10.17081/psico.19.35.1205 
Rodríguez, M. Á., Del Barrio, M. V. y Carrasco, M. Á. (2009). ¿Cómo perciben los hijos la crianza materna y paterna?: Diferencias por edad y sexo. Escritos de Psicología, 2(2), 10-18. Recuperado de http://scielo.isciii.es/pdf/ep/v2n2/original2.pdf

Rosenblum, G., \& Lewis, M. (2003). Emotional development in adolescence. En M. Berzonsky \& G. Adams (Eds.)., The Blackwell handbook of adolescence (pp. 269289). Nueva York, NY: Blackwell Publishing.

Ruiz, P. y Carranza,R. (2018). Inteligencia emocional, género y clima familiar en adolescentes peruanos. Acta Colombiana de Psicología, 21(2), 188-199. http://www.scielo.org.co/pdf/acp/v21n2/0123-9155-acp-21-02-188.pdf

Saculinggan, M., \& Balase, E. A. (2013). Empirical power comparison of goodness of fit tests for normality in the presence of outliers. Journal of Physics: Conference Series, 435(1), 012041. https://doi.org/10.1088/1742-6596/435/1/012041

Salguero, J., Fernández-Berrocal, P., Ruiz-Aranda, D., Castillo, R., y Palomera, R. (2011). Inteligencia emocional y ajuste psicosocial en la adolescencia: El papel de la percepción emocional. European Journal of Education and Psychology, 4(2), 143-152. https://doi.org/10.30552/ejep.v4i2.71

Salovey, P., Bedell, B., Detweiler, J., \& Mayer, J. (1999). Coping intelligently. En R. Snyder (Ed.) Coping: The Psychology of what Works (pp. 141-160). Nueva York: Oxford University Press.

Samper, P., Cortés, M., Mestre, V., Nácher, M. J. y Tur, A. (2006). Adaptación del Child's Report of Parent Behavior Inventory a población española. Psicothema, 18(2), 263-271. Recuperado de https://www.unioviedo.es/reunido/index.php/PST/article/view/8503/8367

Sánchez, A. (2009). El valor de la inteligencia emocional: Ser emocionalmente inteligente para hallar la felicidad y mejorar la calidad de vida. Jaén: Formación Alcalá.

Sánchez-Núñez, M. y Latorre, J. (2012). Inteligencia emocional y clima familiar. Psicología Conductual, 20(1), 103-117. Recuperado de https://www.researchgate.net/profile/M_Sanchez- 
Nunez/publication/263656705_Inteligencia_Emocional_y_Clima_Familiar/links 1542f9b0a0cf27e39fa995b4c/Inteligencia-Emocional-y-Clima-Familiar.pdf

Sumari, W., \& Vaca, L. (2017). Inteligencia emocional y riesgo suicida en estudiantes de quinto año de la Institución Educativa Secundaria Comercial $N^{\circ} 45$ Emilio Romero Padilla, Puno - 2017 (Tesis de licenciatura). Universidad Peruana Unión, Juliaca.

Recuperado

de https://repositorio.upeu.edu.pe/bitstream/handle/UPEU/706/Wendy_Tesis_bachi 1ler_2017.pdf?sequence=1\&isAllowed=y

Torío, S., Peña, J. y Rodríguez, M. (2008). Estilos educativos parentales. Revisión bibliográfica y reformulación teórica. Teoría de la Educación, 20, 151-178.

Trishala, M., \& Kiran, S. (2015). Impact of perceived parenting styles on the emotional maturity among adolescents. Indian Journal of Health and Wellbeing, 6(2), 212215.

Trujillo, M. y Rivas, L. (2005). Orígenes, evolución y modelos de inteligencia emocional. Innovar, $\quad$ 15(25), $\quad 9-24 . \quad$ Recuperado de http://www.scielo.org.co/pdf/inno/v15n25/v15n25a01.pdf

Ugarriza, N. y Pajares, L. (2005). “Adaptación y estandarización del inventario de Inteligencia Emocional de BarOn ICE: NA, en niños y adolescentes" [Instrumento de medición]. Lima

Ugarriza, N. y Pajares, L. (2005). La evaluación de la inteligencia emocional a través del inventario de BarOn ICE: NA, en una muestra de niños y adolescentes. Persona, O(008), 11-58. http://dx.doi.org/10.26439/persona2005.n008.893

Youngblade, L. M., Theokas, C., Schulenberg, J., Curry, L., Huang, I. C., \& Novak, M. (2007). Risk and promotive factors in families, schools, and communities: A contextual model of positive youth development in adolescence. Pediatrics, 119(1), S47-S53. Recuperado de http://pediatrics.aappublications.org/content/pediatrics/119/Supplement_1/S47.f ull.pdf 
APÉNDICES 


\section{APÉNDICE 1: CONSENTIMIENTO INFORMADO}

El propósito de esta ficha de consentimiento es brindarle al padre/madre/apoderado del menor una explicación clara respecto a la naturaleza de la presente investigación, así como de su rol en ella como participante:

La investigación será conducida por Claudia Alessandra Bio Sam, de la Universidad de Lima. La meta del estudio es conocer la relación entre los estilos parentales y la inteligencia emocional en adolescentes de 13 a 17 años.

Si usted accede a que su menor hijo(a) participe en este estudio, se le solicitará que este responda a las preguntas de dos cuestionarios y una encuesta. Esto tomará aproximadamente 40 minutos de su tiempo.

La participación en esta investigación es estrictamente voluntaria. La información que se recoja será confidencial y no se utilizará para ningún otro propósito fuera de los de este estudio.

Si tiene alguna duda sobre este proyecto, puede realizar consultas en cualquier momento durante su participación en él. Asimismo, puede retirarse del mismo sin que eso lo perjudique en ninguna forma.

Desde ya le agradecemos su participación.

Acepto voluntariamente que mi hijo(a) participe en esta investigación, conducida por Claudia Alessandra Bio Sam. He sido informado(a) de que la meta de este estudio es conocer la relación entre los estilos parentales y la inteligencia emocional en adolescentes de 13 a 17 años.

Me han indicado, también, que mi menor hijo(a) tendrá que responder a dos cuestionarios y una encuesta, lo cual tomará aproximadamente 40 minutos.

Reconozco que la información que provea mi menor hijo(a) en el curso de esta investigación es estrictamente anónima pues no se mostrarán nombres y apellidos, y no será usada para ningún otro propósito fuera de los de este estudio sin mi consentimiento. He sido informado de que puedo hacer preguntas sobre el proyecto en cualquier momento y que puedo retirarme del mismo cuando así lo decida, sin que esto acarree perjuicio alguno para mi persona. De tener preguntas sobre la participación me hijo(a) en este estudio, puedo contactar a Claudia Alessandra Bio Sam al teléfono 949339800.

Entiendo que una copia de esta ficha de consentimiento me será entregada, y que puedo pedir información sobre los resultados de este estudio cuando este haya concluido. Para esto, puedo contactar a Claudia Alessandra Bio Sam al teléfono anteriormente mencionado.

Nombre de padre/madre/apoderado

Firma del padre/madre/apoderado

Lima, de del 2018 


\section{APÉNDICE 2: ENCUESTA SOCIODEMOGRÁFICA}

Completa la siguiente encuesta. La información recogida será confidencial y se utilizará para fines de aprendizaje.

Edad:

Colegio:

Gestión del colegio: Pública ( ) Privada ( )

Grado:

Sexo: Femenino ( ) Masculino ( )

Vivo con...

Madre ( ) Padre ( ) Ambos padres ( )

Otros:

Estado civil:

Madre: $\quad$ Soltera ( ) Casada ( ) Divorciada ( ) Separada ( )

Padre: $\quad$ Soltero ( ) Casado ( ) Divorciado ( ) Separado ( )

¿Tienes hermanos? Sí ( ) No ( )

¿Cuántos?

Posición ordinal

¿Actualmente te encuentras en algún tipo de tratamiento psicoterapéutico y/o farmacológico?

Sí ( ) No( ) 


\section{APÉNDICE 3: ESCALA DE ESTILOS PARENTALES DISFUNCIONALES}




\section{APÉNDICE 4: ICE NA INVENTARIO DE LA INTELIGENCIA EMOCIONAL DE BARON}




\section{APÉNDICE 5: LIBRO DE CÓDIGOS}

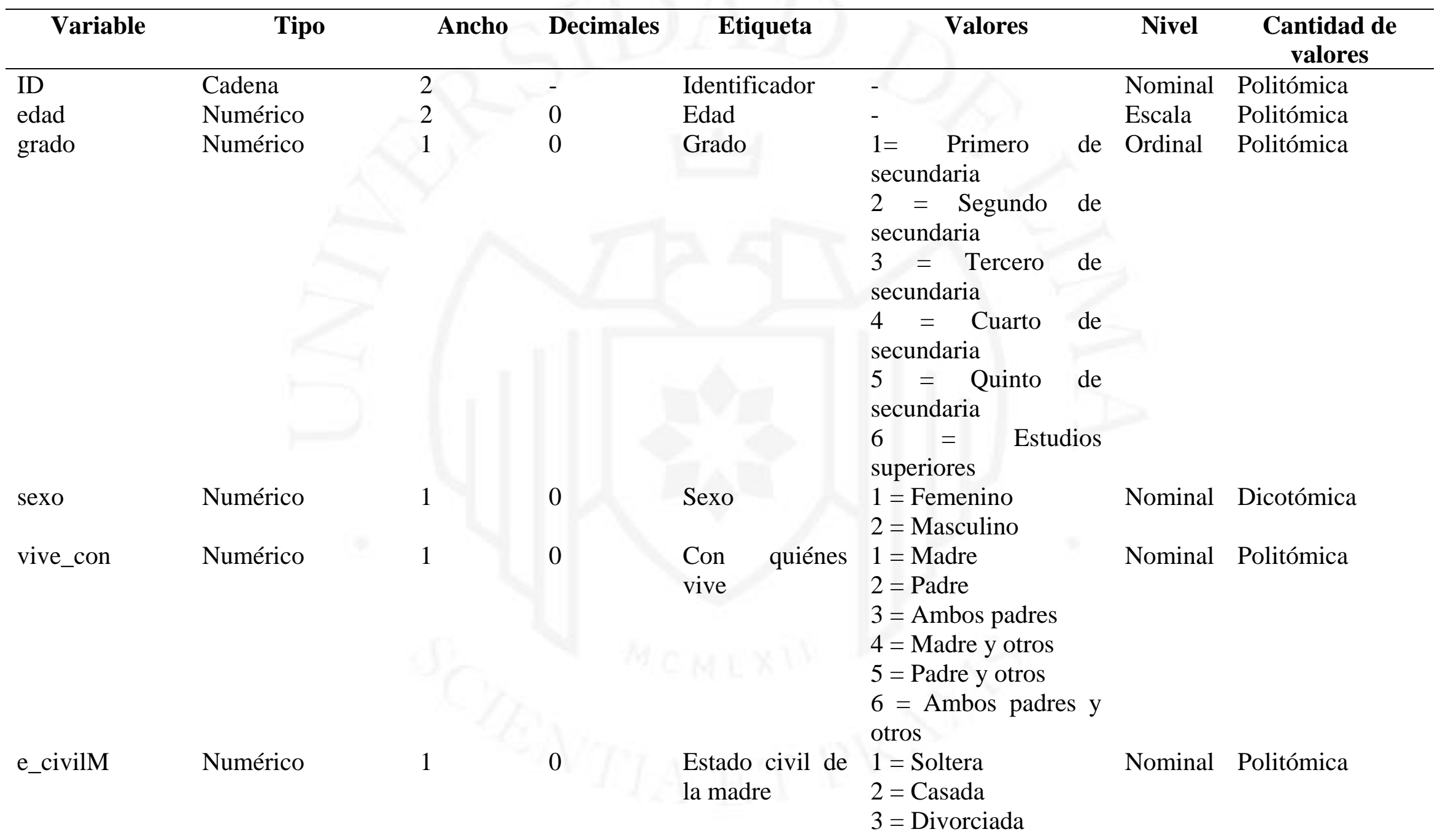




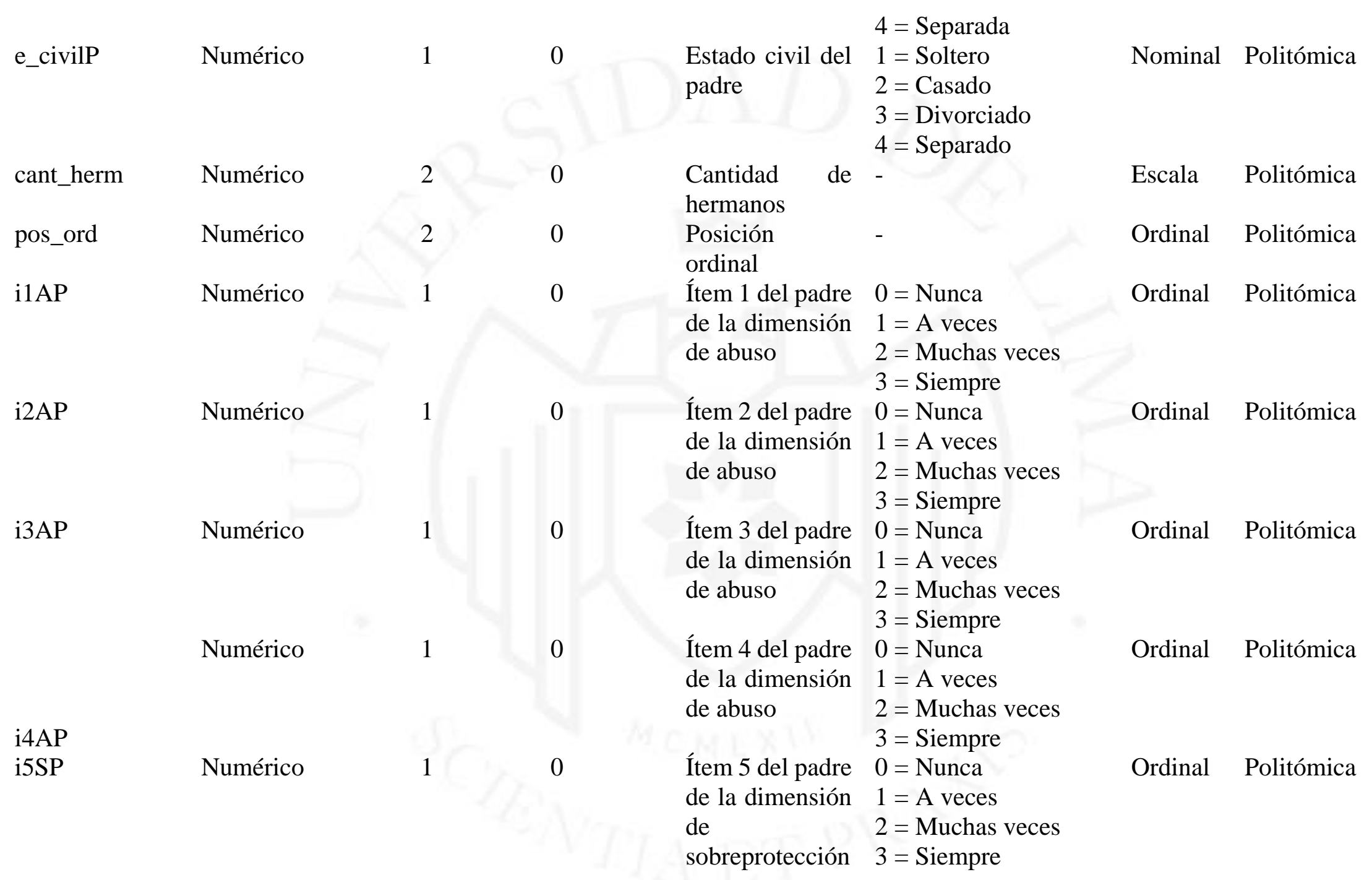




\begin{tabular}{|c|c|c|c|c|c|c|c|}
\hline i6AP & Numérico & 1 & 0 & $\begin{array}{l}\text { Ítem } 6 \text { del padre } \\
\text { de la dimensión } \\
\text { de abuso }\end{array}$ & $\begin{array}{l}0=\text { Nunca } \\
1=A \text { veces } \\
2=\text { Muchas veces }\end{array}$ & Ordinal & Politómica \\
\hline i7IP & Numérico & 1 & 0 & $\begin{array}{l}\text { Ítem } 7 \text { del padre } \\
\text { de la dimensión } \\
\text { de indiferencia }\end{array}$ & $\begin{array}{l}0=\text { Nunca } \\
1=\text { A veces } \\
2=\text { Muchas veces } \\
3=\text { Siempre }\end{array}$ & Ordinal & Politómica \\
\hline i8AP & Numérico & 1 & 0 & $\begin{array}{l}\text { Ítem } 8 \text { del padre } \\
\text { de la dimensión } \\
\text { de abuso }\end{array}$ & $\begin{array}{l}0=\text { Nunca } \\
1=\text { A veces } \\
2=\text { Muchas veces } \\
3=\text { Siempre }\end{array}$ & Ordinal & Politómica \\
\hline i9AP & Numérico & 1 & 0 & $\begin{array}{l}\text { Ítem } 9 \text { del padre } \\
\text { de la dimensión } \\
\text { de abuso }\end{array}$ & $\begin{array}{l}0=\text { Nunca } \\
1=A \text { veces } \\
2=\text { Muchas veces }\end{array}$ & Ordinal & Politómica \\
\hline i10IP & Numérico & 1 & 0 & $\begin{array}{lcr}\text { Ítem } 10 & \text { del } \\
\text { padre de } & \text { la } \\
\text { dimensión } & \text { de } \\
\text { indiferencia } & \end{array}$ & $\begin{array}{l}5=\text { Nunca } \\
0=\text { A veces } \\
1=\text { Muchas veces } \\
2=\text { Siempre }\end{array}$ & Ordinal & Politómica \\
\hline i11IP & Numérico & 1 & 0 & $\begin{array}{lcr}\text { Ítem } 11 & \text { del } \\
\text { padre de } & \text { la } \\
\text { dimensión } & \text { de } \\
\text { indiferencia } & \end{array}$ & $\begin{array}{l}0=\text { Nunca } \\
1=\text { A veces } \\
2=\text { Muchas veces } \\
3=\text { Siempre }\end{array}$ & Ordinal & Politómica \\
\hline i12IP & Numérico & 1 & 0 & $\begin{array}{lcr}\text { Ítem } 12 & \text { del } \\
\text { padre de } & \text { la } \\
\text { dimensión } & \text { de } \\
\text { indiferencia } & \end{array}$ & $\begin{array}{l}0=\text { Nunca } \\
1=\text { A veces } \\
2=\text { Muchas veces } \\
3=\text { Siempre }\end{array}$ & Ordinal & Politómica \\
\hline i13IP & Numérico & 1 & 0 & $\begin{array}{lcr}\text { Ítem } & 13 & \text { del } \\
\text { padre } & \text { de } & \text { la }\end{array}$ & $\begin{array}{l}0=\text { Nunca } \\
1=A \text { veces }\end{array}$ & Ordinal & Politómica \\
\hline
\end{tabular}




\begin{tabular}{|c|c|c|c|c|c|c|c|}
\hline & & & & indiferencia & $3=$ Siempre & & \\
\hline i14SP & Numérico & 1 & 0 & $\begin{array}{lcr}\text { Ítem } 14 & \text { del } \\
\text { padre de } & \text { la } \\
\text { dimensión de } & \text { dobreprotección }\end{array}$ & $\begin{array}{l}0=\text { Nunca } \\
1=\text { A veces } \\
2=\text { Muchas veces } \\
3=\text { Siempre }\end{array}$ & Ordinal & Politómica \\
\hline i1 AM & Numérico & 1 & 0 & $\begin{array}{ll}\text { Ítem } 1 \text { de la } \\
\text { madre de } & \text { la } \\
\text { dimensión } & \text { de } \\
\text { abuso } & \end{array}$ & $\begin{array}{l}0=\text { Nunca } \\
1=\text { A veces } \\
2=\text { Muchas veces } \\
3=\text { Siempre }\end{array}$ & Ordinal & Politómica \\
\hline i2SM & Numérico & 1 & 0 & $\begin{array}{l}\text { Ítem } 2 \text { de la } \\
\text { madre de la } \\
\text { dimensión de } \\
\text { sobreprotección }\end{array}$ & $\begin{aligned} 0 & =\text { Nunca } \\
1 & =\text { A veces } \\
2 & =\text { Muchas veces } \\
& \quad 3=\text { Siempre }\end{aligned}$ & Ordinal & Politómica \\
\hline i3AM & Numérico & 1 & 0 & $\begin{array}{ll}\text { Ítem } 3 \text { de la } \\
\text { madre de la } \\
\text { dimensión } \\
\text { abuso }\end{array}$ & $\begin{array}{l}0=\text { Nunca } \\
1=\text { A veces } \\
2=\text { Muchas veces } \\
3=\text { Siempre }\end{array}$ & Ordinal & Politómica \\
\hline i4AM & Numérico & 1 & 0 & $\begin{array}{ll}\text { Ítem } 4 \text { de la } \\
\text { madre de la } \\
\text { dimensión } \\
\text { abuso }\end{array}$ & $\begin{array}{l}0=\text { Nunca } \\
1=\text { A veces } \\
2=\text { Muchas veces } \\
3=\text { Siempre }\end{array}$ & Ordinal & Politómica \\
\hline i5SM & Numérico & 1 & 0 & $\begin{array}{l}\text { Ítem } 5 \text { de la } \\
\text { madre de la } \\
\text { dimensión de } \\
\text { sobreprotección }\end{array}$ & $\begin{array}{l}0=\text { Nunca } \\
1=\text { A veces } \\
2=\text { Muchas veces } \\
3=\text { Siempre }\end{array}$ & Ordinal & Politómica \\
\hline i6AM & Numérico & 1 & 0 & $\begin{array}{ll}\text { Ítem } 6 \text { de la } \\
\text { madre de la } \\
\text { dimensión } \\
\text { abuso }\end{array}$ & $\begin{array}{l}0=\text { Nunca } \\
1=\text { A veces } \\
2=\text { Muchas veces } \\
3=\text { Siempre }\end{array}$ & Ordinal & Politómica \\
\hline
\end{tabular}




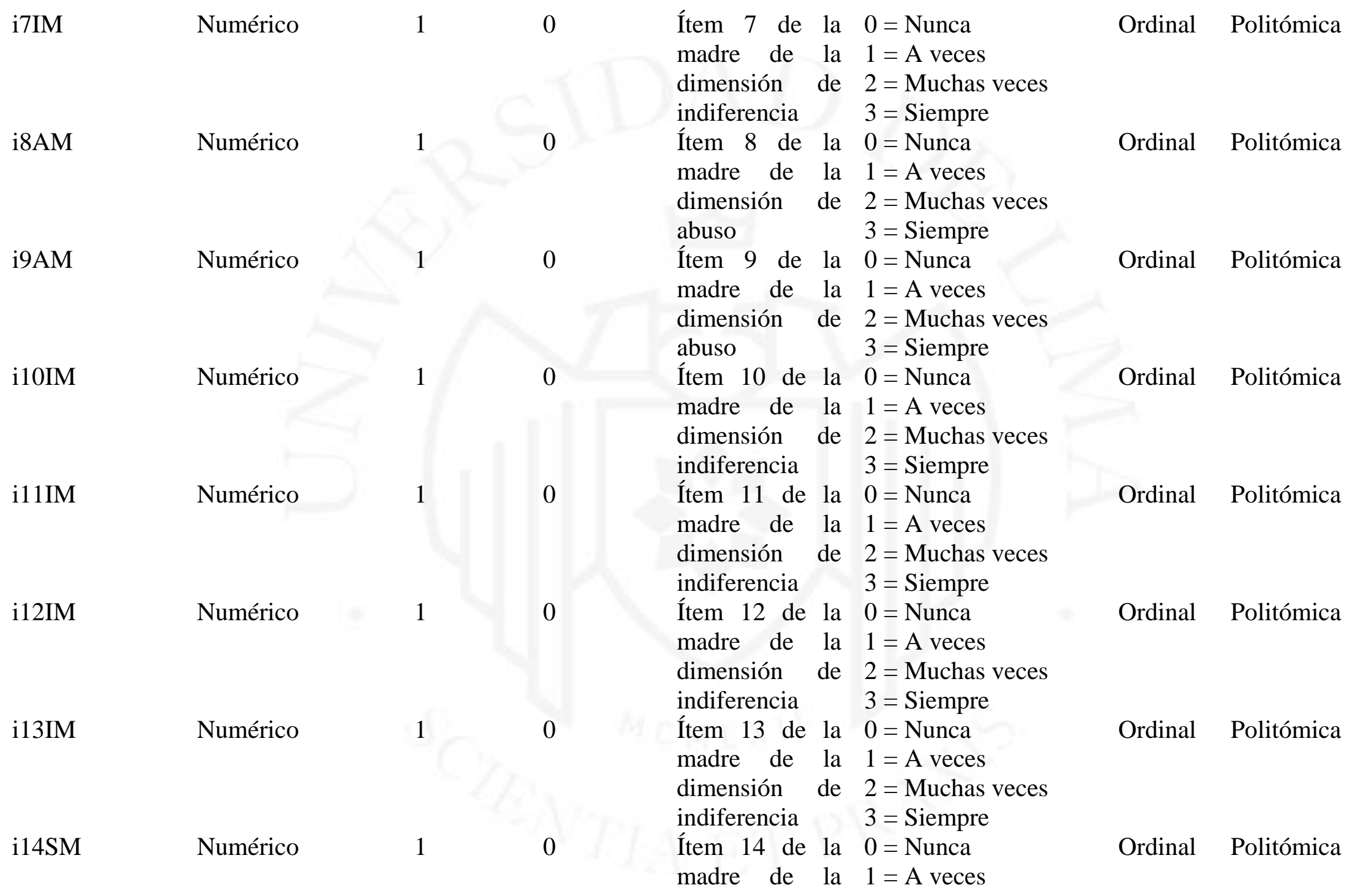




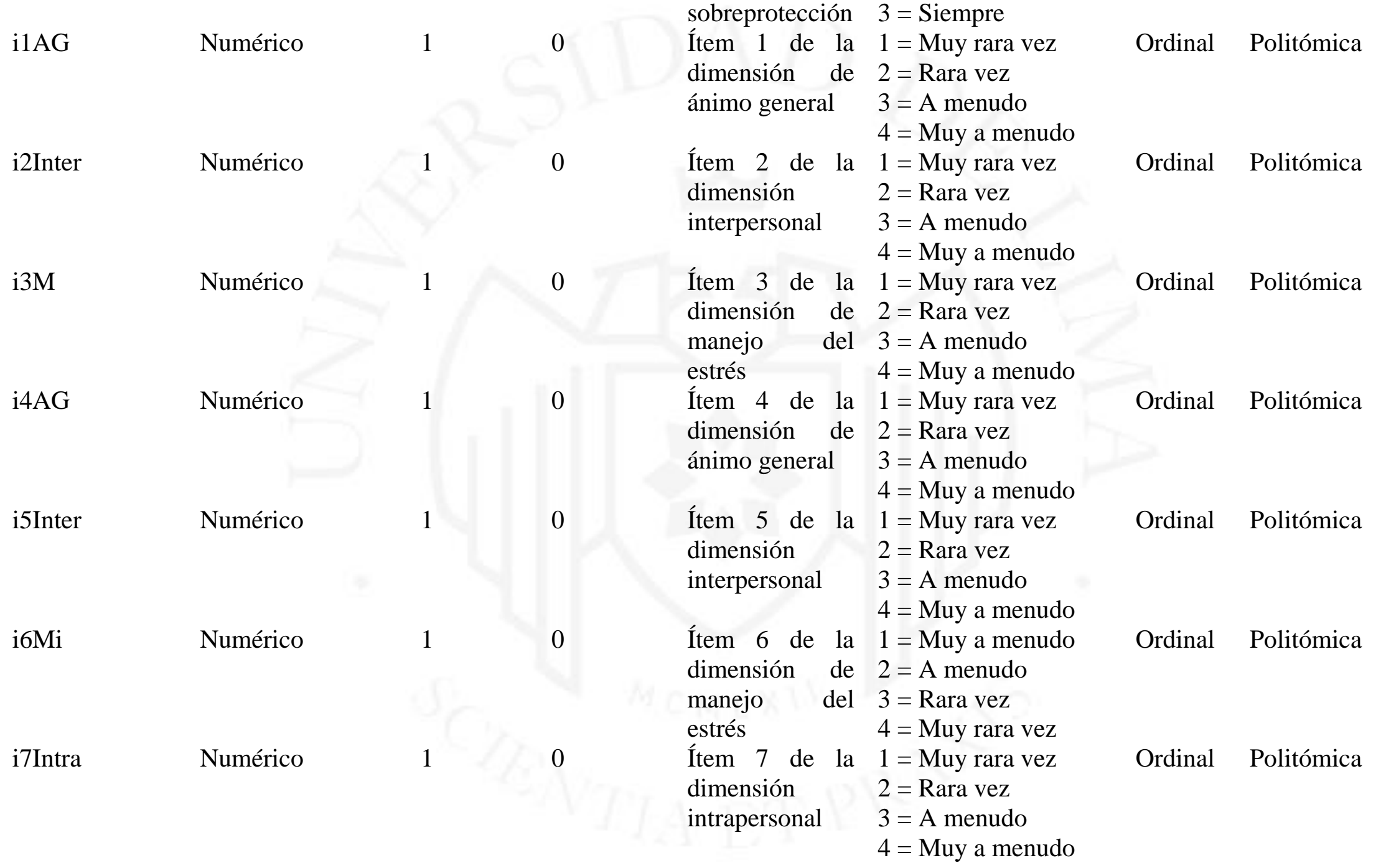




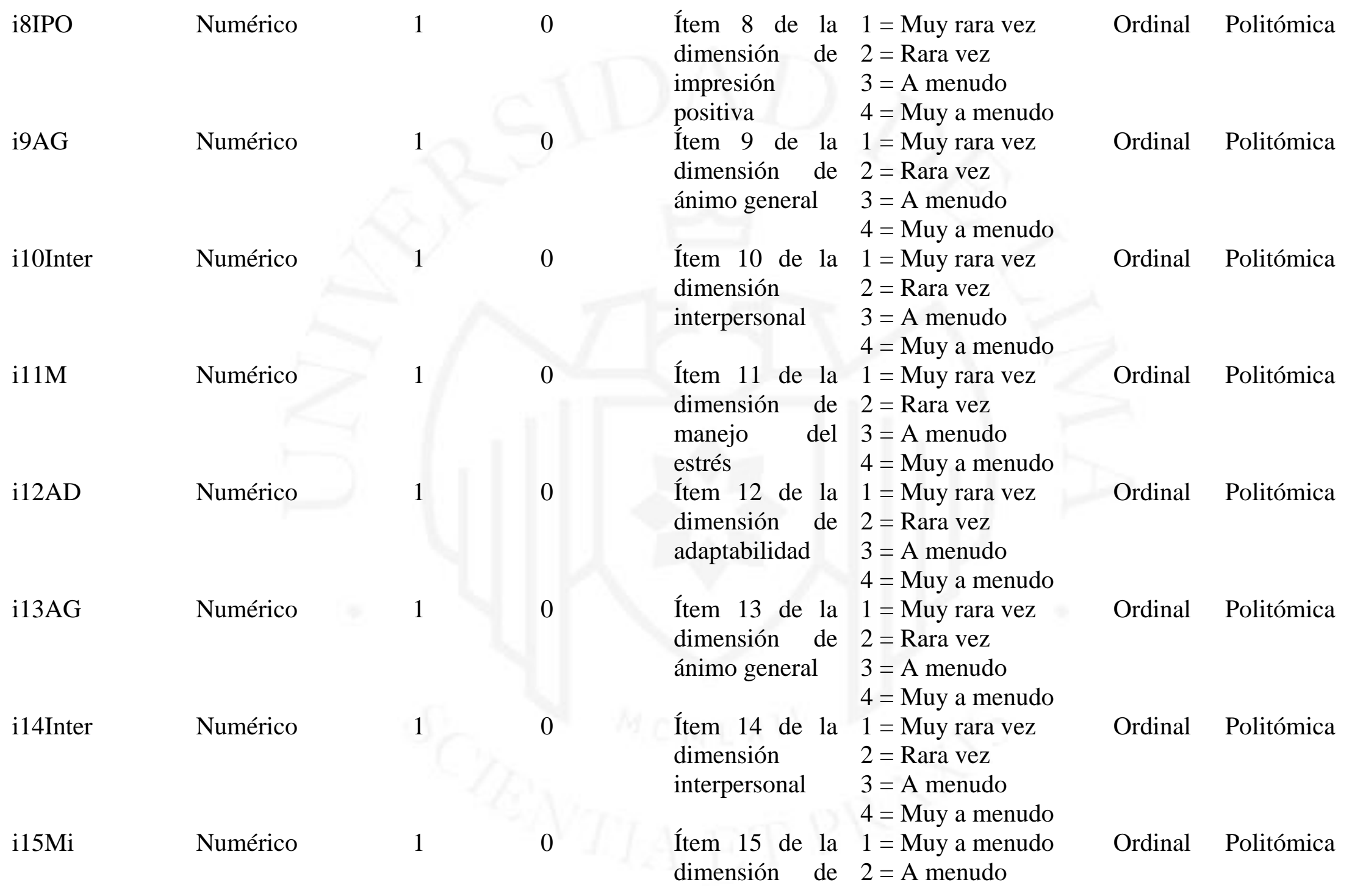




\begin{tabular}{|c|c|c|c|c|c|c|c|}
\hline & & & & manejo del & $3=$ Rara vez & & \\
\hline i16AD & Numérico & 1 & 0 & $\begin{array}{l}\text { estrés } \\
\text { Ítem } 16 \text { de la } \\
\text { dimensión de } \\
\text { ánimo general }\end{array}$ & $\begin{array}{l}4=\text { Muy rara vez } \\
1=\text { Muy rara vez } \\
2=\text { Rara vez } \\
3=\text { A menudo } \\
4=\text { Muy a menudo }\end{array}$ & Ordinal & Politómica \\
\hline i17Intra & Numérico & 1 & 0 & $\begin{array}{l}\text { Ítem } 17 \text { de la } \\
\text { dimensión } \\
\text { intrapersonal }\end{array}$ & $\begin{array}{l}1=\text { Muy rara vez } \\
2=\text { Rara vez } \\
3=\text { A menudo } \\
4=\text { Muy a menudo }\end{array}$ & Ordinal & Politómica \\
\hline i18IPO & Numérico & 1 & 0 & $\begin{array}{l}\text { Ítem } 18 \text { de la } \\
\text { dimensión de } \\
\text { impresión } \\
\text { positiva }\end{array}$ & $\begin{array}{l}1=\text { Muy rara vez } \\
2=\text { Rara vez } \\
3=\text { A menudo } \\
4=\text { Muy a menudo }\end{array}$ & Ordinal & Politómica \\
\hline i19AG & Numérico & 1 & 0 & $\begin{array}{l}\text { Îtem } 19 \text { de la } \\
\text { dimensión de } \\
\text { ánimo general }\end{array}$ & $\begin{array}{l}1=\text { Muy rara vez } \\
2=\text { Rara vez } \\
3=\text { A menudo } \\
4=\text { Muy a menudo }\end{array}$ & Ordinal & Politómica \\
\hline i20Inter & Numérico & 1 & 0 & $\begin{array}{l}\text { Ítem } 20 \text { de la } \\
\text { dimensión } \\
\text { interpersonal }\end{array}$ & $\begin{array}{l}1=\text { Muy rara vez } \\
2=\text { Rara vez } \\
3=\text { A menudo } \\
4=\text { Muy a menudo }\end{array}$ & Ordinal & Politómica \\
\hline i21Mi & Numérico & 1 & 0 & $\begin{array}{ll}\text { Ítem } 21 \text { de } & \text { la } \\
\text { dimensión } & \text { de } \\
\text { manejo } & \text { del } \\
\text { estrés } & \end{array}$ & $\begin{array}{l}1=\text { Muy a menudo } \\
2=\text { A menudo } \\
3=\text { Rara vez } \\
4=\text { Muy rara vez }\end{array}$ & Ordinal & Politómica \\
\hline i22AD & Numérico & 1 & 0 & $\begin{array}{l}\text { Ítem } 22 \text { de la } \\
\text { dimensión de } \\
\text { adaptabilidad }\end{array}$ & $\begin{array}{l}1=\text { Muy rara vez } \\
2=\text { Rara vez } \\
3=\text { A menudo } \\
4=\text { Muy a menudo }\end{array}$ & Ordinal & Politómica \\
\hline
\end{tabular}




\begin{tabular}{|c|c|c|c|c|c|c|c|}
\hline $\mathrm{i} 23 \mathrm{AG}$ & Numérico & 1 & 0 & Ítem 23 de la & $1=$ Muy rara vez & Ordinal & Politómica \\
\hline & & & & $\begin{array}{l}\text { dimensión de } \\
\text { ánimo general }\end{array}$ & $\begin{array}{l}2=\text { Rara vez } \\
3=\text { A menudo } \\
4=\text { Muy a menudo }\end{array}$ & & \\
\hline i24Inter & Numérico & 1 & 0 & $\begin{array}{l}\text { Ítem } 24 \text { de la } \\
\text { dimensión } \\
\text { interpersonal }\end{array}$ & $\begin{array}{l}1=\text { Muy rara vez } \\
2=\text { Rara vez } \\
3=\text { A menudo } \\
4=\text { Muy a menudo }\end{array}$ & Ordinal & Politómica \\
\hline i25AD & Numérico & 1 & 0 & $\begin{array}{l}\text { Ítem } 25 \text { de la } \\
\text { dimensión de } \\
\text { adaptabilidad }\end{array}$ & $\begin{array}{l}1=\text { Muy rara vez } \\
2=\text { Rara vez } \\
3=\text { A menudo } \\
4=\text { Muy a menudo }\end{array}$ & Ordinal & Politómica \\
\hline i26Mi & Numérico & 1 & 0 & $\begin{array}{lr}\text { Ítem } 26 \text { de } & \text { la } \\
\text { dimensión } & \text { de } \\
\text { manejo } & \text { del }\end{array}$ & $\begin{array}{l}1=\text { Muy a menudo } \\
2=\text { A menudo } \\
3=\text { Rara vez }\end{array}$ & Ordinal & Politómica \\
\hline i27IPO & Numérico & 1 & 0 & $\begin{array}{l}\text { estrés } \\
\text { Ítem } 27 \text { de la } \\
\text { dimensión de } \\
\text { impresión } \\
\text { positiva }\end{array}$ & $\begin{array}{l}4=\text { Muy rara vez } \\
1=\text { Muy rara vez } \\
2=\text { Rara vez } \\
3=\text { A menudo } \\
4=\text { Muy a menudo }\end{array}$ & Ordinal & Politómica \\
\hline i28Intrai & Numérico & 1 & 0 & $\begin{array}{l}\text { Î́tem } 28 \text { de la } \\
\text { dimensión } \\
\text { intrapersonal }\end{array}$ & $\begin{array}{l}1=\text { Muy a menudo } \\
2=\text { A menudo } \\
3=\text { Rara vez } \\
4=\text { Muy rara vez }\end{array}$ & Ordinal & Politómica \\
\hline i29AG & Numérico & 1 & 0 & $\begin{array}{l}\text { Ítem } 29 \text { de la } \\
\text { dimensión de } \\
\text { ánimo general }\end{array}$ & $\begin{array}{l}1=\text { Muy rara vez } \\
2=\text { Rara vez } \\
3=\text { A menudo } \\
4=\text { Muy a menudo }\end{array}$ & Ordinal & Politómica \\
\hline
\end{tabular}




\begin{tabular}{|c|c|c|c|c|c|c|c|}
\hline i30AD & Numérico & 1 & 0 & Ítem 30 de la & $1=$ Muy rara vez & Ordinal & Politómica \\
\hline & & & & $\begin{array}{l}\text { dimensión de } \\
\text { adaptabilidad }\end{array}$ & $\begin{array}{l}2=\text { Rara vez } \\
3=\text { A menudo } \\
4=\text { Muy a menudo }\end{array}$ & & \\
\hline i31Intra & Numérico & 1 & 0 & $\begin{array}{l}\text { Ítem } 31 \text { de la } \\
\text { dimensión } \\
\text { intrapersonal }\end{array}$ & $\begin{array}{l}1=\text { Muy rara vez } \\
2=\text { Rara vez } \\
3=\text { A menudo } \\
4=\text { Muy a menudo }\end{array}$ & Ordinal & Politómica \\
\hline $\mathrm{i} 32 \mathrm{AG}$ & Numérico & 1 & 0 & $\begin{array}{l}\text { Ítem } 32 \text { de la } \\
\text { dimensión de } \\
\text { ánimo general }\end{array}$ & $\begin{array}{l}1=\text { Muy rara vez } \\
2=\text { Rara vez } \\
3=A \text { menudo }\end{array}$ & Ordinal & Politómica \\
\hline i33IPO & Numérico & 1 & 0 & $\begin{array}{l}\text { Ítem } 33 \text { de la } \\
\text { dimensión de } \\
\text { impresión } \\
\text { positiva }\end{array}$ & $\begin{array}{l}4=\text { Muy a menudo } \\
1=\text { Muy rara vez } \\
2=\text { Rara vez } \\
3=\text { A menudo } \\
4=\text { Muy a menudo }\end{array}$ & Ordinal & Politómica \\
\hline i34AD & Numérico & 1 & 0 & $\begin{array}{l}\text { Îtem } 34 \text { de la } \\
\text { dimensión de } \\
\text { adaptabilidad }\end{array}$ & $\begin{array}{l}1=\text { Muy rara vez } \\
2=\text { Rara vez } \\
3=\text { A menudo } \\
4=\text { Muy a menudo }\end{array}$ & Ordinal & Politómica \\
\hline i35Mi & Numérico & 1 & 0 & $\begin{array}{l}\text { Ítem } 35 \text { de la } \\
\text { dimensión } \text { de } \\
\text { manejo } \\
\text { estrés }\end{array}$ & $\begin{array}{l}1=\text { Muy a menudo } \\
2=\text { A menudo } \\
3=\text { Rara vez } \\
4=\text { Muy rara vez }\end{array}$ & Ordinal & Politómica \\
\hline i36Inter & Numérico & 1 & 0 & $\begin{array}{l}\text { Ítem } 36 \text { de la } \\
\text { dimensión } \\
\text { interpersonal }\end{array}$ & $\begin{array}{l}1=\text { Muy rara vez } \\
2=\text { Rara vez } \\
3=\text { A menudo } \\
4=\text { Muy a menudo }\end{array}$ & Ordinal & Politómica \\
\hline
\end{tabular}




\begin{tabular}{|c|c|c|c|c|c|c|c|}
\hline i37AGi & Numérico & 1 & 0 & Ítem 37 de la & $1=$ Muy a menudo & Ordinal & Politómica \\
\hline & & & & ánimo general & $\begin{array}{l}3=\text { Rara vez } \\
4=\text { Muy rara vez }\end{array}$ & & \\
\hline i38AD & Numérico & 1 & 0 & $\begin{array}{l}\text { Ítem } 38 \text { de la } \\
\text { dimensión de } \\
\text { adaptabilidad }\end{array}$ & $\begin{array}{l}1=\text { Muy rara vez } \\
2=\text { Rara vez } \\
3=\text { A menudo } \\
4=\text { Muy a menudo }\end{array}$ & Ordinal & Politómica \\
\hline $\mathrm{i} 39 \mathrm{M}$ & Numérico & 1 & 0 & $\begin{array}{ll}\text { Ítem } 39 \text { de la } \\
\text { dimensión } & \text { de } \\
\text { manejo } & \text { del } \\
\text { estrés } & \end{array}$ & $\begin{array}{l}1=\text { Muy rara vez } \\
2=\text { Rara vez } \\
3=\text { A menudo } \\
4=\text { Muy a menudo }\end{array}$ & Ordinal & Politómica \\
\hline $\mathrm{i} 40 \mathrm{AG}$ & Numérico & 1 & 0 & $\begin{array}{l}\text { Ítem } 40 \text { de la } \\
\text { dimensión de } \\
\text { ánimo general }\end{array}$ & $\begin{array}{l}1=\text { Muy rara vez } \\
2=\text { Rara vez } \\
3=\text { A menudo }\end{array}$ & Ordinal & Politómica \\
\hline i41Inter & Numérico & 1 & 0 & $\begin{array}{l}\text { Ítem } 41 \text { de la } \\
\text { dimensión } \\
\text { interpersonal }\end{array}$ & $\begin{array}{l}1=\text { Muy rara vez } \\
2=\text { Rara vez } \\
3=\text { A menudo } \\
4=\text { Muy a menudo }\end{array}$ & Ordinal & Politómica \\
\hline i42IPO & Numérico & 1 & 0 & $\begin{array}{l}\text { Ítem } 42 \text { de la } \\
\text { dimensión de } \\
\text { impresión } \\
\text { positiva }\end{array}$ & $\begin{array}{l}1=\text { Muy rara vez } \\
2=\text { Rara vez } \\
3=\text { A menudo } \\
4=\text { Muy a menudo }\end{array}$ & Ordinal & Politómica \\
\hline i43Intra & Numérico & 1 & 0 & $\begin{array}{l}\text { Îtem } 43 \text { de la } \\
\text { dimensión } \\
\text { intrapersonal }\end{array}$ & $\begin{array}{l}1=\text { Muy rara vez } \\
2=\text { Rara vez } \\
3=\text { A menudo } \\
4=\text { Muy a menudo }\end{array}$ & Ordinal & Politómica \\
\hline
\end{tabular}




\begin{tabular}{|c|c|c|c|c|c|c|c|}
\hline i44AD & Numérico & 1 & 0 & Ítem 44 de la & $1=$ Muy rara vez & Ordinal & Politómica \\
\hline & & & & adaptabilidad & $\begin{array}{l}3=\text { A menudo } \\
4=\text { Muy a menudo }\end{array}$ & & \\
\hline i45Inter & Numérico & 1 & 0 & $\begin{array}{l}\text { Ítem } 45 \text { de la } \\
\text { dimensión } \\
\text { interpersonal }\end{array}$ & $\begin{array}{l}1=\text { Muy rara vez } \\
2=\text { Rara vez } \\
3=\text { A menudo } \\
4=\text { Muy a menudo }\end{array}$ & Ordinal & Politómica \\
\hline i46Mi & Numérico & 1 & 0 & $\begin{array}{l}\text { Ítem } 46 \text { de la } \\
\text { dimensión de } \\
\text { manejo } \\
\text { estrés }\end{array}$ & $\begin{array}{l}1=\text { Muy a menudo } \\
2=\text { A menudo } \\
3=\text { Rara vez } \\
4=\text { Muy rara vez }\end{array}$ & Ordinal & Politómica \\
\hline i47AG & Numérico & 1 & 0 & $\begin{array}{l}\text { Ítem } 47 \text { de la } \\
\text { dimensión de } \\
\text { ánimo general }\end{array}$ & $\begin{array}{l}1=\text { Muy rara vez } \\
2=\text { Rara vez } \\
3=\text { A menudo }\end{array}$ & Ordinal & Politómica \\
\hline i48AD & Numérico & 1 & 0 & $\begin{array}{l}\text { Ítem } 48 \text { de la } \\
\text { dimensión de } \\
\text { adaptabilidad }\end{array}$ & $\begin{array}{l}4=\text { Muy a menudo } \\
1=\text { Muy rara vez } \\
2=\text { Rara vez } \\
3=\text { A menudo } \\
4=\text { Muy a menudo }\end{array}$ & Ordinal & Politómica \\
\hline i49Mi & Numérico & 1 & 0 & $\begin{array}{l}\text { Ítem } 49 \text { de la } \\
\text { dimensión } \\
\text { manejo } \\
\text { estrés }\end{array}$ & $\begin{array}{l}1=\text { Muy a menudo } \\
2=\text { A menudo } \\
3=\text { Rara vez } \\
4=\text { Muy rara vez }\end{array}$ & Ordinal & Politómica \\
\hline i50AG & Numérico & 1 & 0 & $\begin{array}{l}\text { Ítem } 50 \text { de la } \\
\text { dimensión de } \\
\text { ánimo general }\end{array}$ & $\begin{array}{l}1=\text { Muy rara vez } \\
2=\text { Rara vez } \\
3=\text { A menudo } \\
4=\text { Muy a menudo }\end{array}$ & Ordinal & Politómica \\
\hline
\end{tabular}




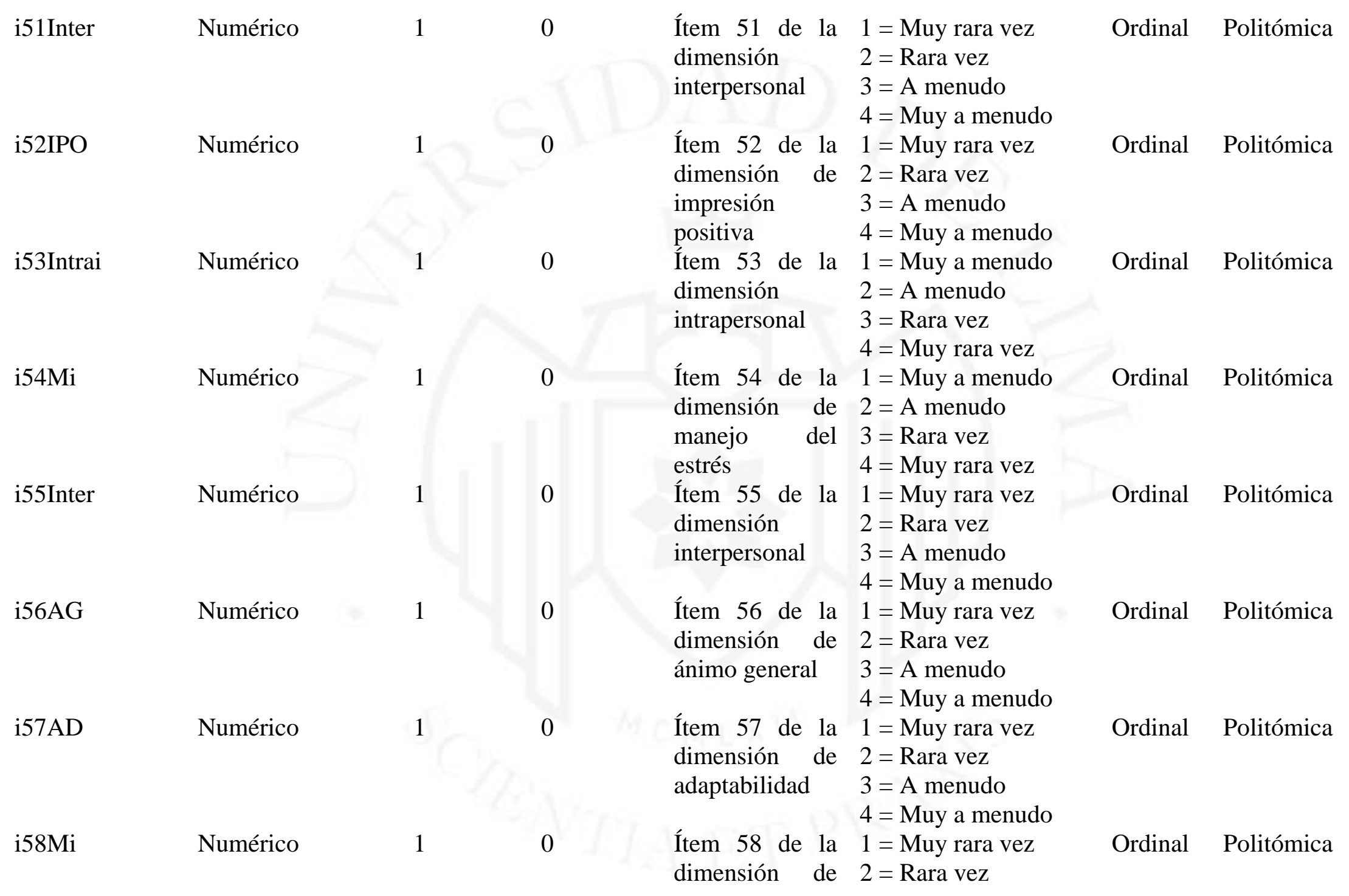




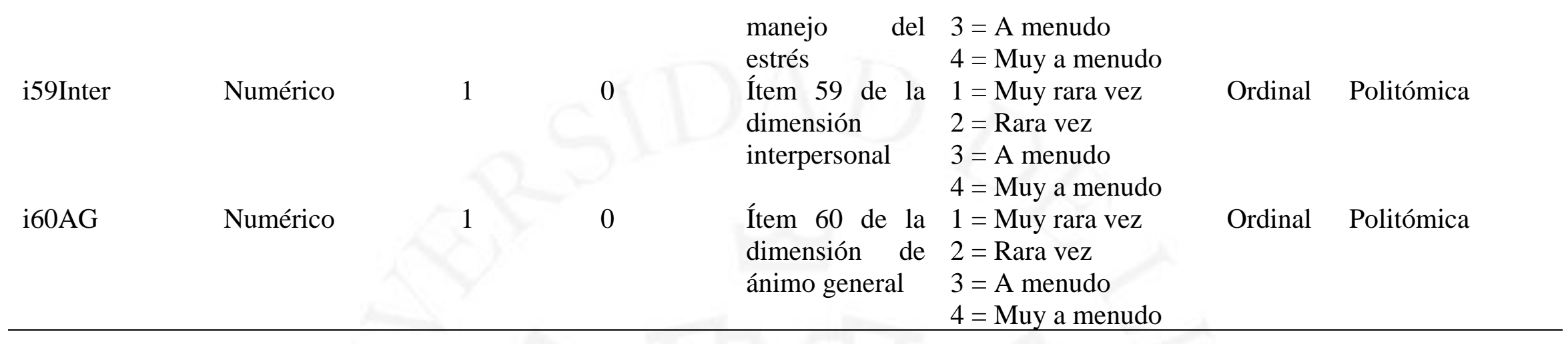




\section{APÉNDICE 6: GRÁFICOS DE DISPERSIÓN}

Figura 1

Relación lineal entre la dimensión de abuso del padre y la dimensión intrapersonal

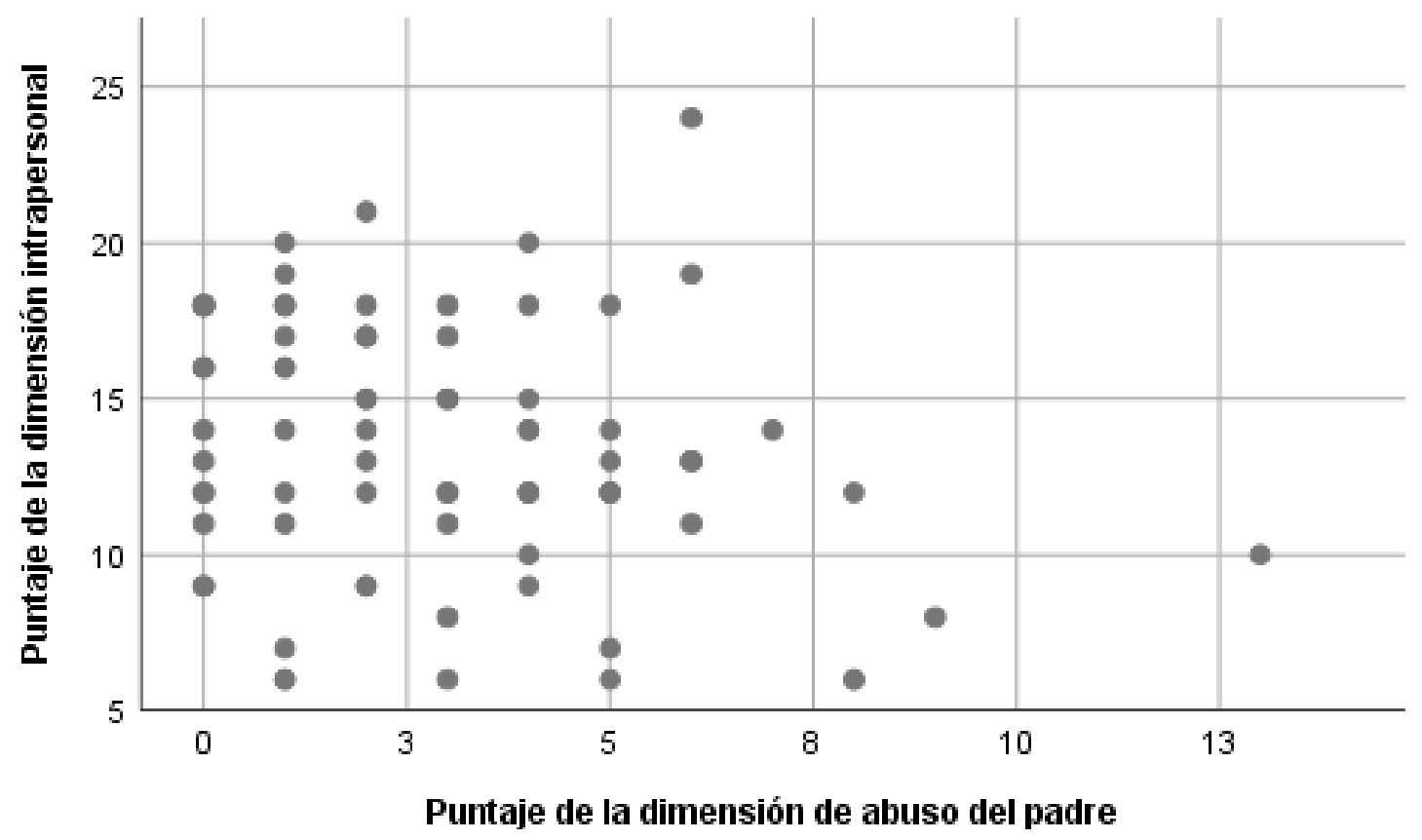

Figura 2

Relación lineal entre la dimensión de abuso del padre y la dimensión interpersonal

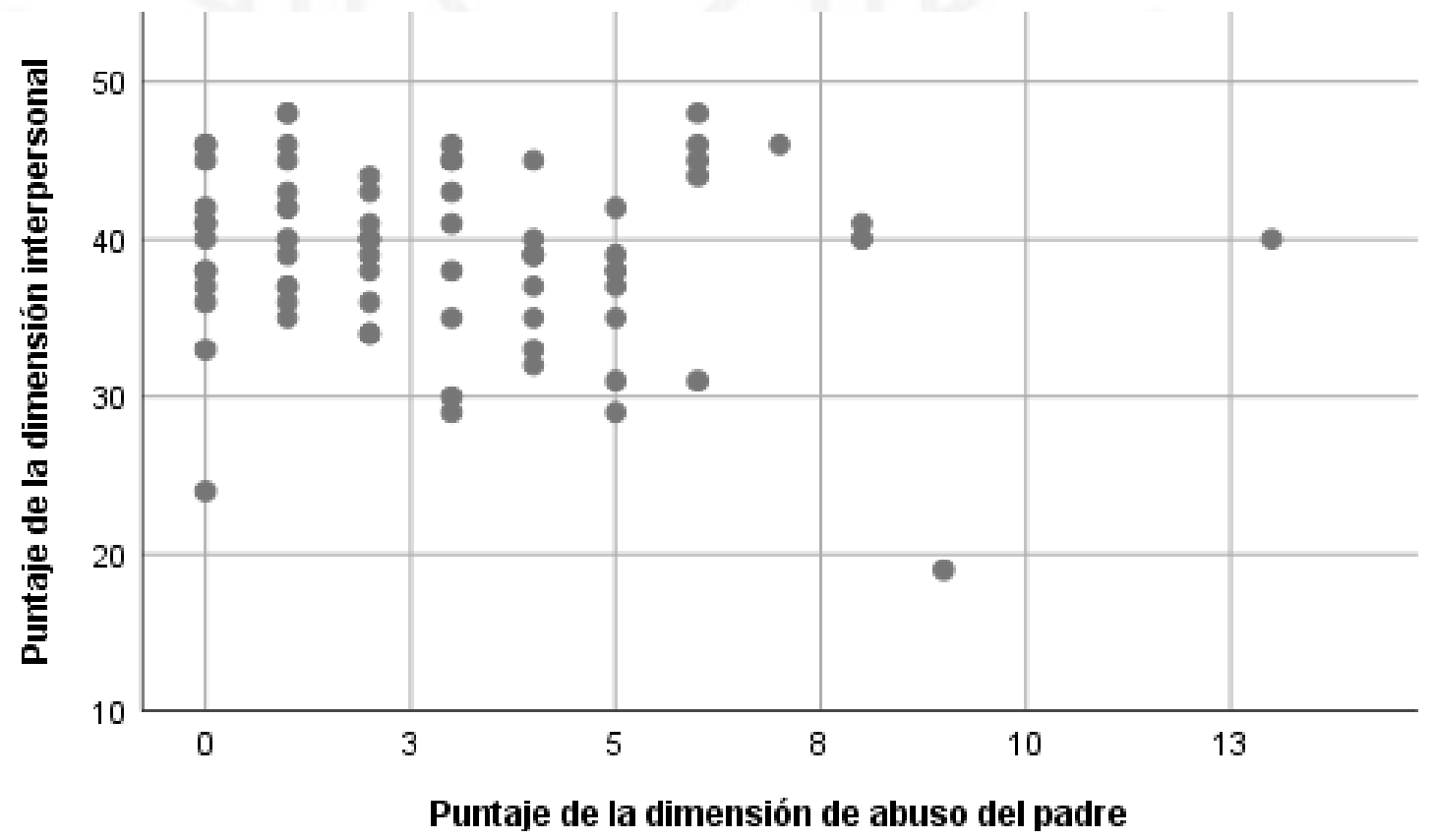


Figura 3

Relación lineal entre la dimensión de abuso del padre y la dimensión de adaptabilidad

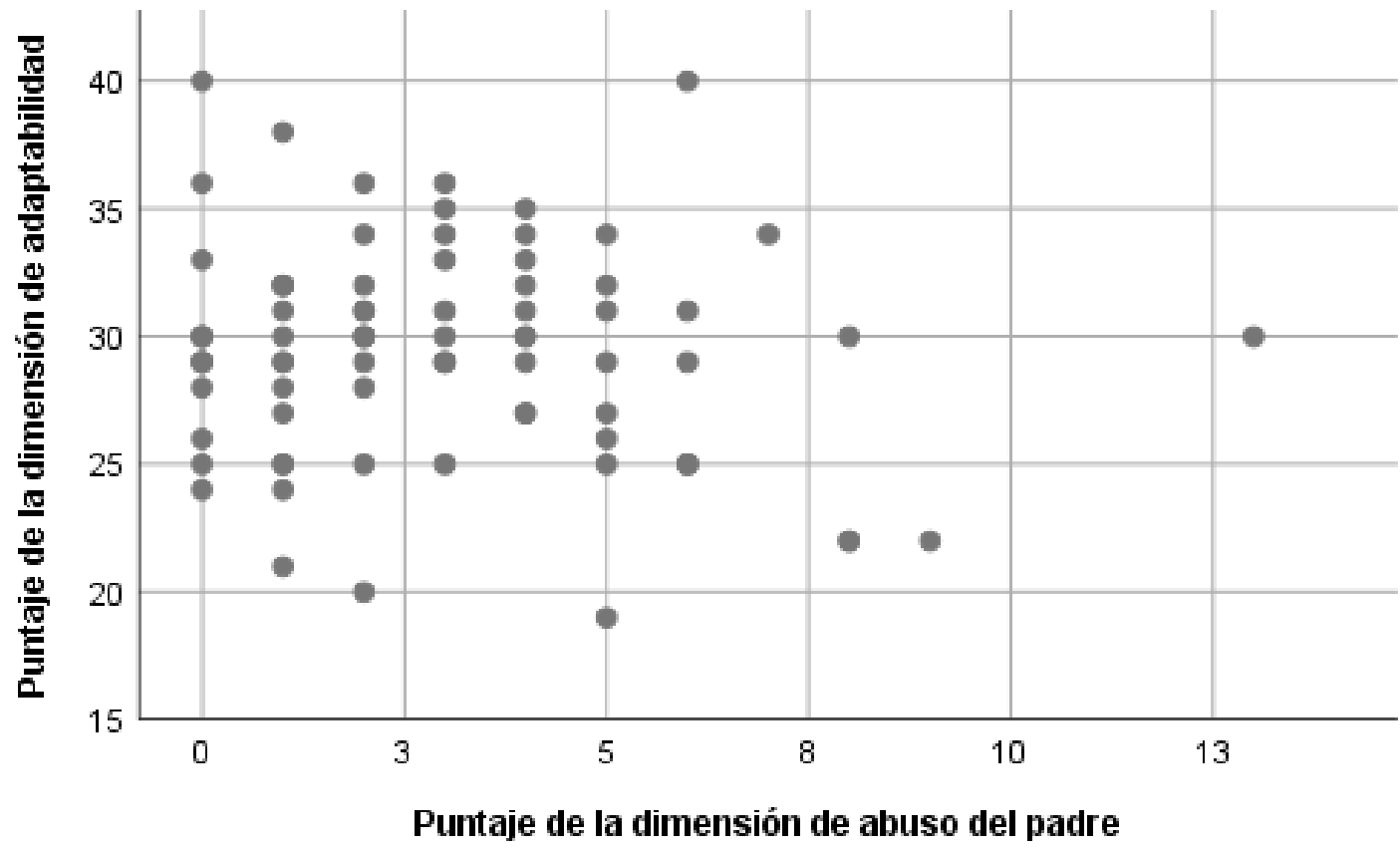

Figura 4

Relación lineal entre la dimensión de abuso del padre y la dimensión de manejo del estrés

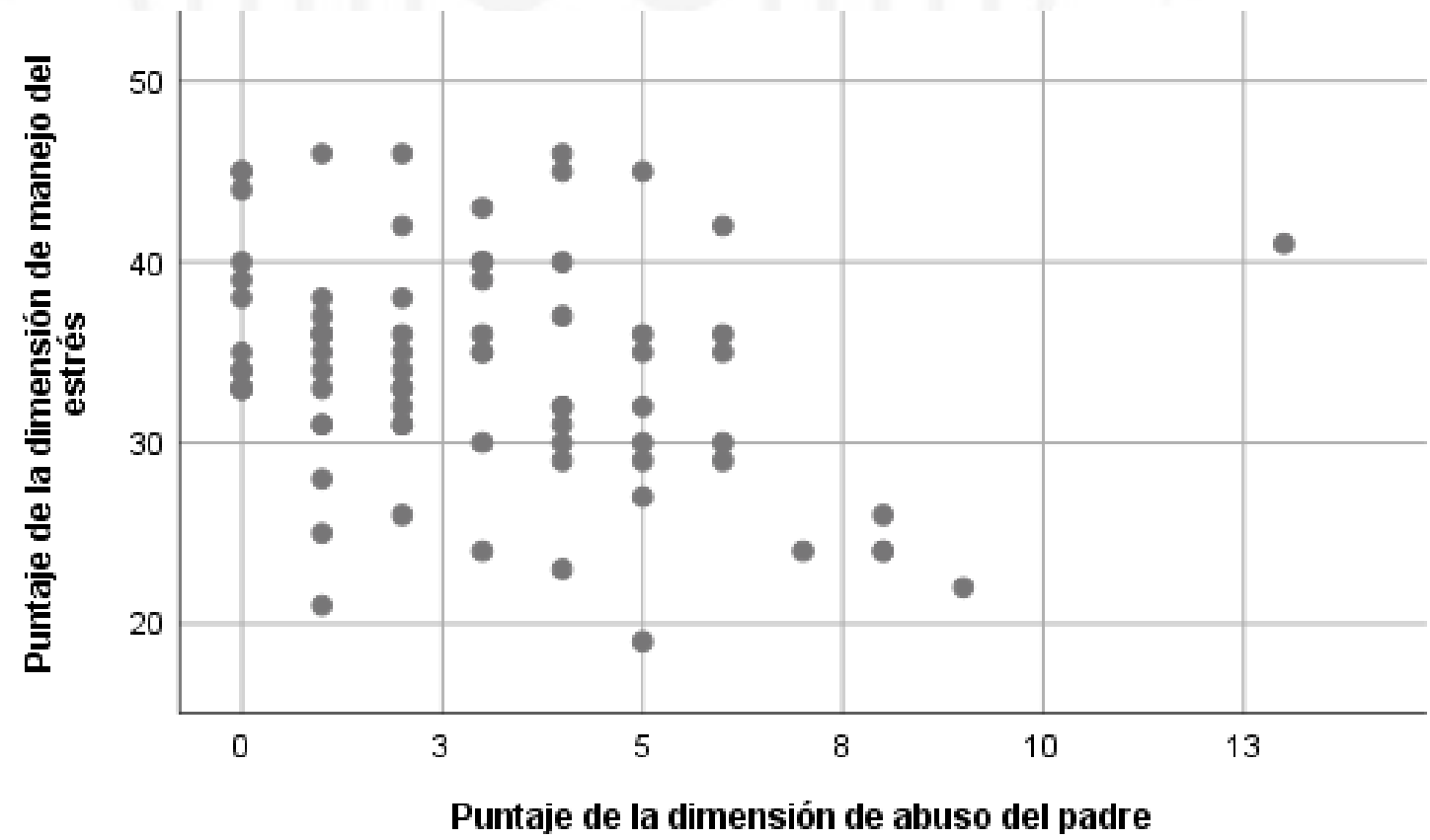


Figura 5

Relación lineal entre la dimensión de abuso del padre y la dimensión de estado de ánimo

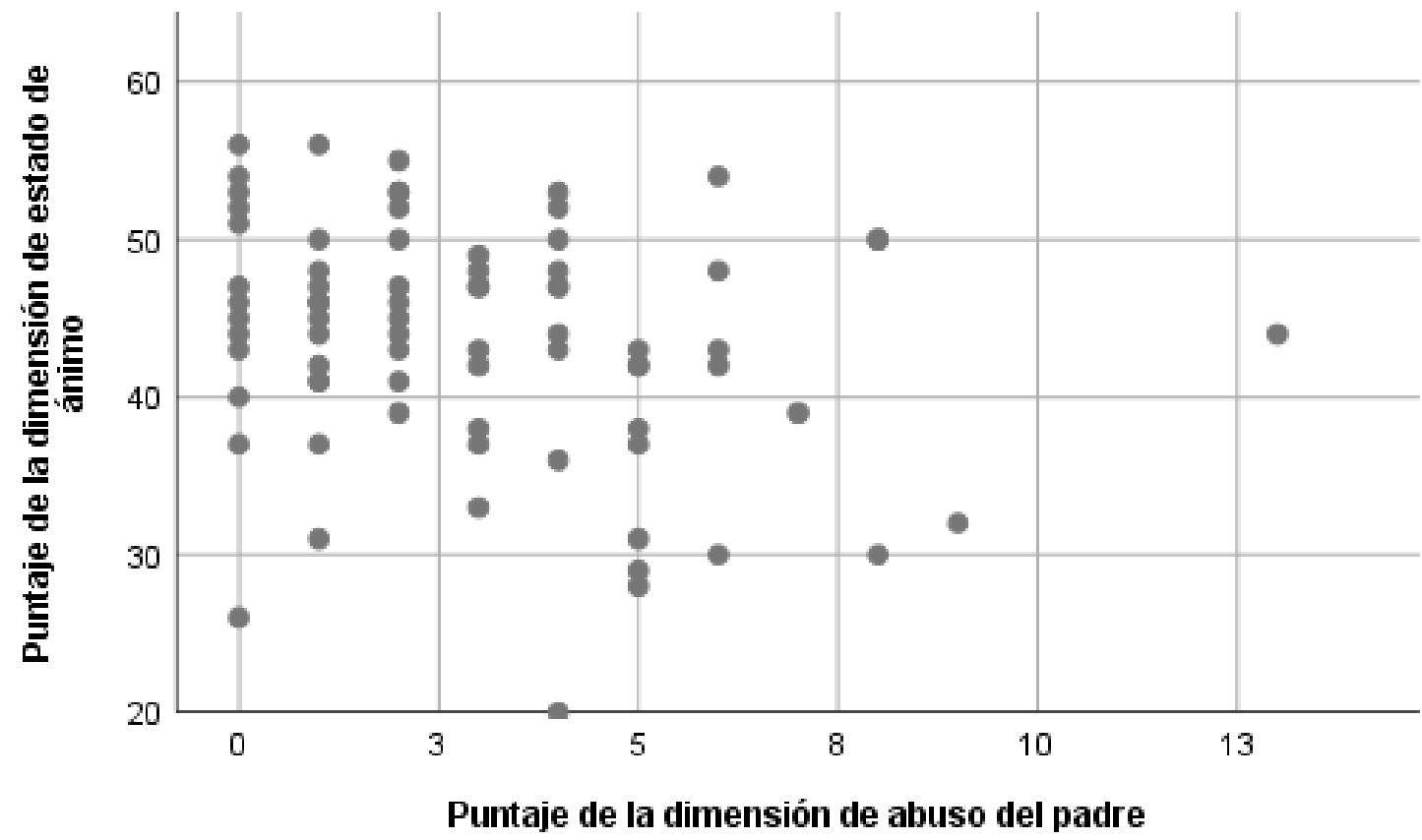

Figura 6

Relación lineal entre la dimensión de sobreprotección del padre y la dimensión intrapersonal

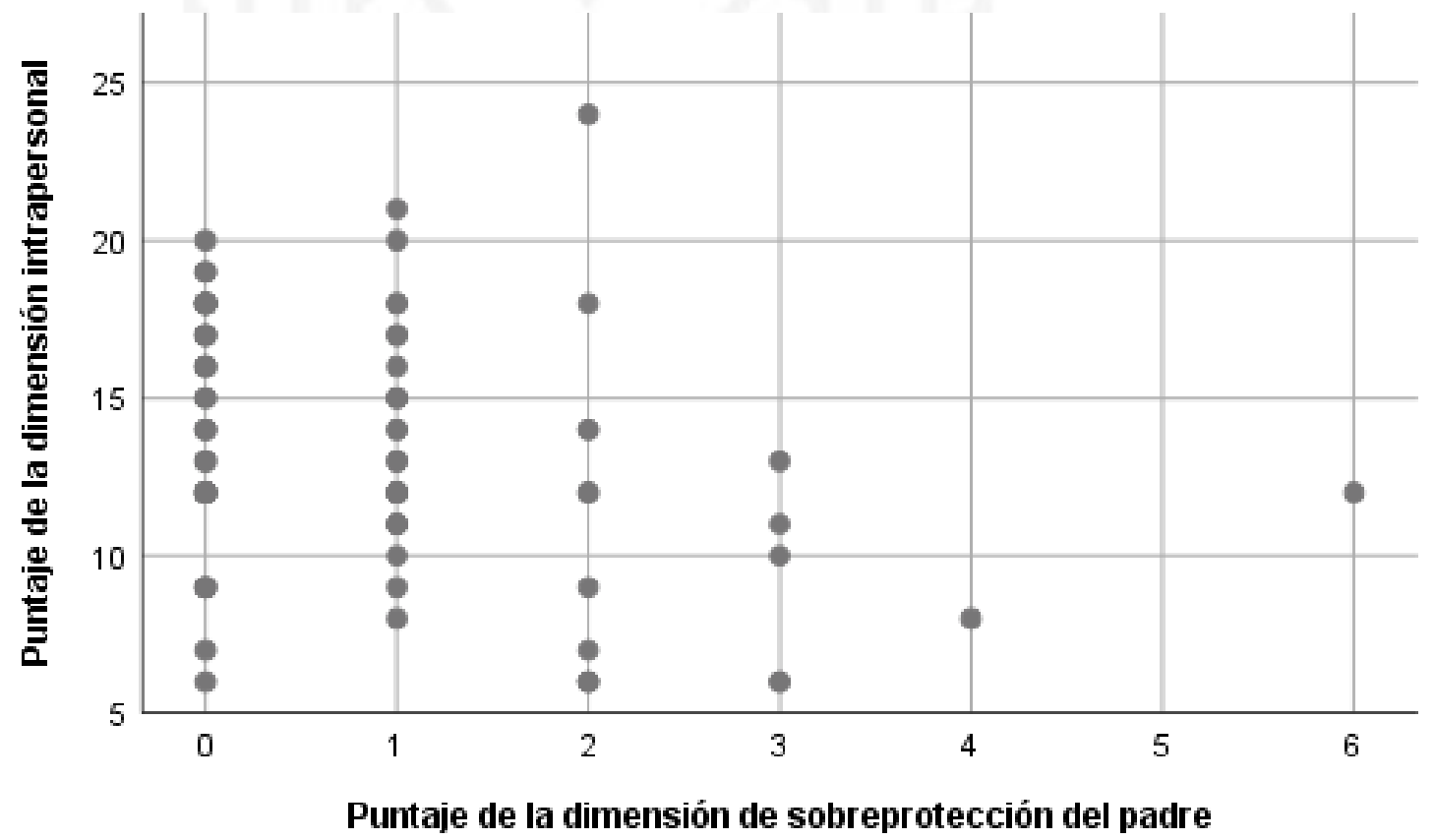


Figura 7

Relación lineal entre la dimensión de sobreprotección del padre y la dimensión interpersonal

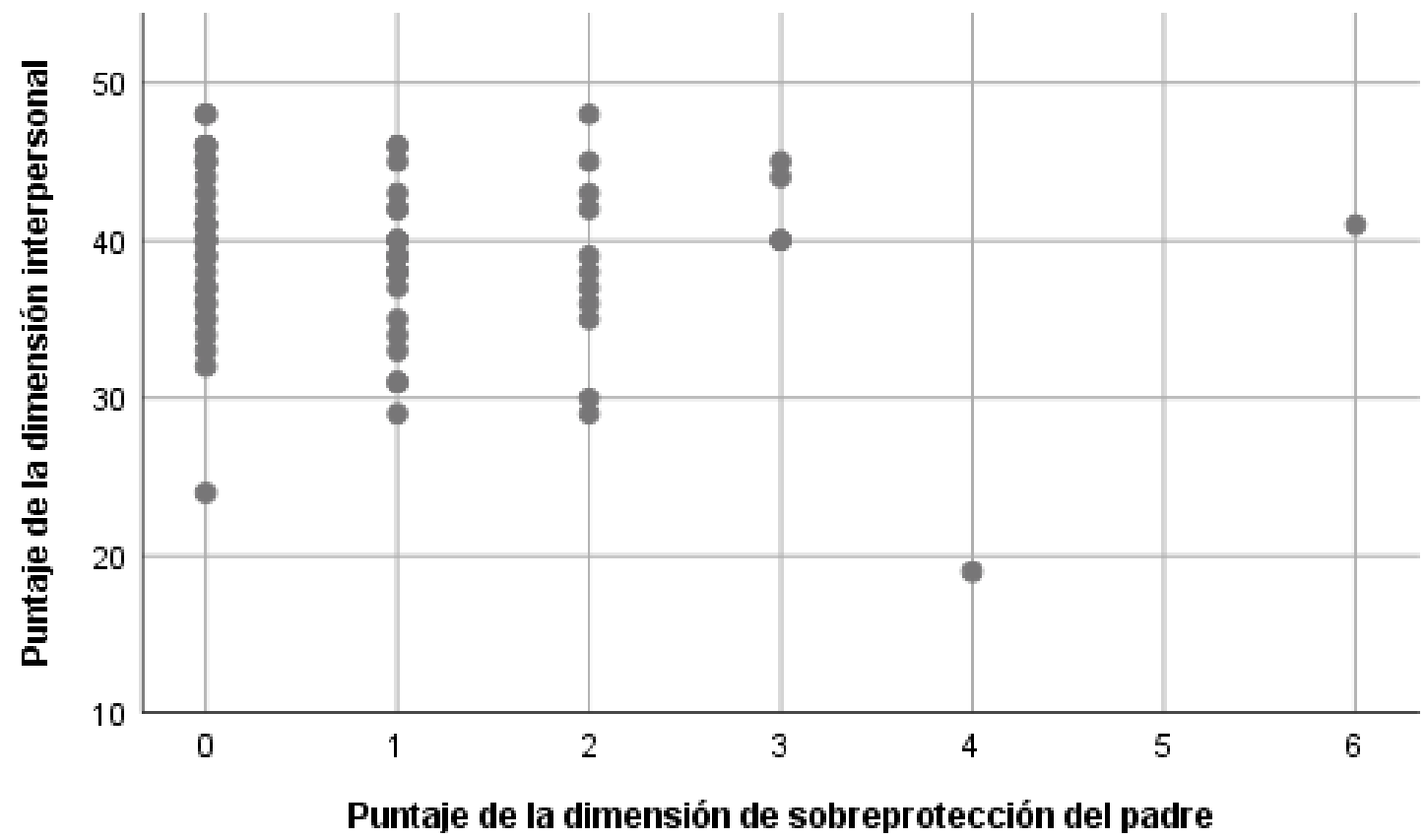

Figura 8

Relación lineal entre la dimensión de sobreprotección del padre y la dimensión de adaptabilidad

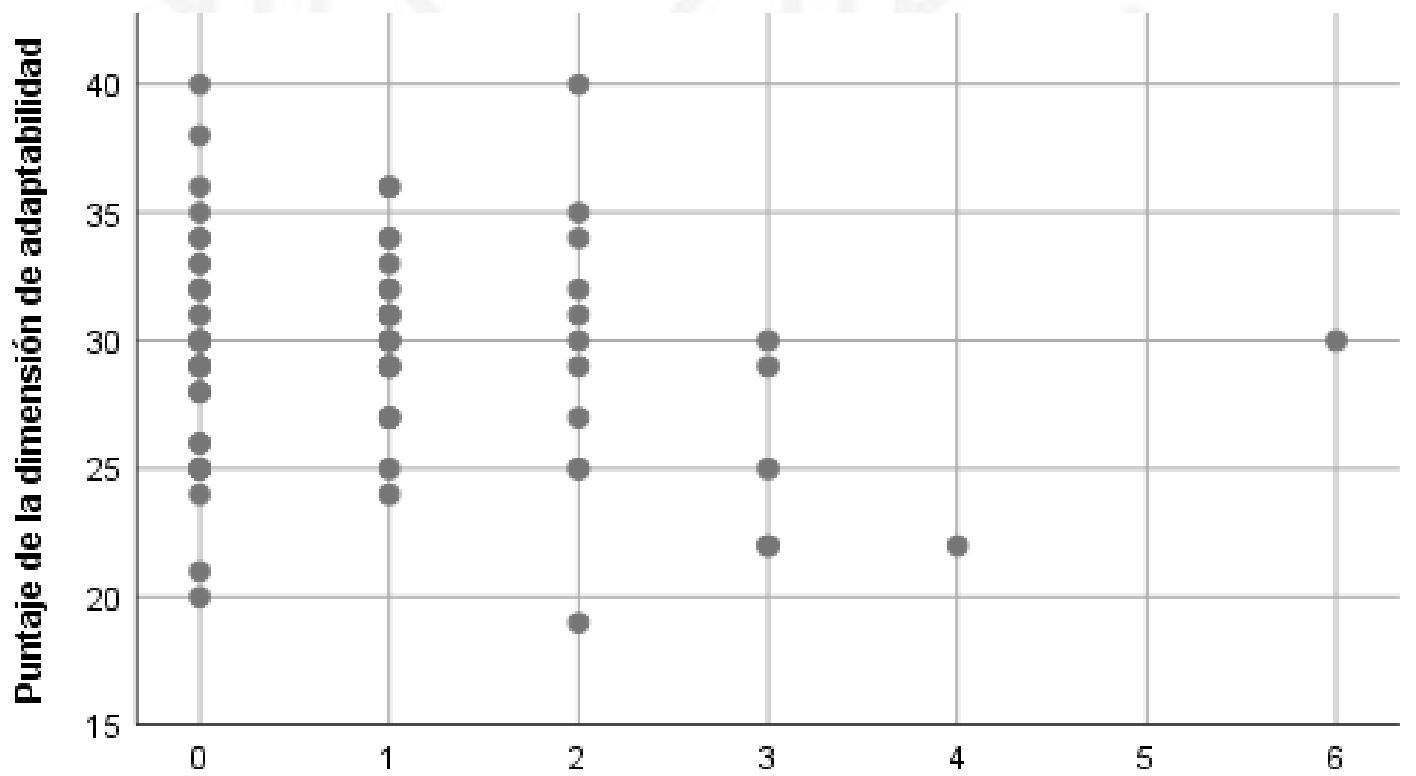

Puntaje de la dimensión de sobreprotección del padre 
Figura 9

Relación lineal entre la dimensión de sobreprotección del padre y la dimensión de manejo del estrés

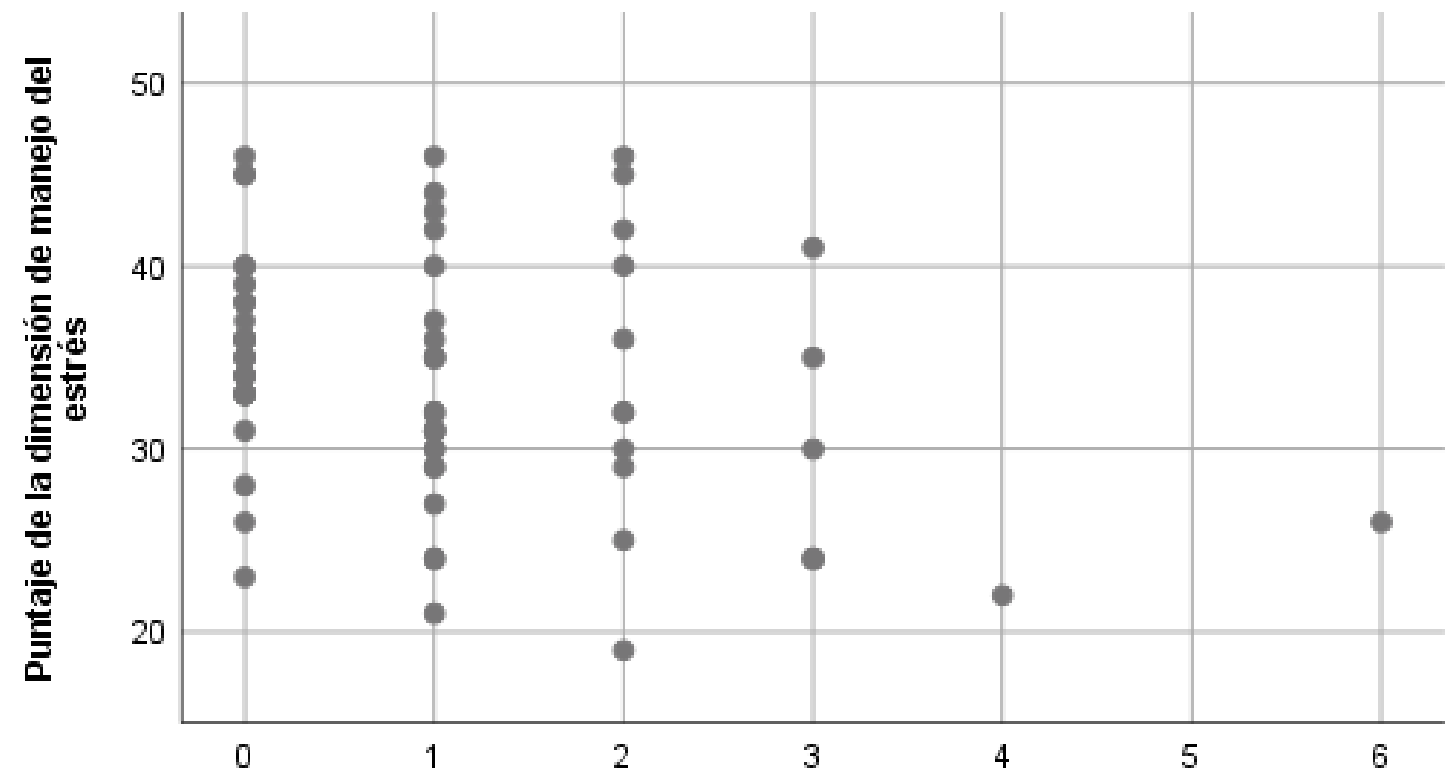

Puntaje de la dimensión de sobreprotección del padre

Figura 10

Relación lineal entre la dimensión de sobreprotección del padre y la dimensión de estado de ánimo

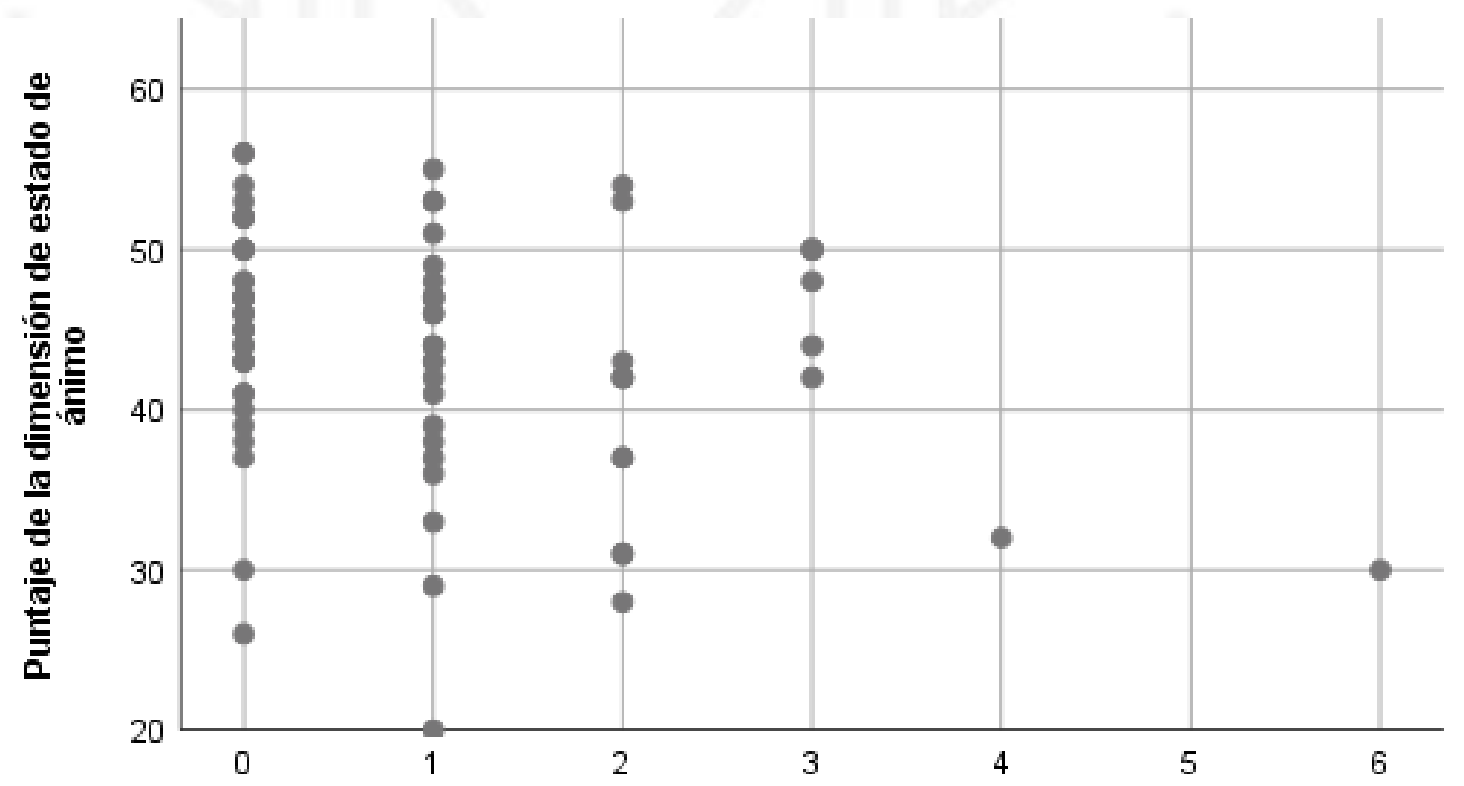

Puntaje de la dimensión de sobreprotección del padre 
Figura 11

Relación lineal entre la dimensión de indiferencia del padre y la dimensión intrapersonal

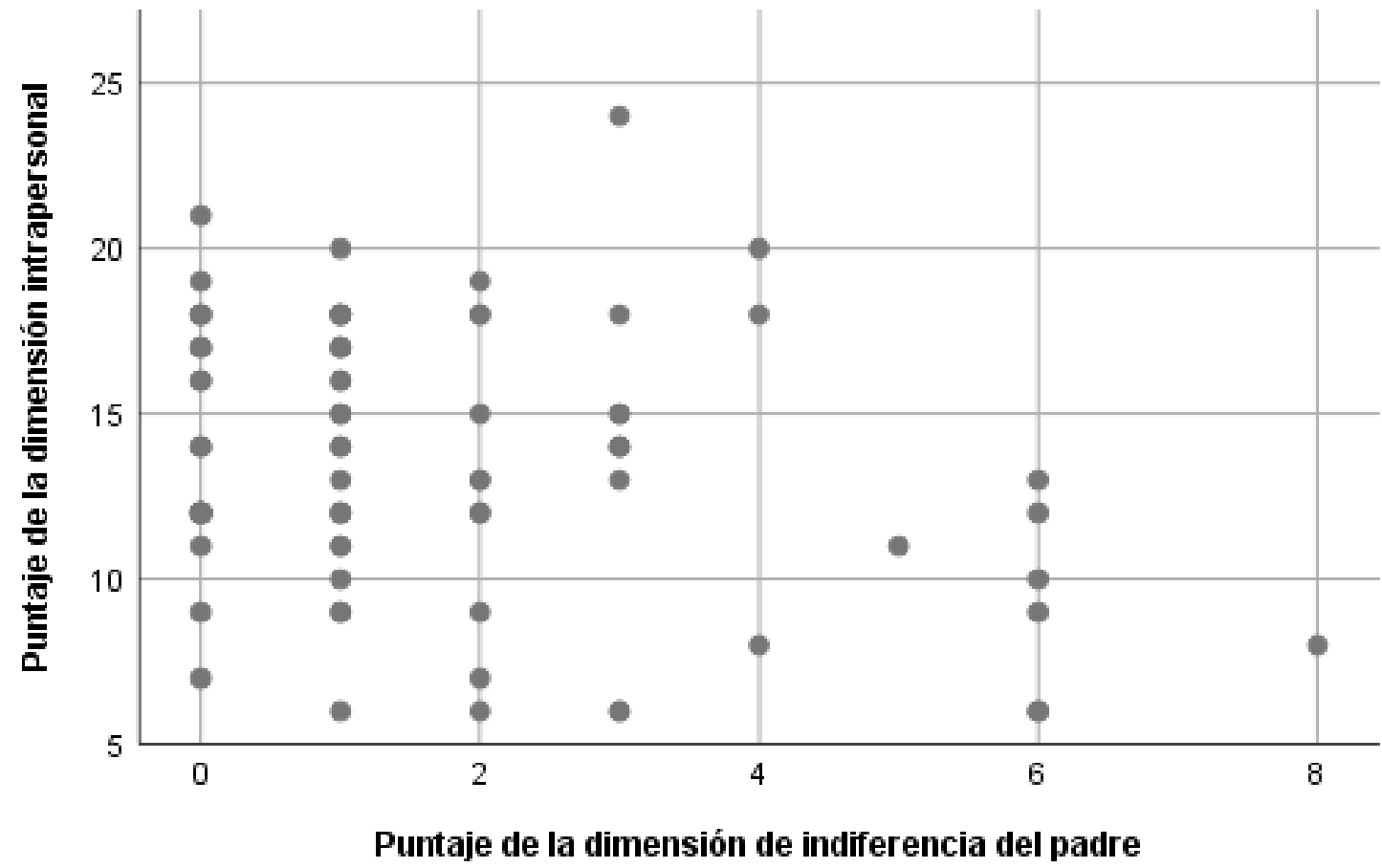

Figura 12

Relación lineal entre la dimensión de indiferencia del padre y la dimensión interpersonal

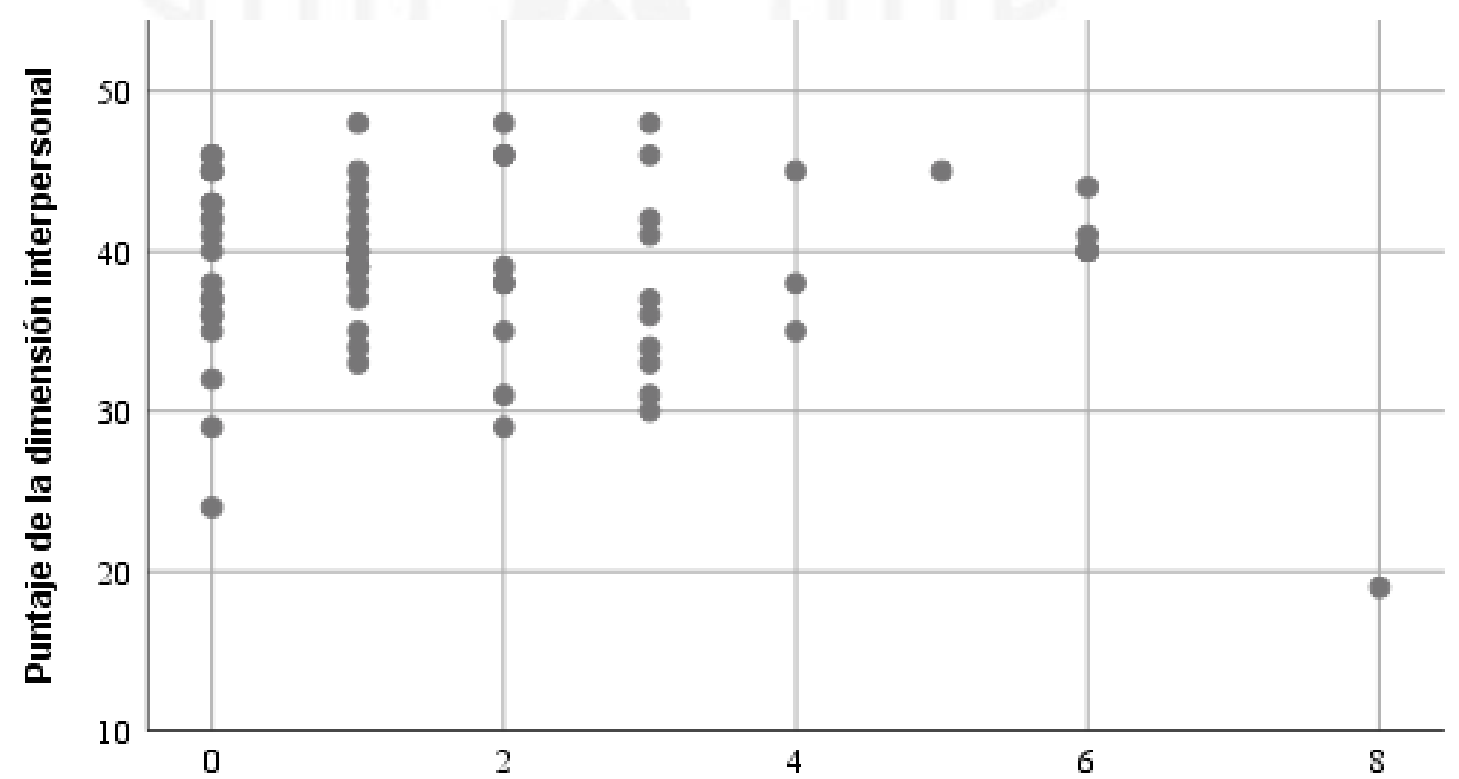

Puntaje de la dimensión de indiferencia del padre 
Figura 13

Relación lineal entre la dimensión de indiferencia del padre y la dimensión de adaptabilidad

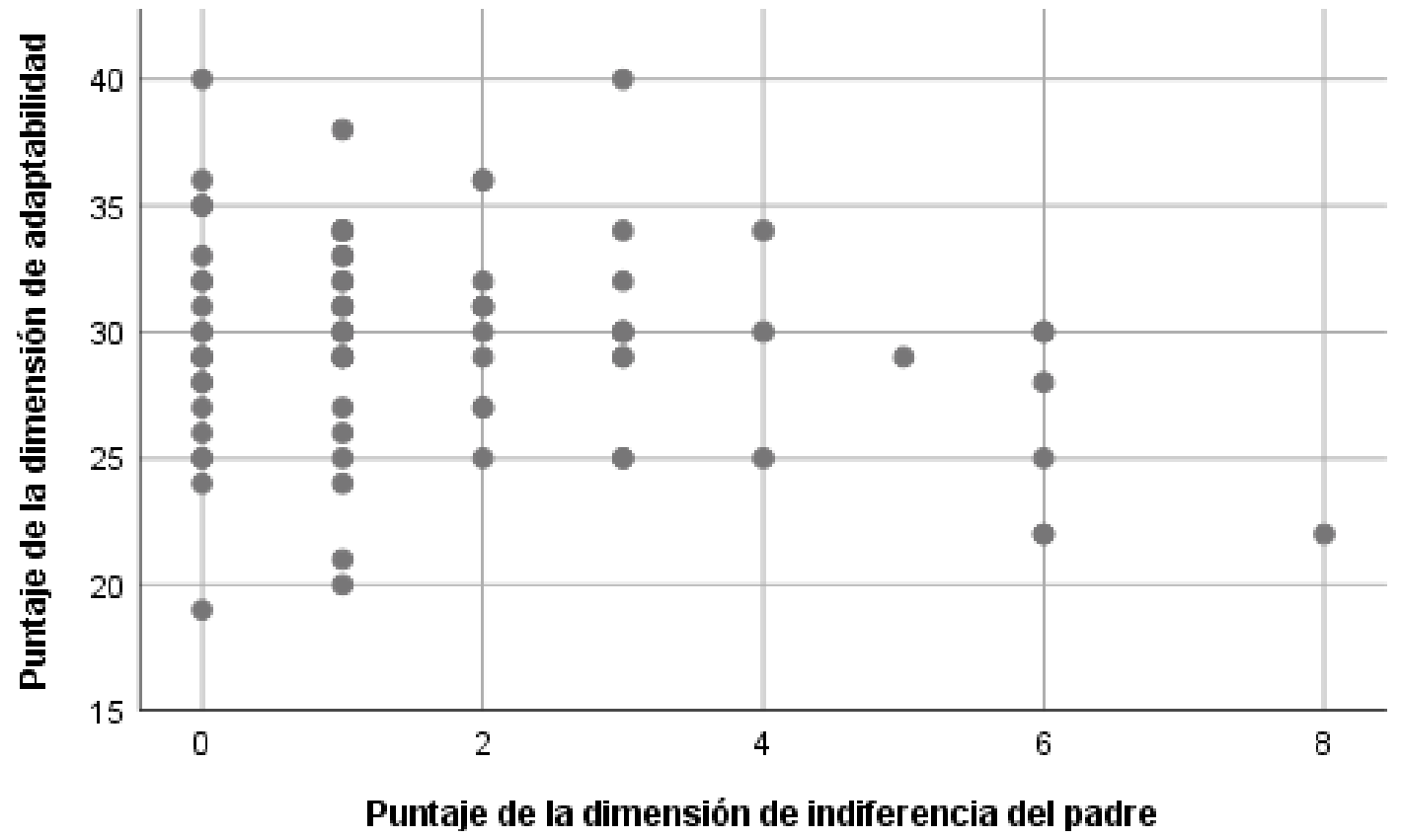

Figura 14

Relación lineal entre la dimensión de indiferencia del padre y la dimensión de manejo del estrés

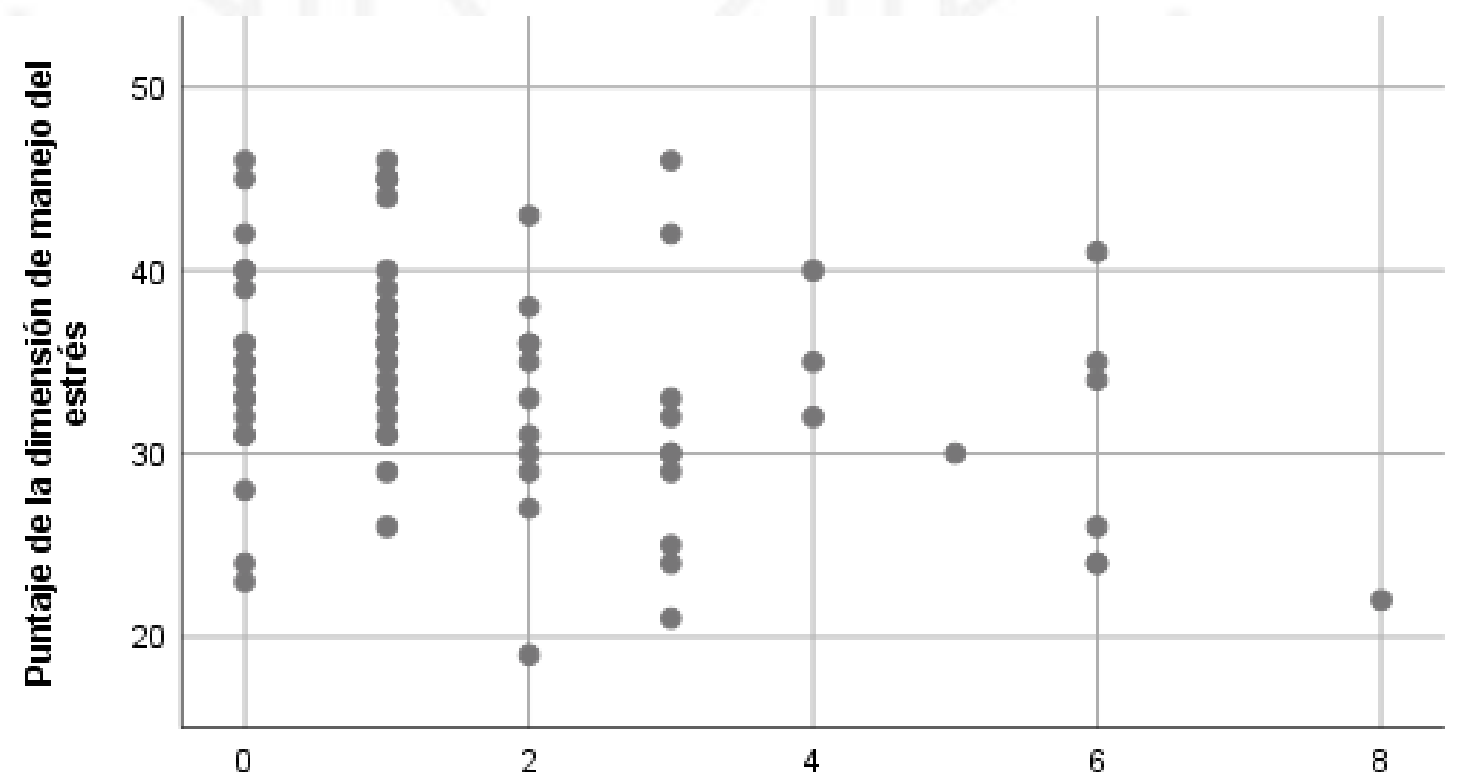

Puntaje de la dimensión de indiferencia del padre 
Figura 15

Relación lineal entre la dimensión de indiferencia del padre y la dimensión de estado de ánimo

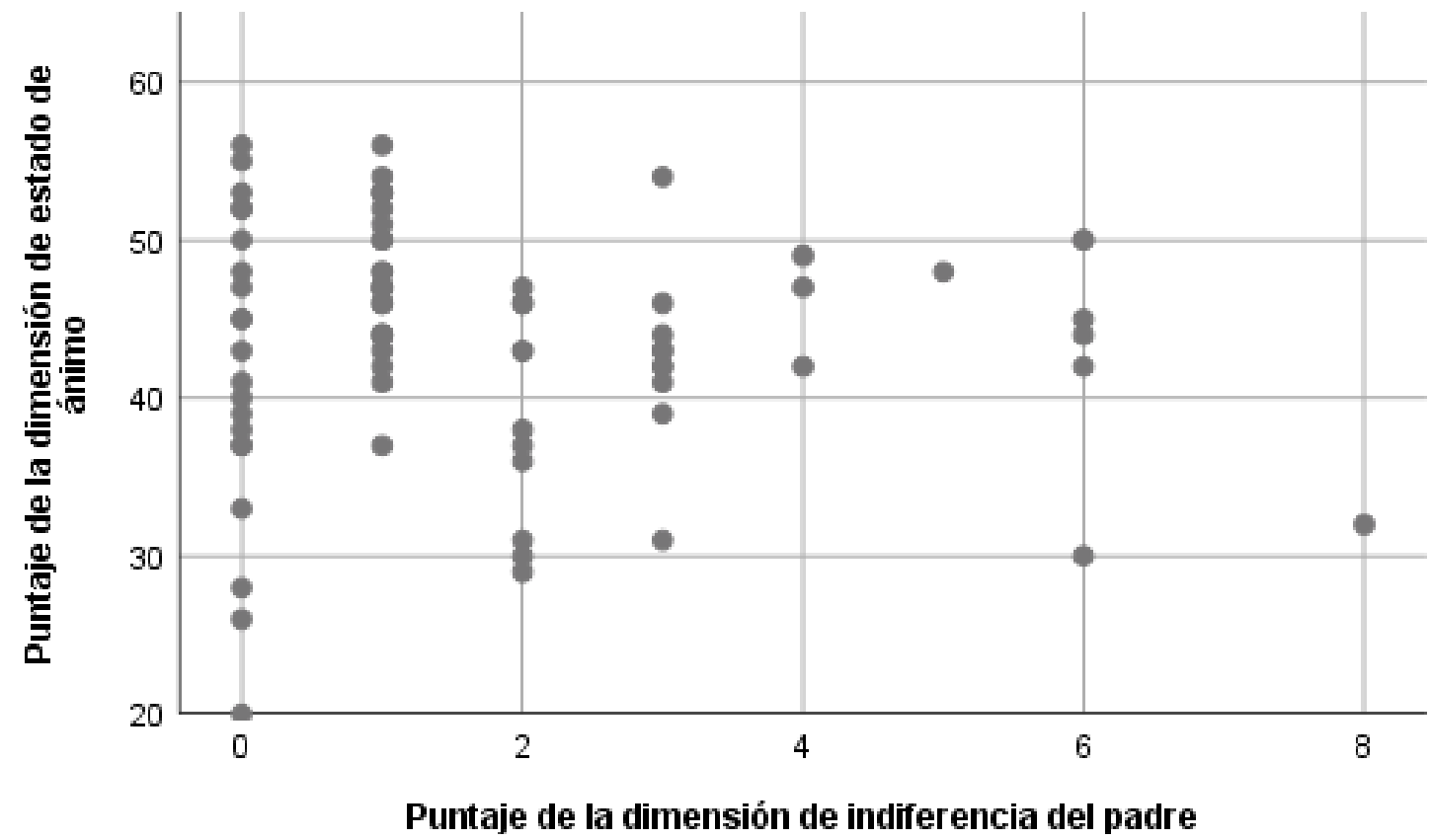

Figura 16

Relación lineal entre la dimensión de abuso de la madre y la dimensión intrapersonal

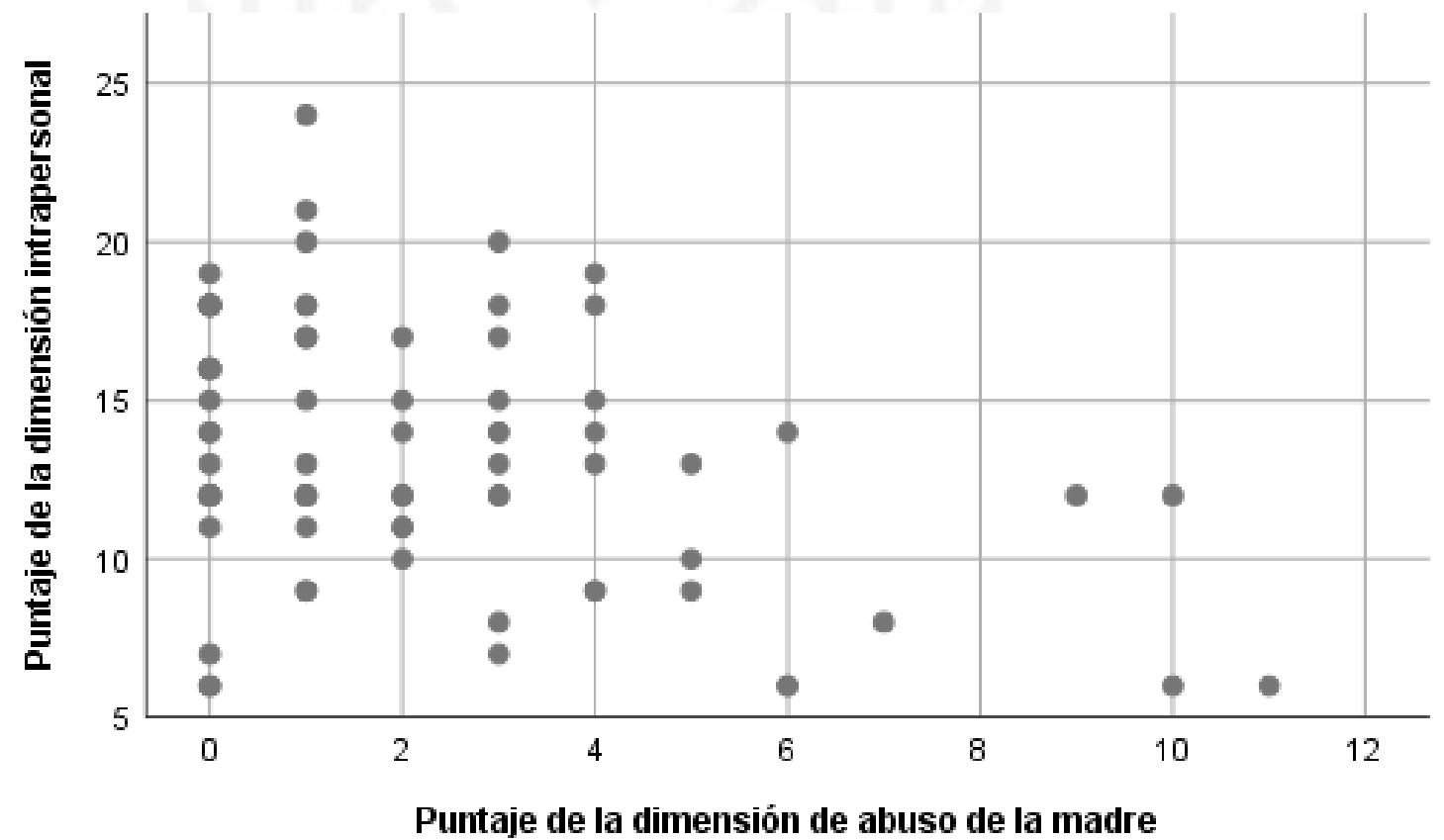


Figura 17

Relación lineal entre la dimensión de abuso de la madre y la dimensión interpersonal

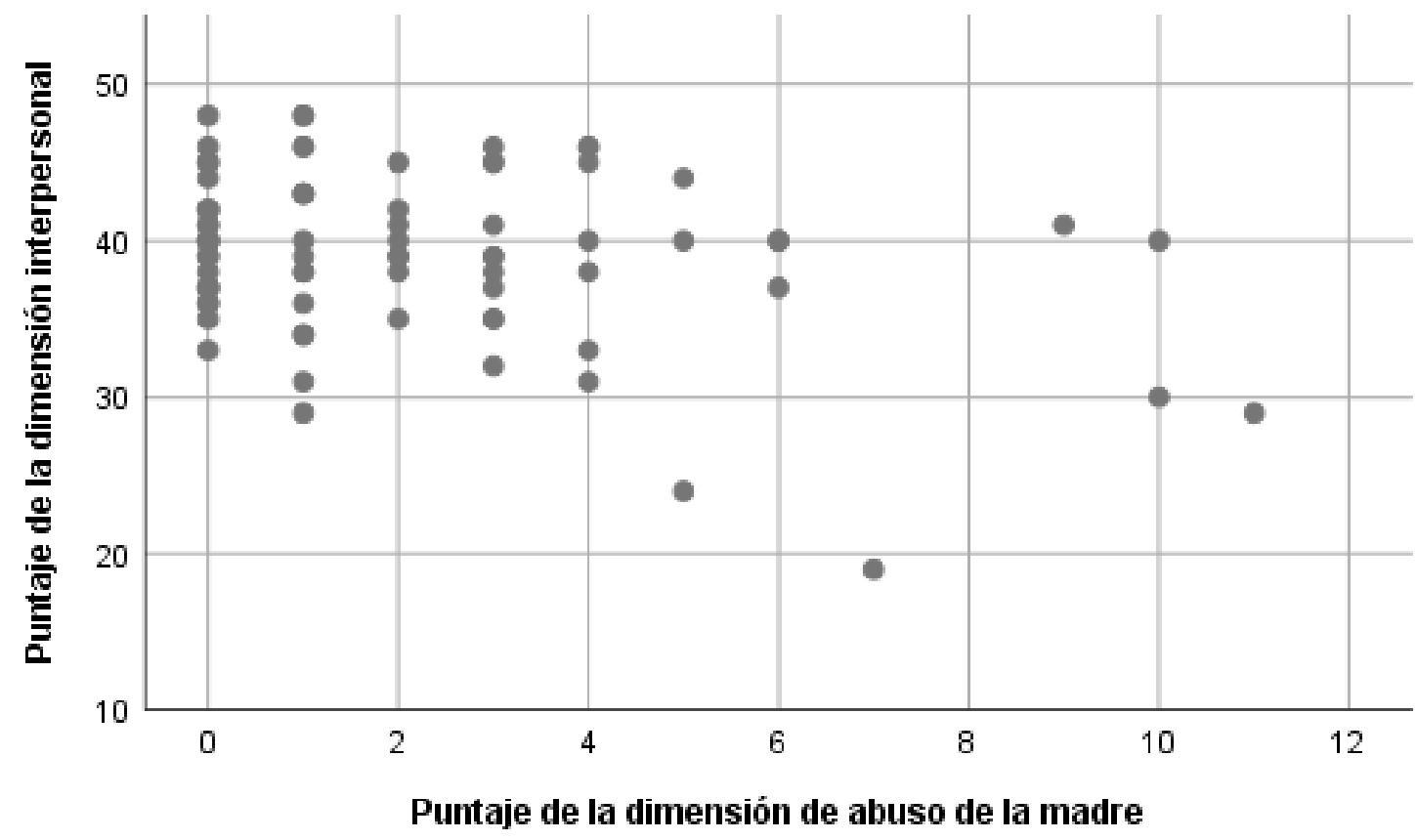

Figura 18

Relación lineal entre la dimensión de abuso de la madre y la dimensión de adaptabilidad

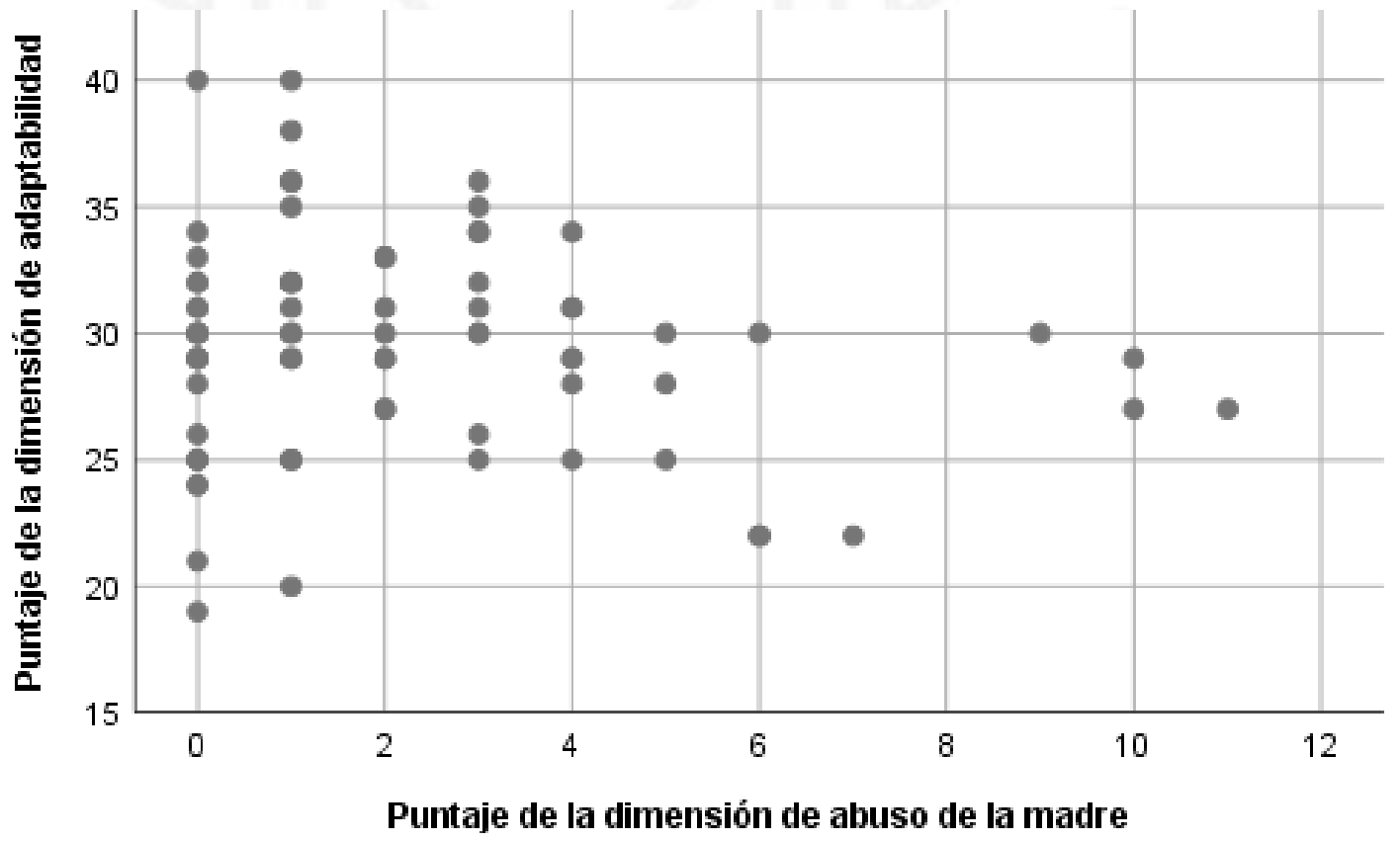


Figura 19

Relación lineal entre la dimensión de abuso de la madre y la dimensión de manejo del estrés

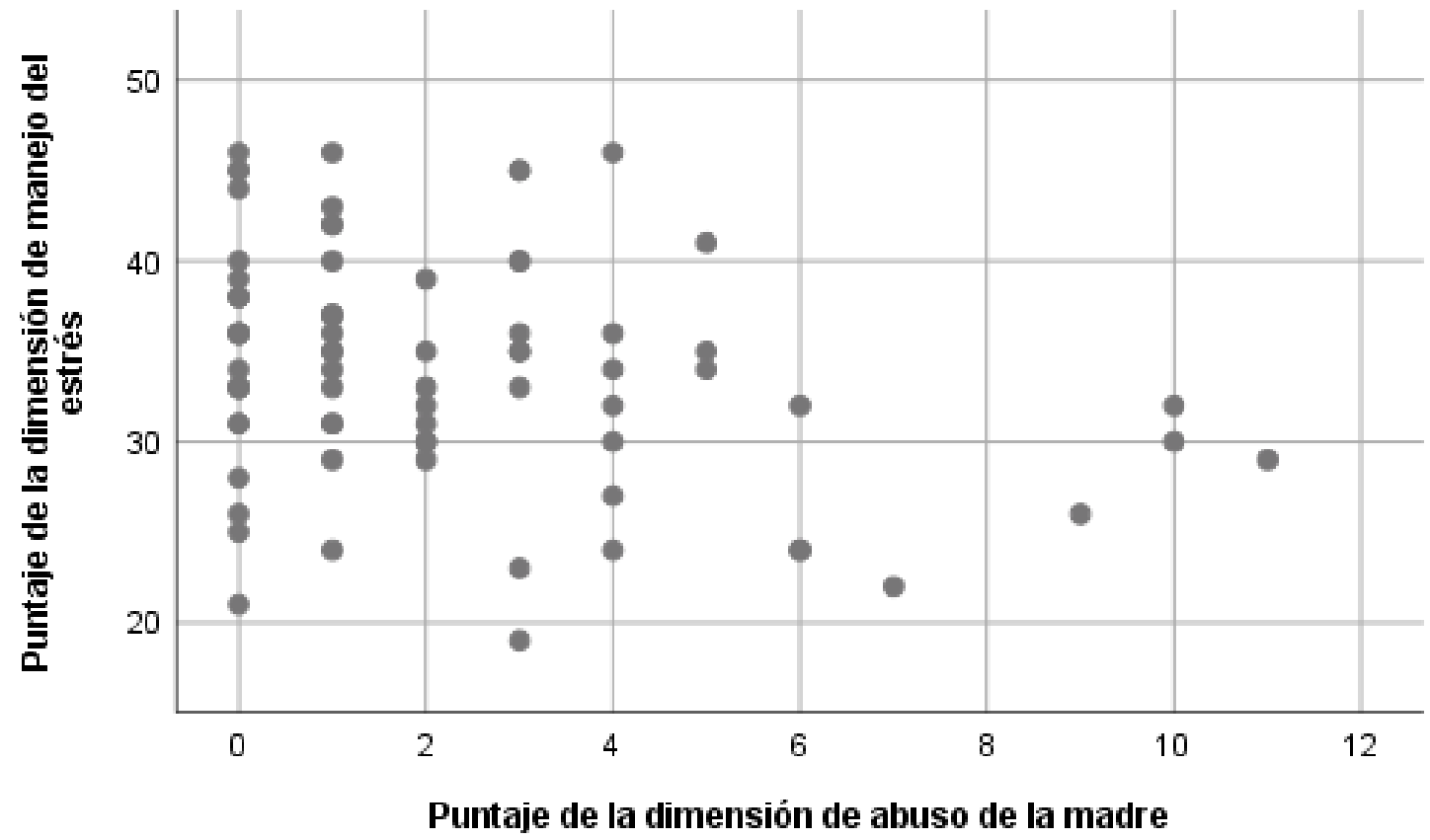

Figura 20

Relación lineal entre la dimensión de abuso de la madre y la dimensión de estado de ánimo

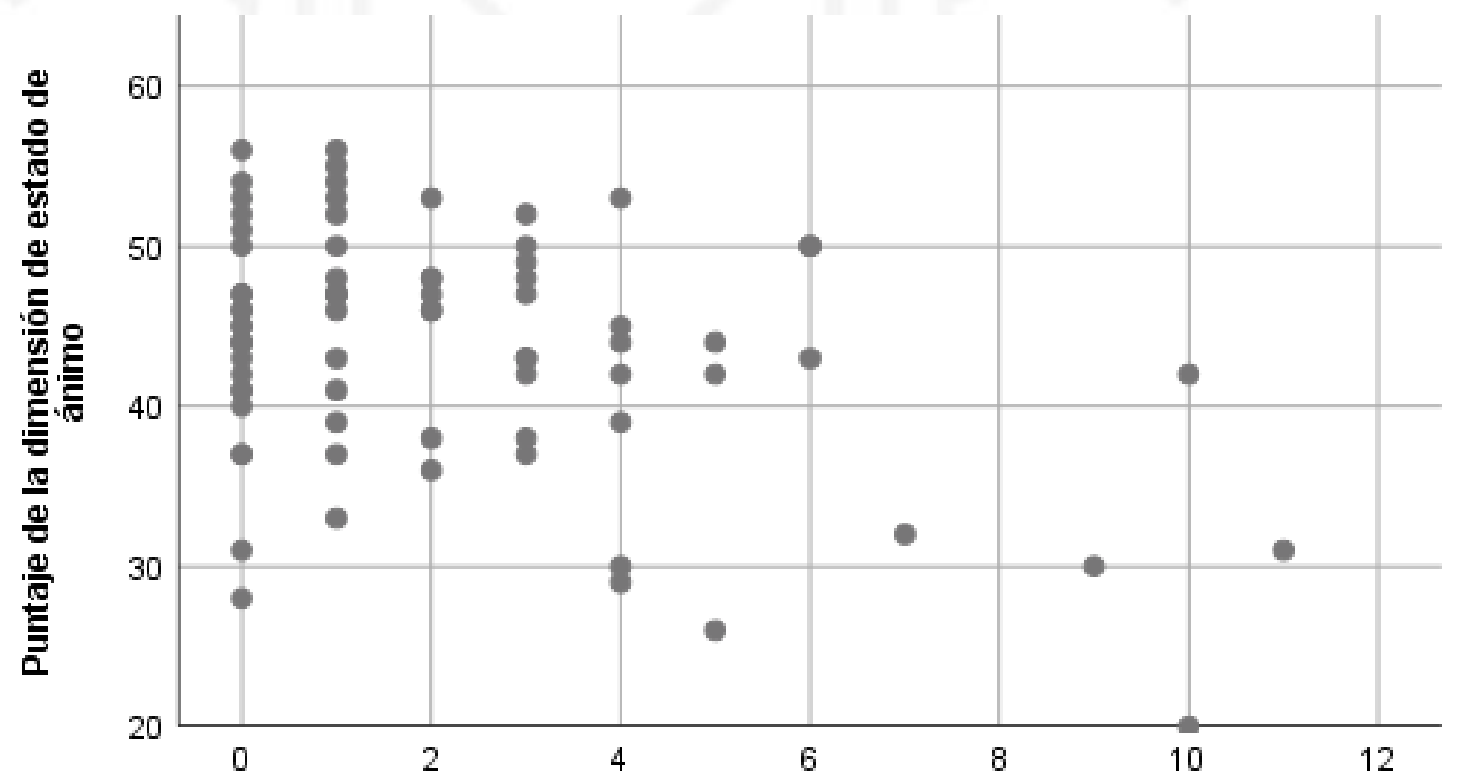

Puntaje de la dimensión de abuso de la madre 
Figura 21

Relación lineal entre la dimensión de sobreprotección de la madre y la dimensión intrapersonal

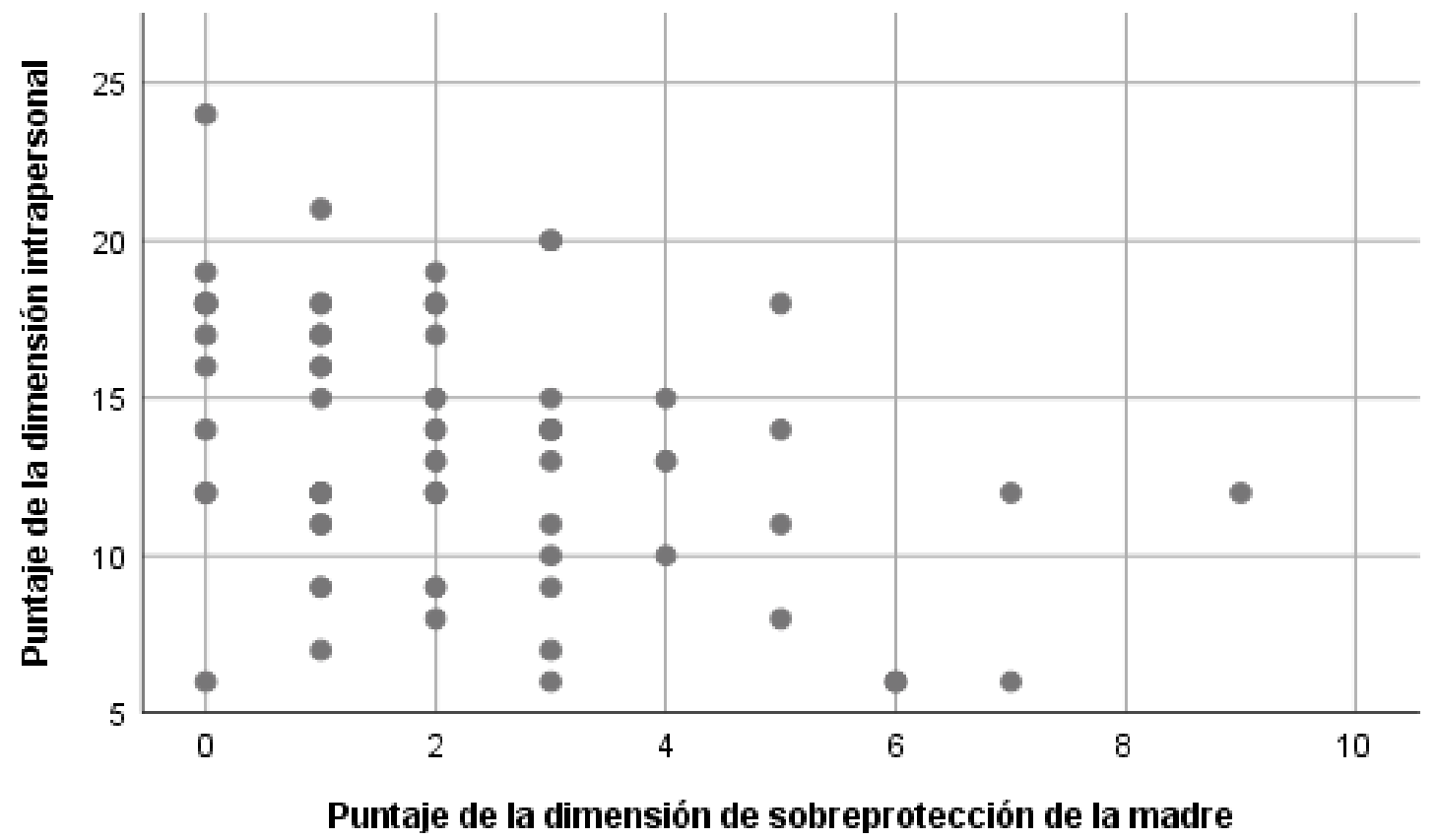

Figura 22

Relación lineal entre la dimensión de sobreprotección de la madre y la dimensión interpersonal

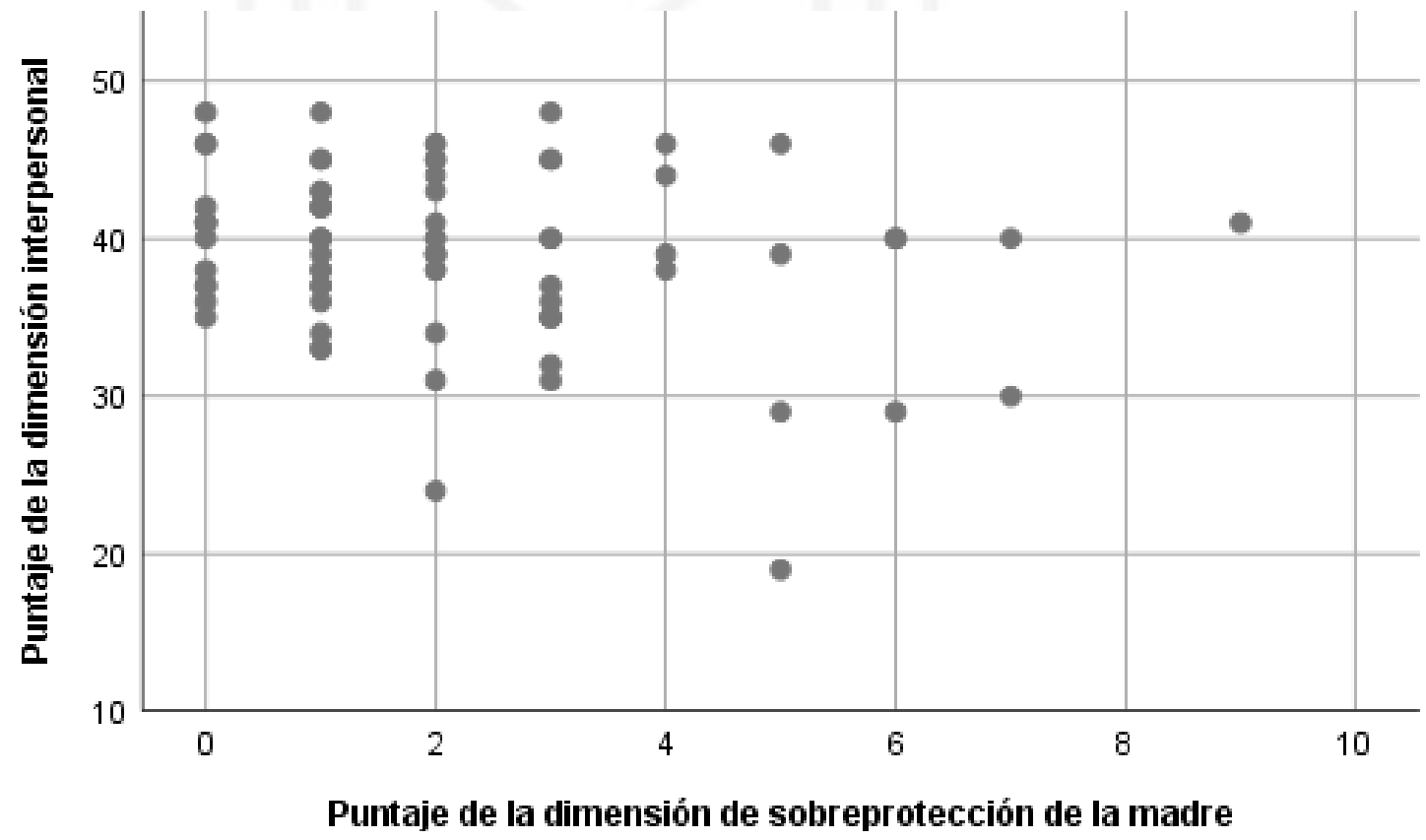


Figura 23

Relación lineal entre la dimensión de sobreprotección de la madre y la dimensión de adaptabilidad

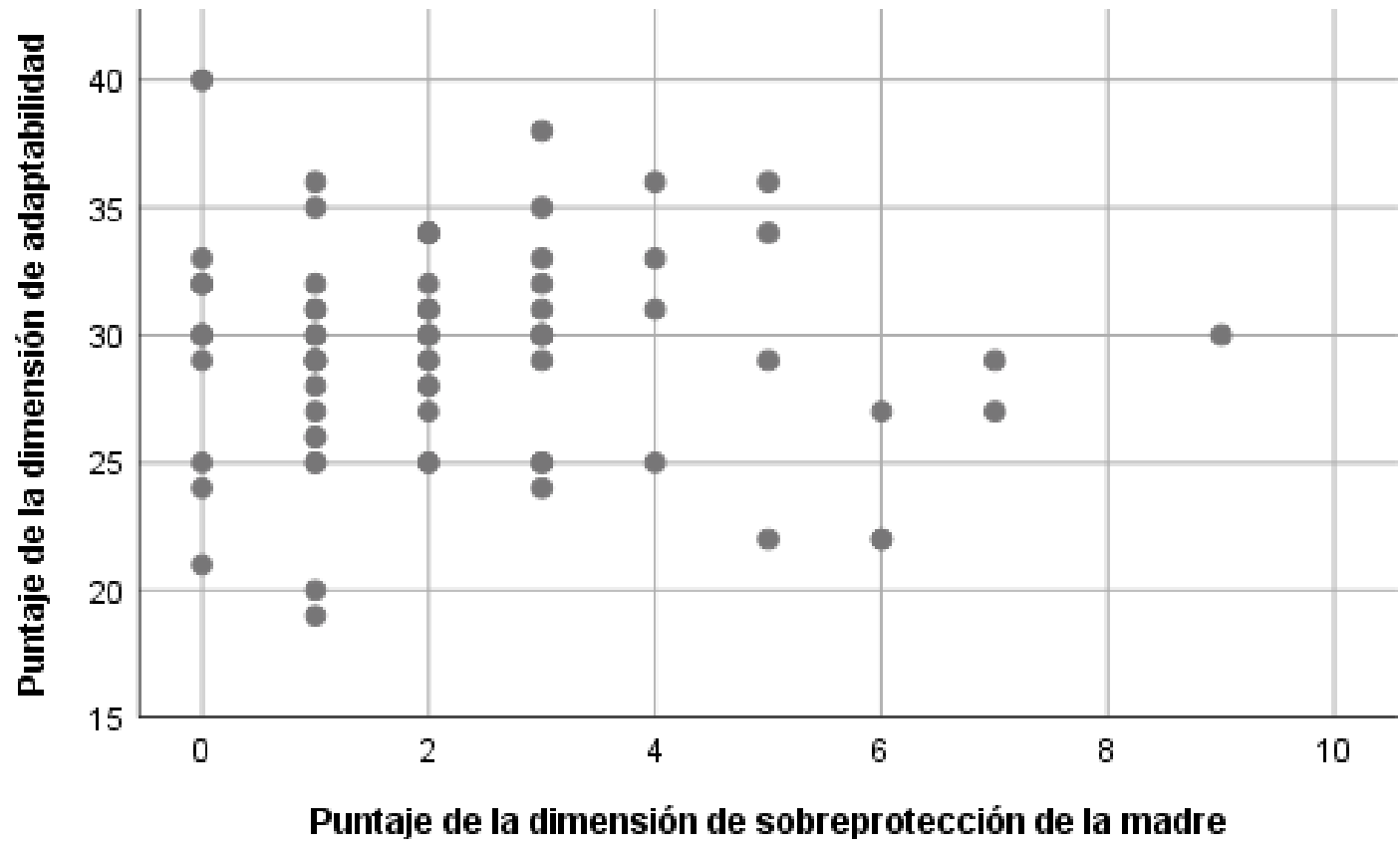

Figura 24

Relación lineal entre la dimensión de sobreprotección de la madre y la dimensión de manejo del estrés

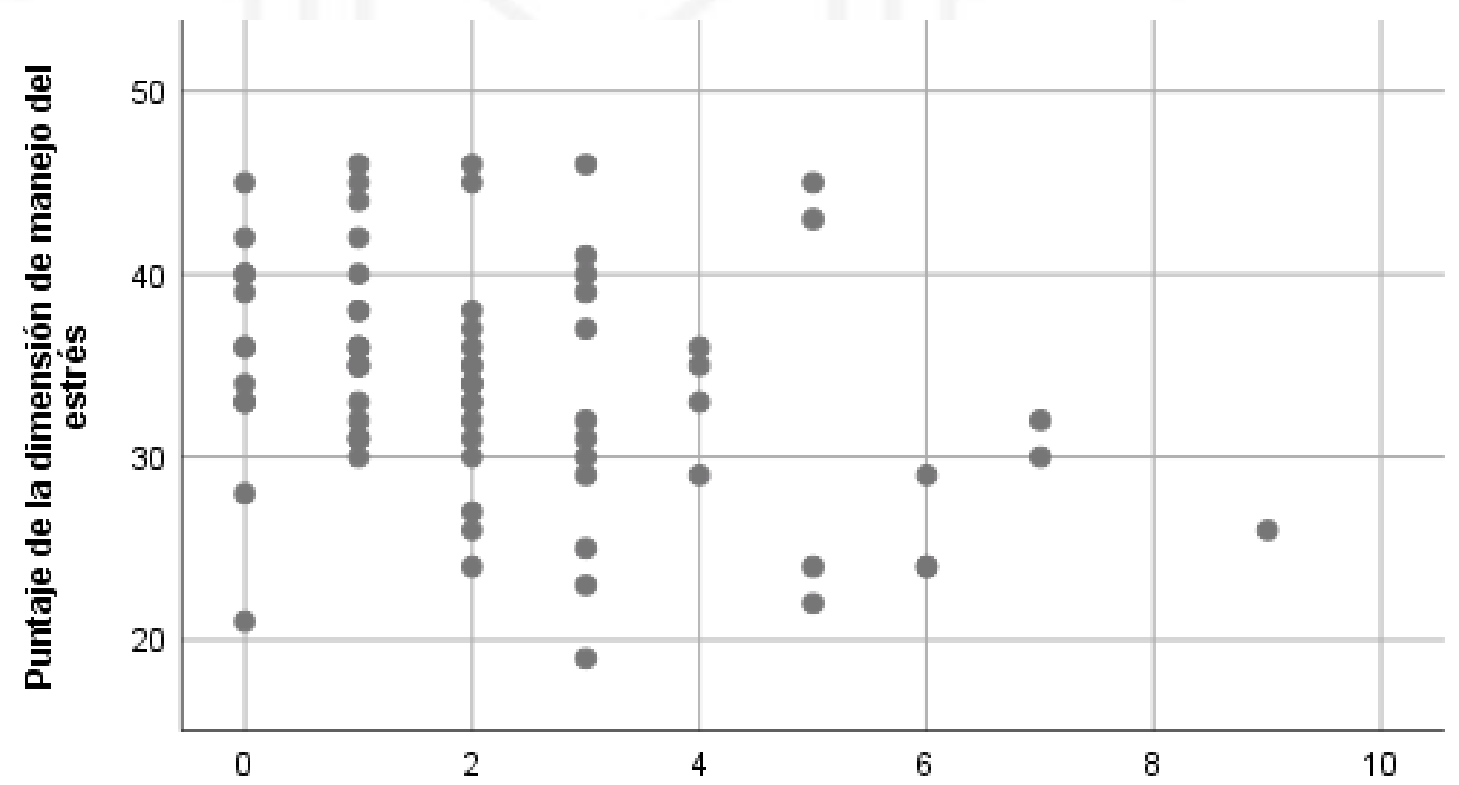

Puntaje de la dimensión de sobreprotección de la madre 
Figura 25

Relación lineal entre la dimensión de sobreprotección de la madre y la dimensión de estado de ánimo

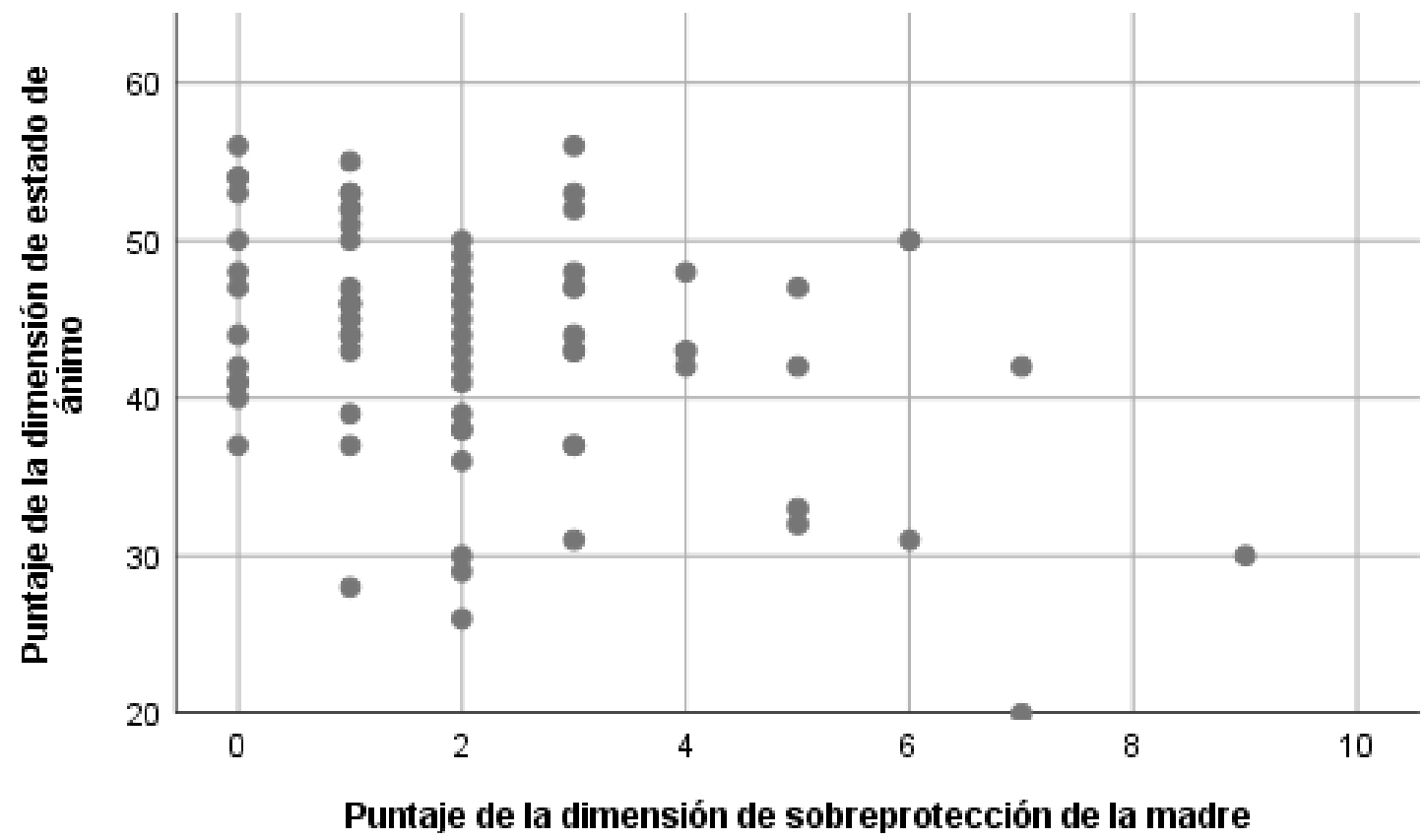

Figura 26

Relación lineal entre la dimensión de indiferencia de la madre y la dimensión intrapersonal

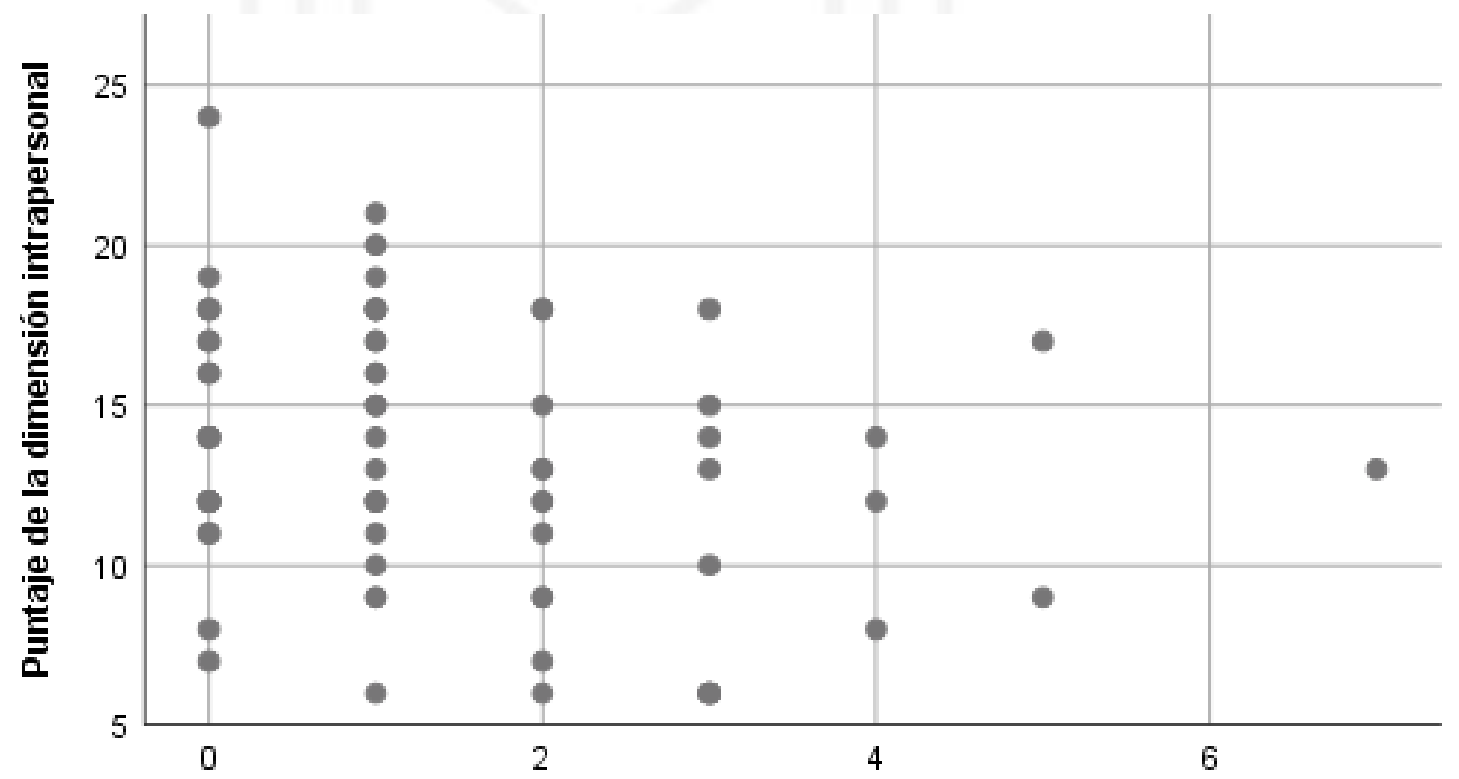

Puntaje de la dimensión de indiferencia de la madre 
Figura 27

Relación lineal entre la dimensión de indiferencia de la madre y la dimensión interpersonal

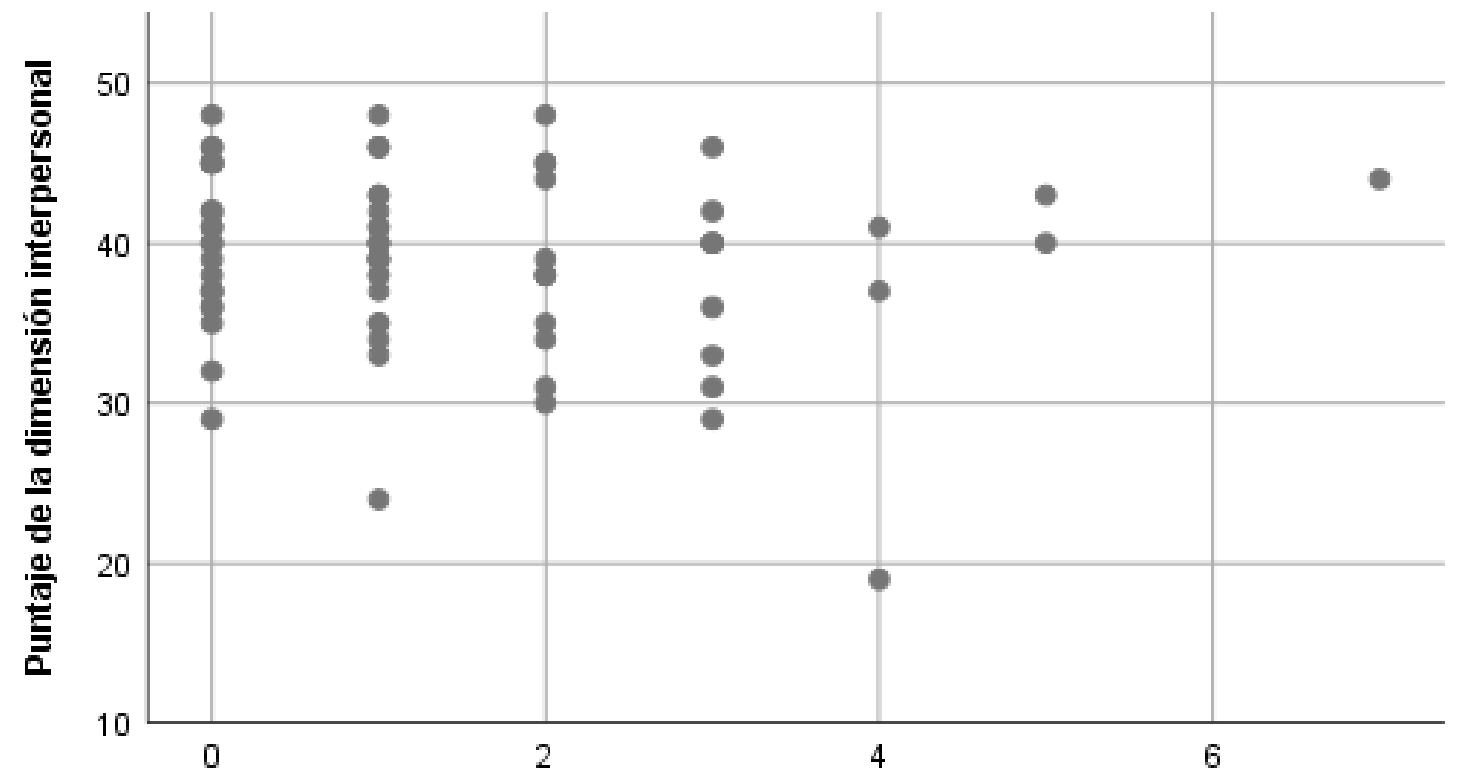

Puntaje de la dimensión de indiferencia de la madre

Figura 28

Relación lineal entre la dimensión de indiferencia de la madre y la dimensión de adaptabilidad

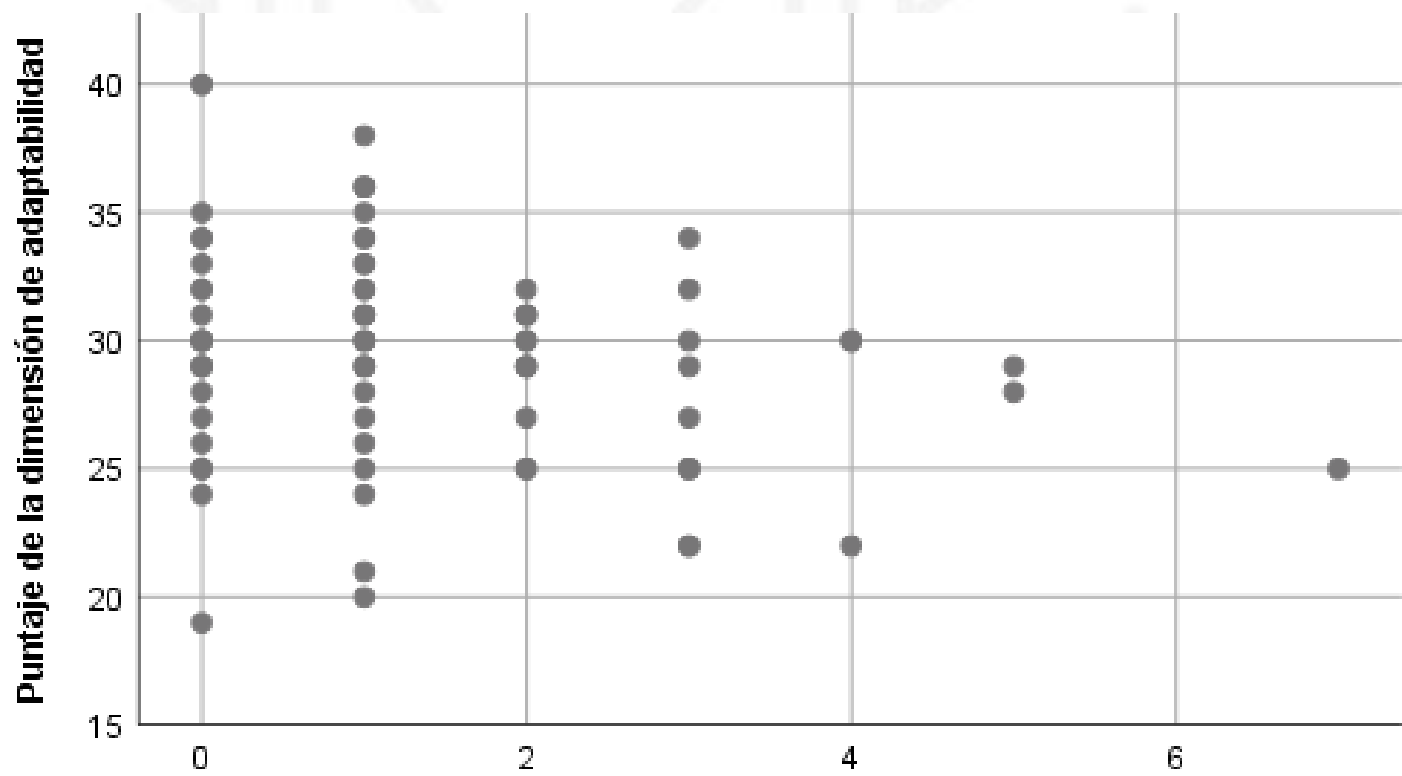

Puntaje de la dimensión de indiferencia de la madre 
Figura 29

Relación lineal entre la dimensión de indiferencia de la madre y la dimensión de manejo del estrés

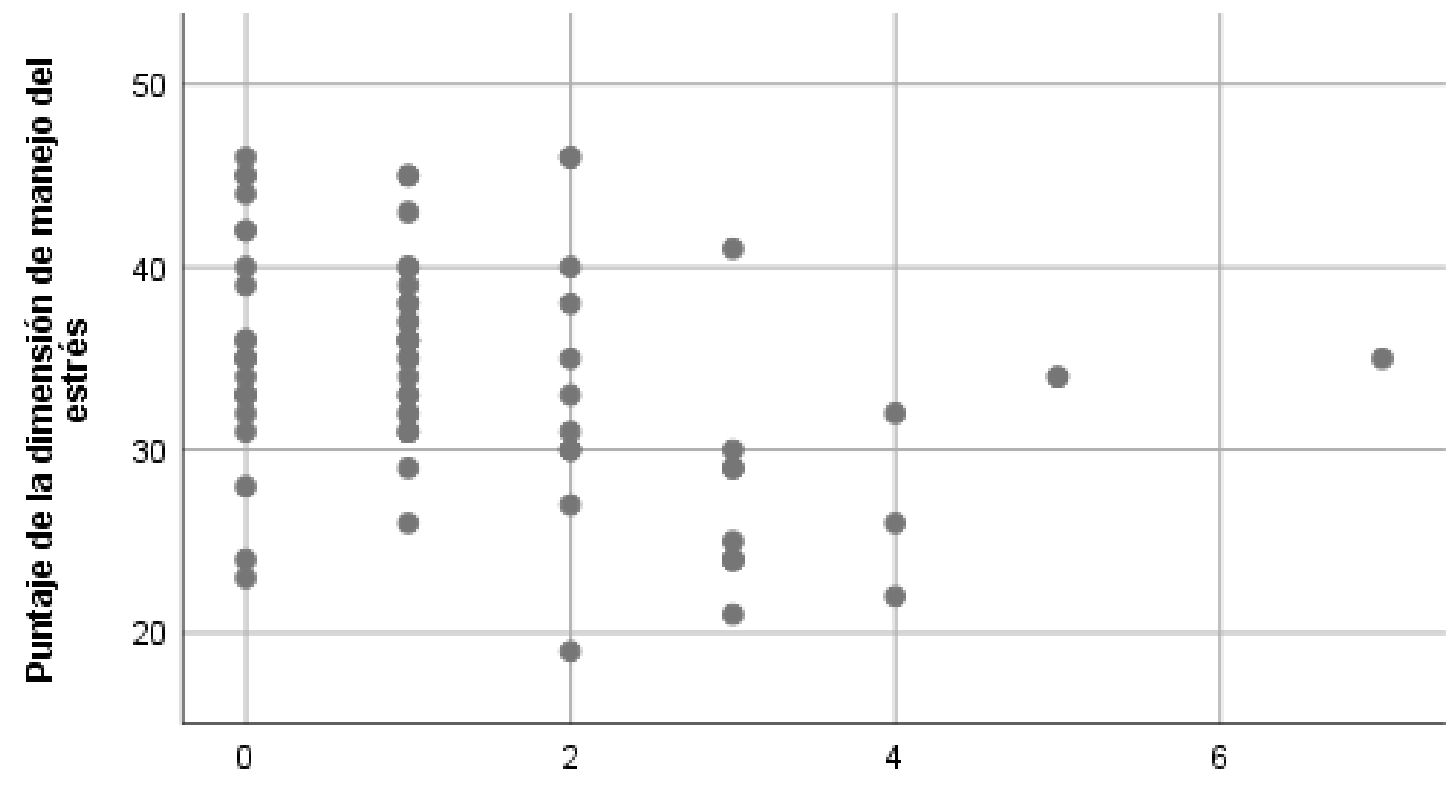

Puntaje de la dimensión de indiferencia de la madre

Figura 30

Relación lineal entre la dimensión de indiferencia de la madre y la dimensión de estado de ánimo

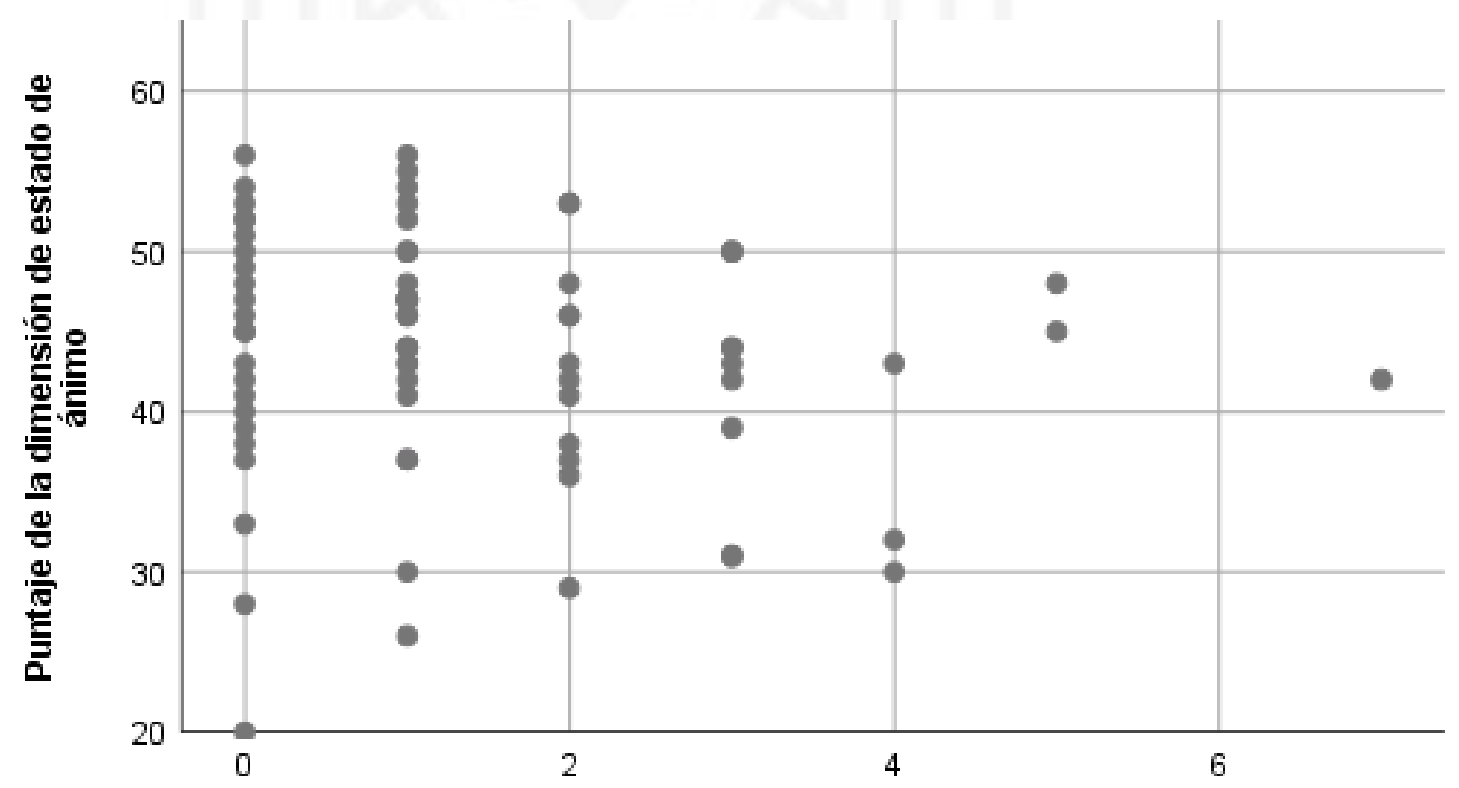

Puntaje de la dimensión de indiferencia de la madre 